\title{
Chromatographic Techniques in the Research Area of Lithium Ion Batteries: Current State-of-the-Art
}

\author{
Yannick Philipp Stenzel ${ }^{1}$, Fabian Horsthemke ${ }^{1}$, Martin Winter ${ }^{1,2}$ and Sascha Nowak ${ }^{1, *(D)}$ \\ 1 University of Münster, MEET Battery Research Center, Corrensstraße 46, 48149 Münster, Germany; \\ yannick.stenzel@uni-muenster.de (Y.P.S.); f.horsthemke@uni-muenster.de (F.H.); \\ martin.winter@uni-muenster.de (M.W.) \\ 2 Helmholtz Institute Münster, IEK-12, Forschungszentrum Jülich, Corrensstraße 46, 48149 Münster, Germany \\ * Correspondence: sascha.nowak@uni-muenster.de; Tel.: +49-251-83-36735
}

Received: 27 February 2019; Accepted: 16 April 2019; Published: 13 May 2019

check for updates

\begin{abstract}
Lithium ion batteries (LIBs) are widely used in numerous application areas, including portable consumer electronics, medicine, grid storage, electric vehicles and hybrid electric vehicles. One major challenge during operation and storage is the degradation of the cell constituents, which is called aging. This phenomenon drastically reduces both storage lifetime and cycle lifetime. Due to numerous aging effects, originating from both the individual LIB cell constituents as well as their interactions, a wide variety of instruments and methods are necessary for aging investigations. In particular, chromatographic methods are frequently applied for the analysis of the typically used liquid non-aqueous battery electrolytes based on organic solvents or ionic liquids. Moreover, chromatographic methods have also been recently used to investigate the composition of electrode materials. In this review, we will give an overview of the current state of chromatographic methods in the context of LIB cell research.
\end{abstract}

Keywords: lithium ion batteries; electrolyte; ionic liquids; aging; gas chromatography; ion chromatography; liquid chromatography; capillary electrophoresis; chemical ionization; hyphenated techniques

\section{Introduction}

Since Sony first introduced lithium ion batteries (LIBs) in 1991 [1,2], a rapid technology development and market penetration has taken place [3]. Due to optimization and improvement, LIBs are now state-of-the-art for modern portable consumer electronics (smartphones, tablets, laptops or video cameras) [4,5]. Furthermore, they are considered the most promising battery technology for various electric vehicles (EVs), as well as for stationary applications including the storage of renewable energies and grid stabilization [6,7]. This success is based on an excellent mix of performance and cost parameters, e.g., high specific energy $(\mathrm{Wh} / \mathrm{kg})$ and energy density $(\mathrm{Wh} / \mathrm{L})$ and as well as high specific power $(\mathrm{W} / \mathrm{kg}$ ) and power density $(\mathrm{W} / \mathrm{L})$, which come along with an excellent lifetime, energy efficiency and application-relevant safety and costs [8-11]. A LIB cell consists of a carbonaceous anode $[12,13]$ and lithium transition metal oxide or phosphate as cathodes. Furthermore, an electrolyte-soaked separator is placed between the anode and cathode [14-16]. The graphite anode provides a capacity of up to $372 \mathrm{mAh} / \mathrm{g}$ while the mostly used lithium (transition) metal oxide cathode $\left(\mathrm{LiMO}_{2}, \mathrm{M}=\right.$ e.g., $\mathrm{Mn}, \mathrm{Co}, \mathrm{Ni}$ or Al; in varying combinations and ratios) delivers a practical capacity of ca. 150-200 mAh/g [13,17-23]. Generally, the cathode materials are categorized by their structure, which sub-classifies them into one-dimensional, two-dimensional and three-dimensional lithium ion conducting materials [22,24-27]. The electrolyte is comprised of a conducting salt and a solvent. Today, $\mathrm{LiPF}_{6}$ is the commercially applied conducting salt and the solvent is typically a mixture of cyclic and linear carbonates like ethylene 
carbonate (EC), dimethyl carbonate (DMC), diethyl carbonate (DEC) and ethyl methyl carbonate (EMC) [28-33].

A main disadvantage of lithium ion batteries is the degradation process over time and operation, the so-called aging, which causes limited cycle and calendar lives. Understanding of those aging effects is also important regarding the recycling of batteries and the possible application of second life concepts [34-36]. Due to the complexity of the LIB cells, numerous aging mechanisms have been suggested which can be related to the used materials and components, as well as to the interactive reactions of those constituents $[23,25,37]$. For example, $\mathrm{LiPF}_{6}$ is both chemically and thermally unstable and reacts with traces of moisture and organic solvent. Even at room temperature, $\mathrm{LiPF}_{6}$ in solution is in a thermal equilibrium with $\mathrm{PF}_{5}$ and $\mathrm{LiF}$ [38]. This equilibrium is causes decomposition and the conversion of the organic carbonates due to the high reactivity of $\mathrm{PF}_{5}$ [39-42]. The reactions can lead to hydrolysis, organophosphate- and organofluorophosphate-based aging products inside the electrolyte, which are considered potentially toxic [43-51]. Furthermore, under electrochemical operation conditions, a ring opening reaction of the cyclic carbonate EC can occur; subsequent reactions also in the electrolyte present linear carbonates form oligomeric decomposition species [52-57]. In comparison, the electrochemical reduction of the electrolyte at the carbonaceous anode results in the formation of the solid electrolyte interphase (SEI). This protective layer is composed of inorganic and organic decomposition products and is necessary for long-term performance, as it is ideally only permeable for lithium ions, thus protecting the highly reactive anode against further reduction reactions [26,29,58-61]. However, transition metal dissolution (TMD) and TM migration from the cathode can lead to the deposition of the different metals on the anode. Since this process can deteriorate the SEI properties, and therefore has a negative influence on the cycle life, metal migration is known as another harmful degradation effect [62-66]. Similar to the SEI, a protective layer on the cathode is formed due to reactions of the electrolyte and the cathode as well, the cathode electrolyte interphase (CEI). However, the exact structure and thickness is not clear due to its varying nature that is dependent on cathode materials and cycling parameters. The protective nature of this passivation layer is distinct to prevent further electrolyte decomposition and self-discharge of cathodes [28,67-71].

Due to the above-mentioned phenomena and degradations effects, there is a variety of reports about methodologies and analyses in literature regarding the aging behavior of LIB cells. The investigation of the electrolyte aging is intensively based on the application of separation techniques like gas chromatography (GC), ion chromatography (IC), liquid chromatography (LC) and capillary electrophoresis (CE). Furthermore, different ionization techniques like negative and positive chemical ionization and high-resolution mass spectrometry are employed for structural elucidation. Finally, the determination of lithium, transition metals and fluorine are the object of analysis by IC or CE. In this review, we give a comprehensive overview about the applied methods including the several sample preparation steps for analysis of LIBs materials.

\section{Lithium Ion Batteries-Materials and Aging Effects}

\subsection{Lithium Ion Battery Materials and Composition}

In Figure 1, a schematic illustration of a LIB during the discharge process is shown. The negative electrode (anode) consists of graphite and the positive electrode (cathode) of a layered lithium transition metal oxide. A permeable membrane soaked with the electrolyte separates the two electrodes [14-16]. Upon charge, the lithium ions are de-inserted from the positive electrode, transported through the electrolyte, and then intercalated into the negative electrode. The process is then analogously reversed during the discharge process. 


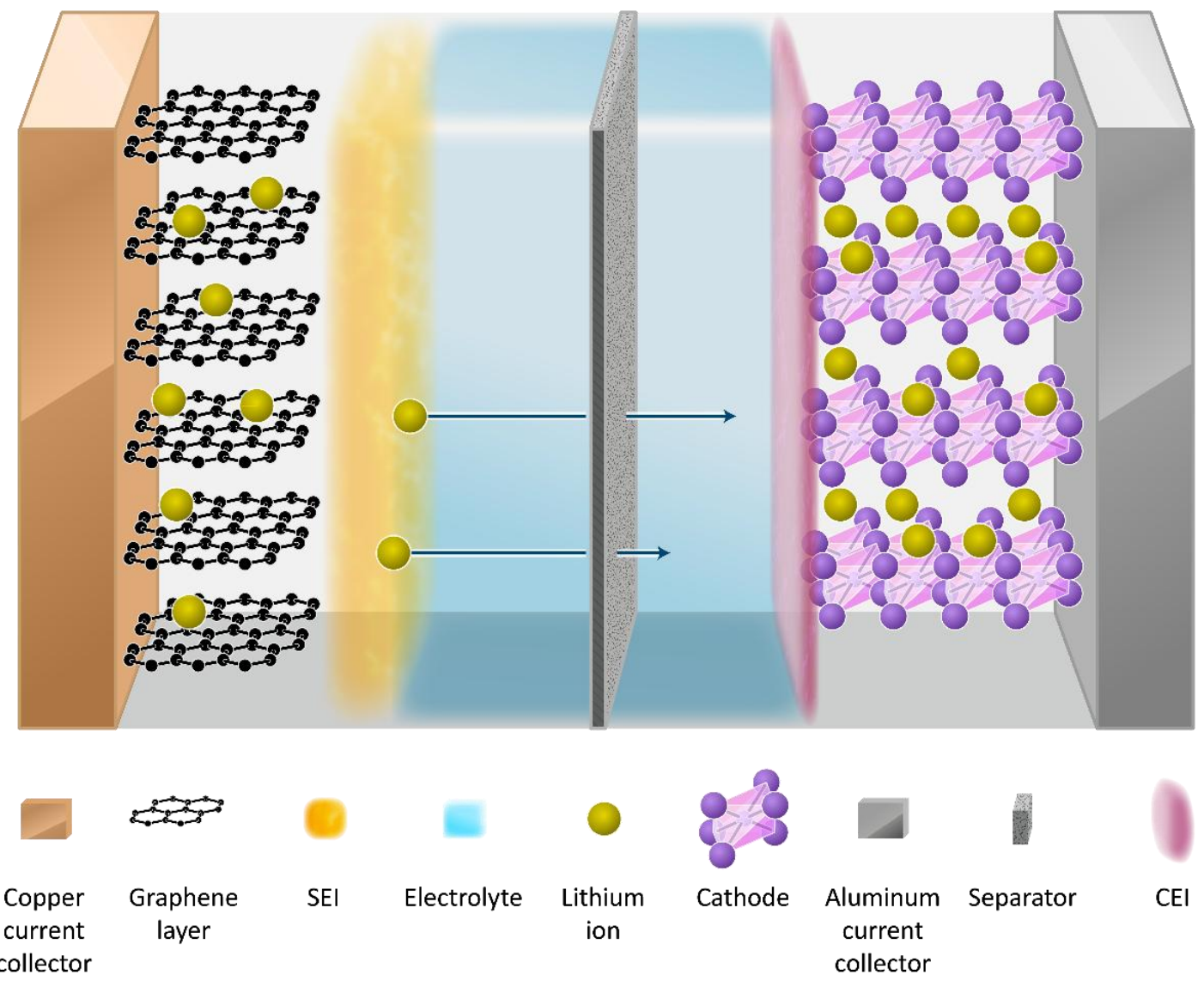

Figure 1. Schematic illustration of the fundamental operating principle of a LIB during discharge.

Cathode materials can be divided into three structural groups: one-dimensional materials (e.g., olivine structures) with a highly anisotropic lithium diffusion in a single direction, two-dimensional materials (layered structures) allowing diffusion in two spatial dimensions, and three-dimensional materials (e.g., spinel structures) which allow diffusion in all three dimensions [72-74]. Lithium cobalt oxide (LCO) was the first commercially employed layered transition metal [75,76]. Nevertheless, in recent years, ternary combinations of cobalt, nickel and manganese are the most promising cathode candidates. It can be applied as $\mathrm{LiNi}_{0.33} \mathrm{Co}_{0.33} \mathrm{Mn}_{\mathrm{o} .33} \mathrm{O}_{2}$ (NCM 111) or in Ni-rich variations (NCM 424, 523, 622 and 811, numbers indicate the relative ratios of TMs) [77-79].

Anode materials can be categorized into three groups as well: intercalation/de-intercalation materials like carbonaceous materials (especially graphite) or $\mathrm{Li}_{4} \mathrm{Ti}_{5} \mathrm{O}_{12}$, alloying elements like $\mathrm{Si}, \mathrm{Ge}$, $\mathrm{Bi}$ or $\mathrm{Sn}$ and conversion materials like $\mathrm{CuO}$ and $\mathrm{NiO}[11,80-82]$. Despite the diversity of materials, carbon is the state-of-the-art material for commercial application. Depending on the degree of crystallinity, carbons are classified as soft (graphitizable) and hard (non-graphitizable). Graphite as a form of graphitizable carbon made at high temperatures $\left(\mathrm{ca} .>2500^{\circ} \mathrm{C}\right.$ ) provides a low operating potential, a high specific capacity, good cycling stability as well as inexpensiveness [12,81,83-86].

Electrolytes for LIBs consist of a conducting salt (typical concentration of $1 \mathrm{M}$ ), which is dissolved in a mixture of linear and cyclic carbonates. As linear carbonates, ethyl methyl carbonate (EMC), ethyl carbonate (DEC) or methyl carbonate (DMC) are commonly applied, while propylene carbonate (PC) or ethylene carbonate (EC) are used as cyclic carbonates [31-33]. Different lithium salts are applicable for conducting salt, e.g., lithium bis(trifluoromethane)sulfonimide (LiTFSI), lithium bis(fluorosulfonyl)imide (LiFSI), lithium bis-(oxalate)borate (LiBOB), lithium difluoro(oxalate)borate (LiDFOB), lithium tetrafluoro borate $\left(\mathrm{LiBF}_{4}\right)$ and lithium hexafluorophosphate $\left(\mathrm{LiPF}_{6}\right)$, where the latter is the typically commercially applied conducting salt [87-92]. Furthermore, additives (up to $5 \%$, either by $\mathrm{v} / \mathrm{v}$ or $\mathrm{w} / \mathrm{w}$ ) [93] can be applied to further modify the different electrolyte properties. These modifications 
include flame retardancy [28-30,94-96] or the enhanced formation of SEI and CEI [97-102]. During the first charge/discharge cycles, also called formation cycles, the SEI is formed and, thus, further prevents decomposition of electrolyte at the anode surface $[58,60,61,103]$. At the cathode surface, a similar passivation layer is formed, which is called the cathode electrolyte interphase (CEI) [71,104,105]. As a green alternative, ionic liquids (ILs) have been reported as electrolytes for LIBs [106]. ILs are by definition molten salts with melting points below $100{ }^{\circ} \mathrm{C}$ which contain organic or inorganic anions and organic cations $[107,108]$. As anions, hexafluorophosphate, tetrafluoroborate, imides, sulfonates or halides are applied, while as cations pyridinium, imidazolium, piperidinium or pyrrolidinium-based quaternary ammonium salts are used [109]. Common examples are 1-methyl-1-propylpyrrolidinium bis(trifluoro methanesulfonyl) imide (PYR 13 TFSI), 1-propyl-1-methyl-pyrrolidinium bis(fluorosulfonyl)imide (PYR ${ }_{13}$ FSI), 1-butyl-1-methylpyrrolidinium bis(trifluoromethanesulfonyl)imide (PYR 14 TFSI) and 1-ethyl-3-methylimidazolium bis(trifluoromethanesulfonyl)imide (EMIM TFSI). ILs meet several crucial requirements for LIB electrolytes like a sufficient ionic conductivity (however only at elevated temperatures) and a high oxidation stability, in case of fluorinated anions. A decent Coulombic efficiency and cycling stability can be achieved when the ILs are used with selected electrode materials. Because of their low vapor pressure and the non-flammability up to high temperatures, they are considered safer than non-aqueous organic solvent-based electrolytes [110-112]. Normally, lithium hexafluorophosphate or the corresponding lithium salt of the IL anion is applied to introduce $\mathrm{Li}^{+}$as charge carrier in the electrolyte $[106,107,113]$.

\subsection{Lithium Ion Battery Aging and Degradation Mechanisms}

Aging can affect all cell components. There are numerous aging mechanisms of the cell and its components, and many of them are based on the interaction of the cell's components with each other $[25,37,114,115]$.

Due to the hygroscopic nature of the conducting salt $\mathrm{LiPF}_{6}$, there are always traces of water present in the electrolyte. Therefore, it is in equilibrium with the gaseous $\mathrm{PF}_{5}$ and $\mathrm{LiF}$, which can further react to $\mathrm{HF}$ and $\mathrm{POF}_{3}$.

Regarding the formation of HF inside the electrolyte, the dissolution of active material is promoted from the cathode and its subsequent migration to the anode. This is especially true for the $\mathrm{LiMn}_{2} \mathrm{O}_{4}$ spinel-type cathode, where TM dissolution and subsequent transport to anode leads to deterioration of the SEI [62-66]. Two dissolution mechanisms were postulated: (I) a disproportionation reaction: $2 \mathrm{Mn}^{3+} \rightarrow \mathrm{Mn}^{2+}+\mathrm{Mn}^{4+}$ and (II) an acidic corrosion, catalyzed by HF or other inorganic acids: $\mathrm{Mn}^{3+}+$ $2 \mathrm{HF} \rightarrow \mathrm{MnF}_{2}+2 \mathrm{H}^{+},[37,79,116]$ however this mechanism was already questioned [117]. While an adaption of the mechanism to NCM-based cells seemed promising, the influence of HF was disproven. Furthermore, the contribution to the overall capacity fade showed less influence of the TMD than previously assumed [118-120]. In comparison, several new influences were stated which foster the mechanical spalling of the TMs, either due to electrochemically induced stress [121] or because of (I) defects within the oxygen host lattice of the NCM material, (II) structural deformation of NCM particles on the atomic scale which leads to particle cracking and (III) due to phase transformation of the particle from layered to spinel or rock salt structures on the nanoscale level $[118,119,121]$. Therefore, the analysis of the stoichiometry of the electrodes can reveal the loss of TMs due to the above-explained effects. While inductively coupled plasma-based methods are routinely used for this purpose, the addition of chromatographic methods can provide valuable information since certified reference materials are not available presently $[59,122-125]$.

With respect to $\mathrm{POF}_{3}$, hydrolysis to inorganic phosphates occurs [126], several reactions with the organic carbonates can lead to the formation of organophosphate-based (Figure 2d), organofluorophosphates-based (Figure 2c) and oligocarbonate-based (Figure 2b) decomposition products [42,49,50,52,53,127-131]. Additionally, $\mathrm{PF}_{5}$ can initiate the transesterification of EMC to DEC and DMC (Figure 2a) [127]. 
2

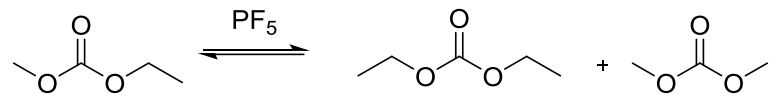<smiles>CC1(c2ccccc2)CC1</smiles>

a

b

C

d<smiles>O[Te](O)=P(O)(O)O</smiles><smiles>[R]OC(=O)O[R]([R])=O</smiles><smiles>O=P(O)(F)F</smiles><smiles>[R]OC(=O)C([R])O[R]</smiles>

$\mathrm{R}=$ Methyl or ethyl

Figure 2. General decomposition pathways for the formation of transesterifications products (a), oligocarbonate-based products (b), organophosphate-based products (d) and organic fluorophosphate-based products (c) and hydrolysis products [42,49,50,52,53,127-132].

Especially organofluorophosphate-based decomposition products have a high potential toxicity. $[46,133]$ Due to the weak P-F bond of these compounds, they can irreversible react with the enzyme acetylcholinesterase (AChE), which hydrolyses acetylcholine, an essential neurotransmitter for the peripheral nervous system (PNS). The subsequent accumulation of the unhydrolysed acetylcholine inside the body can then ultimately lead to death [43-46,134]. Besides the toxicological aspect, the impact of these degradation products on the environment is another important issue as this compound class is also ecologically harmful $[43,44]$. Further, with regard to recycling, these characteristics are of high interest. Therefore, it is necessary to identify possible reaction and decomposition products of the electrolyte in order to get a better understanding of the aging behavior. It is also fundamental to obtain quantitative information about the organo- and organofluorophosphate-based products to evaluate potential toxicities of these compounds and possible harmful effects in case of accidents.

\section{Analysis of Lithium Ion Battery Materials}

Separation techniques are necessary for the analysis of non-aqueous electrolytes. Investigations are focused on the aging behavior including structural and quantitative information about the numerous decomposition products or the determination of fluorine. However, there are reports on the examination of the electrodes or ionic liquids, which will be covered beforehand.

\subsection{Electrode Analysis}

The investigation of electrodes is mainly focused on the quantification of elements of the respective anode of cathode to determine the amount of degradation of transition metal dissolution (TMD) that occurred. 
For analysis of cations in the LIB research context, Vortmann-Westhoven et al. showed a capillary electrophoresis (CE) separation method with UV/vis detection for the determination of lithium and transition metals after microwave digestion [135]. They compared this developed method to results obtained with IC and inductively coupled plasma-optical emission spectroscopy (ICP-OES) and could get comparable results in terms of recovery rates and general analytical figures of merit. Overall, a valuable alternative to the common ICP-OES technique in this regard could be accomplished. In another publication targeting the transition metal dissolution (TMD) in LIBs, Vortmann-Westhoven et al. showed an IC technique with a post-column reactor and serial conductivity as well as spectrophotometric detection [136]. Investigation of different separation columns eventually led to the separation and quantification of transition metals from electrochemically aged electrolyte at different cut-off voltages. The TMD was concluded to increase (especially for nickel and cobalt) with higher cut-off voltage of the investigated NCM111/graphite cells.

\subsection{Ionic Liquid Analysis}

As ionic liquids show superior stability in a wide electrochemical window, analysis is mainly focused on the development of methods that are able no investigate the different ionic species with respect to possible degradation products or impurities. Ion chromatography (IC) and methods that separate charged particles in an electric field in general are the predominant analysis methods of choice. Hyphenation to detectors that provide structural information as well as quantitative detectors (based on conductivity or optical characteristics) are mainly used.

Hao et al. developed an ion chromatographic (IC) method for determination of trace levels of halide impurities in various types ILs: tetrafluoroborate $\left(\mathrm{BF}_{4}^{-}\right)$, bis-(trifluoromethanesulfonyl)imide (TFSI $\left.{ }^{-}\right)$ and bis-perfluoroethylsulfonylimide $\left(\mathrm{BETI}^{-}\right)$[137]. The determined limits of detection (LODs) in the measured solution with conductivity detection, were $0.1,0.2$ and $1.0 \mathrm{ppm}$ for chloride, bromide and iodide, respectively, and $0.02 \mathrm{ppm}$ for iodide with UV detection. For sample preparation, dissolution in $50 \%(\mathrm{v} / \mathrm{v})$ acetonitrile was carried out for the hydrophobic TFSI ${ }^{-}$and $\mathrm{BETI}^{-}$anions. Due to changes in the retention time caused by the sample matrix, they suggested the standard addition for the quantification.

IC with conductivity detection was also applied by Villagrán et al. to investigate chloride impurities in imidazolium-based ILs (Figure 3) [138]. They examined the effect of the different cations on the chloride impurity, the possible interferences of fluoride generated by hydrolysis during sample preparation, the chromatographic system and the matrix effect.

As a result, the chloride ions changed the viscosity and density of the different ILs. LODs and limits of quantification (LOQ) were in the ppb range for all investigated samples. Additionally, the accuracy, precision and reproducibility gave decent values and thus they concluded that IC is well suited to serve as a quality control method in the production of ILs.

In a study by Zhou et al. [139], tetrafluoroborate was investigated by LC with conductivity detection. They achieved a retention time of tetrafluoroborate of less than $1 \mathrm{~min}$, using the following conditions: $0.5 \mathrm{mM}$ TBA and $0.31 \mathrm{mM}$ phthalic acid ( $\mathrm{pH}$ 5.5) as eluent, a column temperature of $30^{\circ} \mathrm{C}$ and a flow rate of $6.0 \mathrm{~mL} / \mathrm{min}$. The reproducibility and relative standard deviation (RSD) were very good and the method was finally applied for the analysis of tetrafluoroborate in ILs. The determined recovery rates in 1-propyl-3-methylimidazolium tetrafluoroborate, 1-butyl-3-methylimidazolium tetrafluoroborate, 1-amyl-3-methylimidazolium tetrafluoroborate and 1-hexyl-3-methylimidazolium tetrafluoroborate were in the range of $98.2-101.5 \%$. 


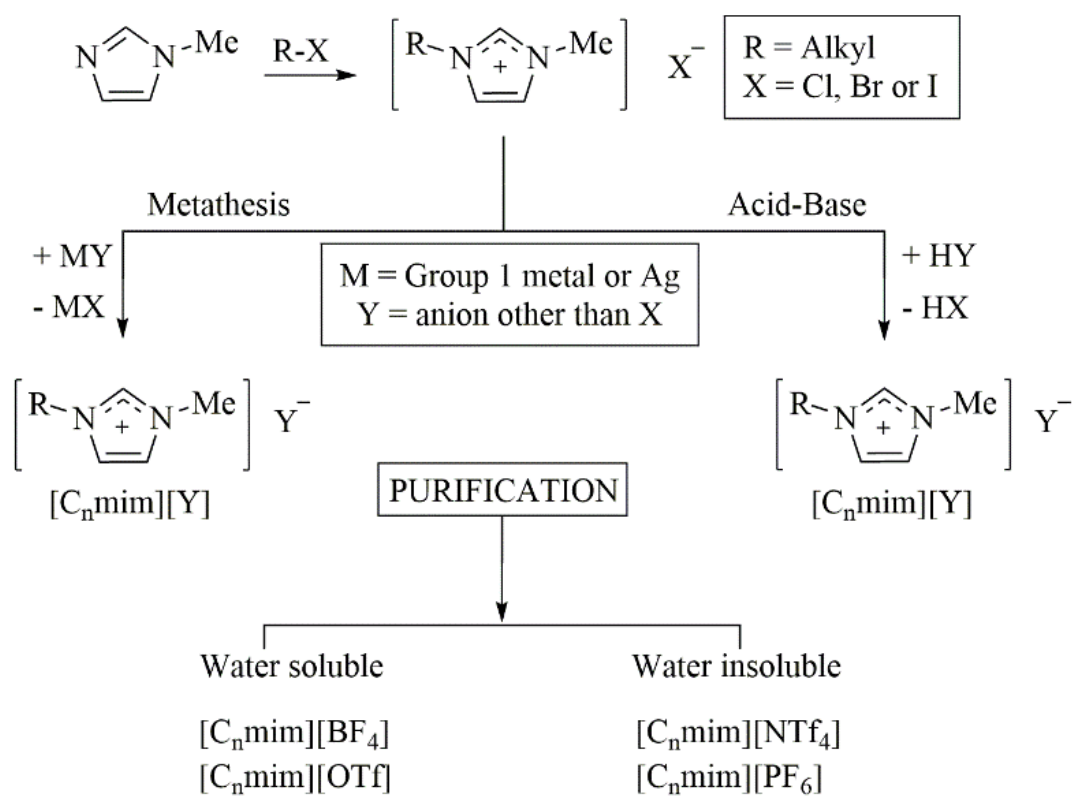

Figure 3. General preparation for the imidazolium-based ILs, which were investigated by Villagrán et al. Reprinted with permission from [138], Copyright 2004 American Chemical Society.

Gao et al. determined four imidazolium-based ILs (1-ethyl-3-methyl-imidazolium tetrafluoroborate $\left(\mathrm{EMIMBF}_{4}\right)$, 1-propyl-3-methyl-imidazolium tetrafluoroborate $\left(\mathrm{PMIMBF}_{4}\right)$, 1-butyl-3-methyl-imidazolium tetrafluoroborate $\left(\mathrm{BMIMBF}_{4}\right)$, 1-amyl-3-methyl-imidazolium tetrafluoroborate $\left.\left(\mathrm{AMIMBF}_{4}\right)\right)$ cations by ion-pair chromatography using direct conductivity detection [140]. For the ion-pair reagent, 1-heptanesulfonic acid sodium was chosen, and along with $10 \%$ acetonitrile + citric acid (for adjustment of the $\mathrm{pH}$ of mobile phase) used as eluent. As in the studies of Zhou et al. [139], several parameters influencing the retention were systematically investigated. Since the flow rate had a significant influence, namely a shortened retention time with increased flow rate, they suggested high flow rates for a fast determination.

Four pyridinium IL cations ( $N$-ethyl-pyridinium, N-butyl-pyridinium, N-butyl-4-methylpyridinium, $N$-hexyl-pyridinium) were separated and determined by reversed phase ion-pair chromatography with ultraviolet-visible detection by Meng et al. [141]. As in previous studies, the influence of the retention time was intensively investigated. After the optimization procedure, two self-synthesized ILs (1-ethyl-3-methylimidazolium tetrafluoroborate $\left(\mathrm{EMIMBF}_{4}\right)$ and 1-butyl-3-methylimidazolium bromide (BMIMBr)) were analyzed with regard to the concentration of the cation. The findings were in accordance to Gao et al. and the analysis of the real sample provided satisfactorily results [140].

Beside IC and LC techniques, CE and capillary zone electrophoresis (CZE) were also reported. CE was applied by Markuszewski and coworkers [142]. The aim of the study was to evaluate a routine capillary electrophoretic method for the separation of selected imidazolium ionic liquid cations. In Figure 4, all investigated compounds are shown. Several buffers were examined, including phosphate, acetate, fumarate, and citrate in order to achieve the best separation. With respect to both the peak shape and the resolution, a citrate buffer of $\mathrm{pH} 4.0$ was preferred for all further investigations. For validation purposes, the method was applied to samples, which were attained during a photo degradation experiment. The target solute could be well separated from its degradation product and quantified.

Qin et al. reported the separation of imidazolium ILs and derivates using a cyclodextrin buffer solution [143]. The synthesis of 1-butyl-3-methylimidazolium chloride was monitored in terms of process control after method development. Additionally, impurities in commercially available EMIMCl and 2-ethylimidazole were probed. The authors concluded that the method could be utilized with high resolution, low LODs and good reproducibility. Furthermore, it was employed in routine analysis such 
as impurity testing of commercial products as well as in reaction mechanism research and synthetic reaction process control.

\begin{tabular}{lllll}
\hline lonic liquid & $\mathrm{R} 1$ & $\mathrm{R} 2$ & $\mathrm{X}^{-}$ & $\mathrm{M}_{\mathrm{r}}$ \\
\hline$[\mathrm{MMIM}][\mathrm{Br}]$ & Methyl & Methyl & $\mathrm{Br}^{-}$ & 194 \\
{$[\mathrm{EMIM}][\mathrm{Br}]$} & Ethyl & Methyl & $\mathrm{Br}^{-}$ & 208 \\
{$[\mathrm{EEIM}][\mathrm{Br}]$} & Ethyl & Ethyl & $\mathrm{Br}^{-}$ & 212 \\
{$[\mathrm{PMIM}][\mathrm{Cl}]$} & $n$-Propyl & Methyl & $\mathrm{Cl}^{-}$ & 177 \\
{$\left[\mathrm{BMIM}\left[\mathrm{BF}_{4}\right]\right.$} & $n$-Butyl & Methyl & $\mathrm{BF}_{4}{ }^{-}$ & 226 \\
{$[\mathrm{HMIM}]\left[\mathrm{BF}_{4}\right]$} & $n$-Hexyl & Methyl & $\mathrm{BF}_{4}{ }^{-}$ & 254 \\
{$[\mathrm{OMIM}]\left[\mathrm{BF}_{4}\right]$} & $n$-Octyl & Methyl & $\mathrm{BF}_{4}{ }^{-}$ & 282 \\
{$[\mathrm{NMIM}]\left[\mathrm{BF}_{4}\right]$} & $n$-Nonyl & Methyl & $\mathrm{BF}_{4}{ }^{-}$ & 296 \\
{$[\mathrm{DMIM}]\left[\mathrm{BF}_{4}\right]$} & $n$-Decyl & Methyl & $\mathrm{Cl}^{-}$ & 275 \\
{$[\mathrm{BzMIM}]\left[\mathrm{BF}_{4}\right]$} & Benzyl & Methyl & $\mathrm{BF}_{4}{ }^{-}$ & 318 \\
[pMBzMIM][Cl] & $p$-Methylbenzyl & Methyl & $\mathrm{Cl}^{-}$ & 223 \\
\hline
\end{tabular}

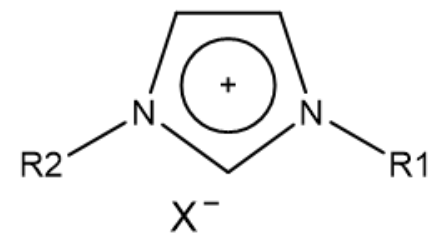

Figure 4. The compounds studied by Markuszewski et al., their R1 and R2 substituents, counter anions, and relative molecular masses (Mr). Reprinted with permission from [142], Copyright 2004 John Wiley \& Sons, Inc.

Two capillary isotachophoresis-based methods for the analysis of ILs were developed by Markowska et al. [144]. They investigated both anions and cations with the respected methods: nitrate $(\mathrm{V})$, chlorate $(\mathrm{V})$, hexafluorophosphate, dicyanimide, trifluoromethanesulfonate, phosphate $(\mathrm{V})$ and bis(trifluoromethanesulfonyl)imide anions and seven short-chain alkylimidazolium, alkylpyrrolidinium, alkylpyridinium and non-chromophoric tetraalkylammonium and tetraalkylphosphonium IL cations. Both methods were optimized, and their applicability to the analysis of soil and freshwater-containing ILs proved successful.

Kosobucki et al. presented another isotachophoretic separation with direct conductivity detection, in this case for different imidazolium ionic liquids [145]. They could obtain detection limits of $10 \mathrm{ng} / \mathrm{L}$ for anions and $25 \mathrm{ng} / \mathrm{L}$ for cations. It was found that isotachophoresis offered a very promising alternative to the chromatographic methods for analysis of ILs. The possibility of determination of cationic and anionic room temperature ILs in reasonable time was established.

A method for the analysis of fluoride in electrolytes and ILs was reported by Pyschik et al. [146]. Electrolytes using $\mathrm{LiPF}_{6}$ in organic carbonate solvents and in ILs after contacted to Li metal were investigated during their work. The developed method was compared to results previously achieved and validated with a fluoride selective electrode (ISE) [147]. Regarding electrolyte analysis, the recovery rate for the CE was $95.3 \%-98.1 \%$ and the RSD was in a range of $1.53 \%-1.79 \%$. The RSD for the ISE was in a range of $0.30 \%-0.68 \%$ and the recovery rate was between $100.0 \%$ and $100.9 \%$. For the analysis of ILs, the recovery rate by CE was determined to be 104.4-105.7\%. The RSD of the CE method was $3.78 \%$. The CE operated with an injection volume in the nanoliter-range; in contrast to ISE where for each measurement $2 \mathrm{~mL}$ of the diluted sample were needed.

Hyphenated techniques of IC and CE with mass spectrometry were published sparsely, at least regarding the analysis of ILs. Pyschik et al. reported a method for the determination of anions of ILs by IC hyphenated to electrospray ionization-mass spectrometry (ESI-MS) [148]. The stability of 1-methyl-1-propylpyrrolidinium bis(trifluoromethanesulfonyl)imide (PYR ${ }_{13} \mathrm{TFSI}$ ) and 1-methyl-1-propylpyrrolidinium bis(fluorosulfonyl)imide ( $\mathrm{PYR}_{13} \mathrm{FSI}$ ) was investigated as well as the influence of different $\mathrm{Li}$ salts $\left(\mathrm{LiPF}_{6}, \mathrm{LiTFSI}\right.$ and $\left.\mathrm{LiClO}_{4}\right)$ on the decomposition. In comparison to previous thermal aging works, the samples were stored at elevated temperatures $\left(60^{\circ} \mathrm{C}\right)$ for six months. In all samples, the formation of hydrolysis-based decomposition products of the hexafluorophosphate anion and HF was witnessed. However, no decomposition products of $\mathrm{PYR}_{13} \mathrm{FSI}$ were detected, 
when mixed with LiTFSI. In contrast, PYR 13 FSI mixed with $\mathrm{LiPF}_{6}$ and $\mathrm{LiClO}_{4}$ formed several decomposition products. Moreover, $\mathrm{PYR}_{13} \mathrm{TFSI}$ did not show any degradation products mixed with any electrolyte salts.

Based on the same methodology, the thermal stability of IL cations was investigated [149]. PYR $_{13}$ TFSI, PYR 13 FSI, PYR 14 TFSI and EMIM TFSI were stored at different temperatures (room temperature and $95^{\circ} \mathrm{C}$ ) and analyzed with an IC-ESI-MS setup. The influence of LiPF 6 , LiTFSI and $\mathrm{LiClO}_{4}$ was analyzed in a long-term stability study at room temperature and $60^{\circ} \mathrm{C}$. It was shown that the side chain of the main molecule cleaved and reacted subsequently with the main cation molecule forming new decomposition products. In comparison, any influence of the three different Li salts could be excluded, since no additional decomposition products were found. However, regarding the influence of the counter ions, different decomposition products were formed in the presence of the investigated $\mathrm{FSI}^{-}$and $\mathrm{TFSI}^{-}$.

The same group further investigated the stability of IL cations [150]. While applying the same samples and sample treatment, the performance of the IC-ESI-MS method and a newly developed CE-MS method were directly compared. The LODs and LOQs were calculated for both methods and compared with each other. The LODs and LOQs for CE method were in the range of $0.3-2.1 \mathrm{mg} / \mathrm{kg}$ and for the IC method 34.9-455.2 $\mathrm{mg} / \mathrm{kg}$. Due to the lower LODs, several new decomposition products could be determined. Furthermore, quantitative analysis was carried out, since standards were available. The PYR ${ }_{14}{ }^{+}$concentration decreased by $4 \%$ at $60{ }^{\circ} \mathrm{C}$, while the $\mathrm{PYR}_{13}{ }^{+}$and $\mathrm{EMIM}^{+}$ concentration decreased by more than $10 \%$ aged at $60{ }^{\circ} \mathrm{C}$ in contrast to the sample which was aged at room temperature.

The first investigations focusing on the gassing behavior of IL-based electrolytes were performed by Chancelier et al. [151]. Besides DSC and TGA measurements the gases emerging from 1-butyl-3-methylimidazolium bis(trifluoromethanesulfonyl)imide BMIM TFSI and PYR ${ }_{14}$ TFSI with LiTFSI at $350{ }^{\circ} \mathrm{C}$ were investigated. Several hydrocarbons besides trifluoro methane were identified and the nature of present hydrocarbons was reported to change with the utilized cationic species. In follow-up studies of the same group, the stability of IL-based electrolytes in lithium titanate (LTO)/NCM-based cells was investigated and compared to standard organic carbonate solvent-based electrolytes [152,153]. The cells were cycled at $60^{\circ} \mathrm{C}$ and the emerging gases obtained after 100 cycles. The gases were analyzed by gas chromatography-Fourier transform infrared spectroscopy-flame ionization detector (GC-FTIR-FID) and gas chromatography-thermal conductivity detector (GC-TCD) and the DEC/EC-based electrolyte showed the most prominent signals for small hydrocarbons like ethane and propane. In the case of BMIM TFSI being used as solvent, fluorinated decomposition products and carbon monoxide, methane, propane and butane were identified. Overcharge experiments of the cells showed the same main decomposition products. However, the signal intensity of the alkanes-especially methane and butane-were increased and the authors concluded that the stability of the cation and its side chains was decreased in this case.

\subsection{Non-Aqueous Electrolyte Analysis}

State-of-the-art electrolytes are typically based on $\mathrm{LiPF}_{6}$ in a mixture of linear and cyclic carbonates for optimum conductivity reasons. The feasibility of separation and both qualitative and quantitative analysis of various linear carbonates by GC utilizing an argon ionization detector was first reported in 1961 by Gudzinowicz et al. [154]. However, the application of chromatographic methods in the early stages of LIB research was rare. A brief summary of the publication numbers researched by the authors of this review is shown in Figure 5. Especially the utilization of GC techniques to analyze LIB electrolytes increased drastically, which will be reviewed in subchapters concerning the respective analyses and instrumentations. Next to the classically applied hyphenation techniques (e.g., LC hyphenated to conductivity detection or GC-FID for liquids or GC-TCD for gases), a large variety of separation-detection combinations was reported to comprehensively target the analytical 
questions of interest in the respective study (i.e., quantitative analysis, high-sensitive detection, structural elucidation, routine analysis, etc.).

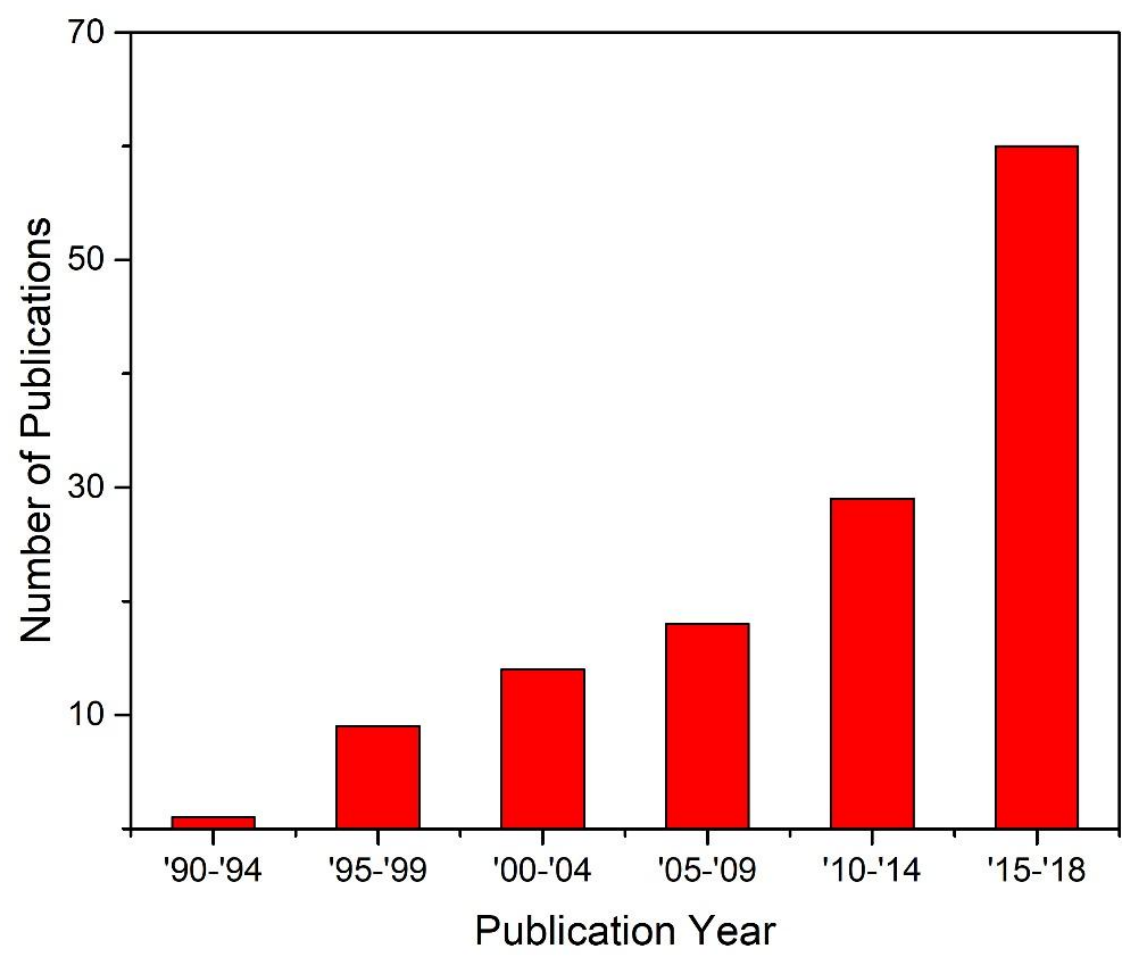

Figure 5. Number of publications researched by the authors focusing on chromatographic techniques in the field of LIB.

In 1994 Yoza et al. reported a separation of monofluoro phosphate (MFP) and difluoro phosphate (DFP) using an isocratic HPLC method [155]. An anion exchange column was utilized, and a post-column chromogenic reactor was applied. The method was able to separate MFP and DFP from polyphosphates introduced as reference samples, while the hexafluorophosphate $\left(\mathrm{PF}_{6}{ }^{-}\right)$anion did not elute in the isocratic setup. Ultimately, the authors reported the elution order of the investigated phosphates in the utilized system. While investigating analytes with relevance in to LIBs, the authors did not explicitly refer to battery research.

Arakawa et al. investigated the anodic oxidation reactions of EC and PC in presence of different conducting salts in lithium metal cells [156]. The emerging gases were sampled by evacuation using a vacuum line, and then investigated by GC-MS. Therefore, a packed polyethylene glycol (PEG) column $(3 \mathrm{~m})$ at isocratic oven temperatures of $30^{\circ} \mathrm{C}$ was used. Besides carbon dioxide, different signals were obtained some of which could be identified and assigned to the degradation of PC; identification of decomposition products originating from EC were not reported.

The storage behavior of charged cylindrical cells with an electrolyte consisting of $1.5 \mathrm{M} \mathrm{LiPF}_{6}$ in EC, DEC, methyl propionate (MP) was investigated by Ohta et al. [157]. The authors reported the presence of different permanent gases-nitrogen, oxygen, methane, carbon monoxide and carbon dioxide-after storage at $60^{\circ} \mathrm{C}$ for 20 days. The produced amount of gas $\left(3\right.$ days; $85^{\circ} \mathrm{C}$ ) was proportional to the specific surface area regardless of the carbonaceous material that was used. Measurements of the liquid residues after 10 days of storage at $85^{\circ} \mathrm{C}$ were showed signals that were assigned to DMC, EMC and ethyl propionate. However, the applied analytical method was not specified for the analysis of permanent gases and the analysis of the liquid residue was noted as GC without further information or inclusion of chromatograms. 
Kominato and coworkers investigated surface films on lithium (EC:DMC electrolyte 1:1 with $\mathrm{LiPF}_{6}$ among others) after electrochemical treatment [158]. Temperature-programmed decomposition mass spectrometry (TPD-MS) was used for the evolving gases depending on decomposition temperature $\left(30-500{ }^{\circ} \mathrm{C}\right.$ ) mainly methane, water, carbon monoxide, methanol, carbon dioxide and ethylene were found. Gases generated between $30^{\circ} \mathrm{C}$ and $200{ }^{\circ} \mathrm{C}$ were trapped and analyzed with GC-MS, reaction of carbonates with lithium were postulated due to a large variety of organic decomposition products showing the feasibility of this method for mechanistic deduction. In addition, lithium-containing carbonates were found as main decomposition products and a first decomposition scheme was postulated. After solvation of the film in water, the total amount of $\mathrm{LiF}$ in the system amounted up to a third of the total lithium in the film. A similar study focusing on a mixture of DEC and EC (1:1) as carbonate solvents was published by Mori et al. from the same research center [159]. The application of TPD-MS as valuable tool regarding thermal analysis was confirmed.

The behavior of the electrolyte during film formation in LCO graphite cells was examined by Yoshida et al. [57]. LC-FTIR was applied to investigate changes in the composition of the carbonate solvents and the conducting salt. Thereby, the transesterification to DMC and DEC was named the predominant aging mechanism in EMC-based electrolytes for the first time. Furthermore, a variety of other aging products was identified as dimethyl-2,5-dioxahexane dicarboxylate (DMDOHC), ethylmethyl-2,5-dioxahexane dicarboxylate (EMDOHC), and diethyl-2,5-dioxahexane dicarboxylate (DEDOHC). Their structure was verified by comparison to specially prepared standards and the presence of the respective compound in DMC- and DEC-based electrolytes was proven. Moreover, the formation gases emerging in single component and mixed carbonate systems were sampled and analyzed by GC-TCD. These experiments exhibited a variety of different permanent gases ranging from hydrogen, carbon monoxide and dioxide to hydrocarbons in different volume fractions. This thorough study is highly cited as it shows high analytical value and serves as an important reference for further investigations with regard to transesterification and the formation of carbonate dimers.

Johnson et al. presented the ability of GC-MS to identify the main carbonate solvents within their study of commercially available LIBs but without detailed specification of the system properties [160]. While Blomgren already discussed the findings of Yoshida et al. in an article about electrolytes for lithium and lithium ion batteries [57,129], they also suggested the formation of carbonate dimers and discussed lithium ethoxide as main catalyst for this reaction.

Heider and coworkers reported of the use of GC, GC-MS and headspace (HS)-GC for the identification of impurities of pristine electrolytes [161]. Their studies involved the analysis of the electrolytes by GC and GC-MS and the first decomposition products of the conducting salt $\left(\mathrm{LiPF}_{6}\right)$ were reported. $\mathrm{POF}_{3}$ and other unknown species were detected using different GC-setups and detectors but could not be structurally resolved. Anyway, the hydrolysis of $\mathrm{PF}_{6}{ }^{-}$was revealed with chromatographic methods for the first time.

Kumai and coworkers investigated the gas release of cells during electrochemical cycling, also with overcharge conditions (Figure 6) [162]. Using GC-FID and GC-TCD, hydrocarbons (mainly methane) and permanent gases (predominantly carbon dioxide most likely generated from oxygen release and subsequent reactions from the cathode) could be analyzed. In addition, after cycling, the electrolyte was leached with acetonitrile as solvent and the changes compared to the initial composition could be analyzed using GC-MS. It could be shown that ester exchange reactions occur during long term cycling (2000-3000 cycles; SOH 50\%). They also suggested the electrochemical decomposition of the conducting salt $\mathrm{LiPF}_{6}$ and formation of phosphate esters, these findings are in accordance with the findings of Heider et al. [161]. 
(a)

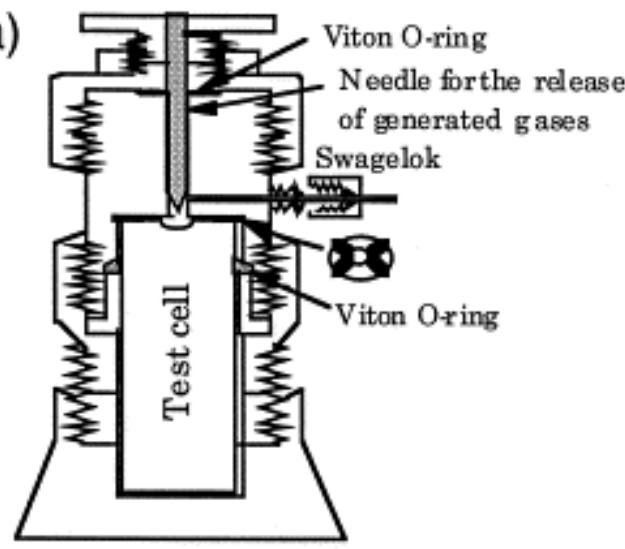

(b)

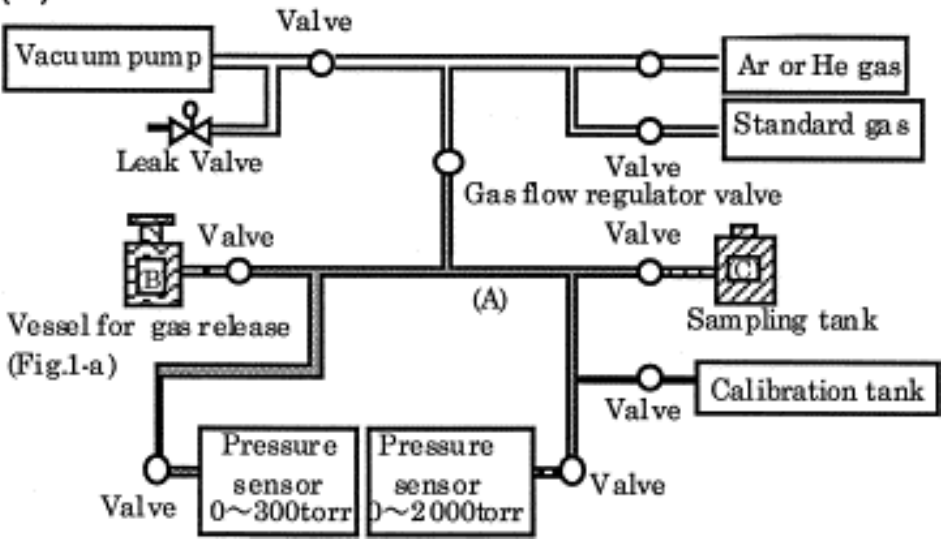

Figure 6. (a) Schematic drawing of the vessel for the release of generated gases in the cells. (b) Schematic diagram of the apparatus for gas volume measurements by Kumai et al. Reprinted with permission from [162], Copyright 1999 Elsevier.

\subsubsection{Liquid Chromatography}

After first approaches of chromatographic analysis of both the conducting salt (although not in the LIB context) [155] and investigations of the carbonates [57], we report on publications relevant to liquid chromatography (LC).

Gourdin et al. investigated the aging of an electrolyte (1.2 $\mathrm{M} \mathrm{LiPF}_{6}$ in DEC, EC, PC (4:3:1)) during the initial charging step of a lithium ion capacitor (Figure 7) [163]. The aim of this study was the separation and identification of electrolyte-soluble products after film formation using LC-MS. Several aging products were detected after exposing the electrolyte to elemental lithium; the amount increased after the first lithiation step. Structural elucidation was performed by a detailed analysis of the obtained mass spectra. Thereby, probable structures for decomposition products could be suggested. With regard to mechanistic inferences, one-electron transfer and resulting carbonate oligomers were discussed and mechanisms were proposed.

Liu and coworkers studied the effect of vinylene carbonate (VC) with regard to effects of the electrolyte aging in LIB cells (lithium iron phosphate (LFP)/graphite) at elevated temperatures of $60{ }^{\circ} \mathrm{C}$ [164]. They concluded a positive effect of VC in the electrolyte regarding the decomposition behavior of $\mathrm{LiPF}_{6}$ and carbonates due to decreased formation of phosphate esters and carbonate oligomers. In an analogous study, Liu and coworkers investigated VC in a setup using a different carbonaceous electrode (LFP/hard carbon) also at elevated temperatures [165]. They concluded that VC positively affects the cycling performance by the formation of thermally resistant organophosphates that were claimed to prevent further degradation of the electrolyte at elevated temperatures. Consequently, 
they also investigated the influence of VC in NCM/graphite cells also at elevated temperatures [166]. The results align with previous studies as VC can trap free alkoxide anions leading to a pronounced reaction of EC with phosphorous compounds. The resulting film appears to be thermally resistant which improves the cycling performance. The results of subsequent studies led to a reaction scheme, explaining the formation mechanism of primary cyclic organophosphates that form on carbonaceous anode materials, although the electrochemical context was more in focus than the analytical point of view.

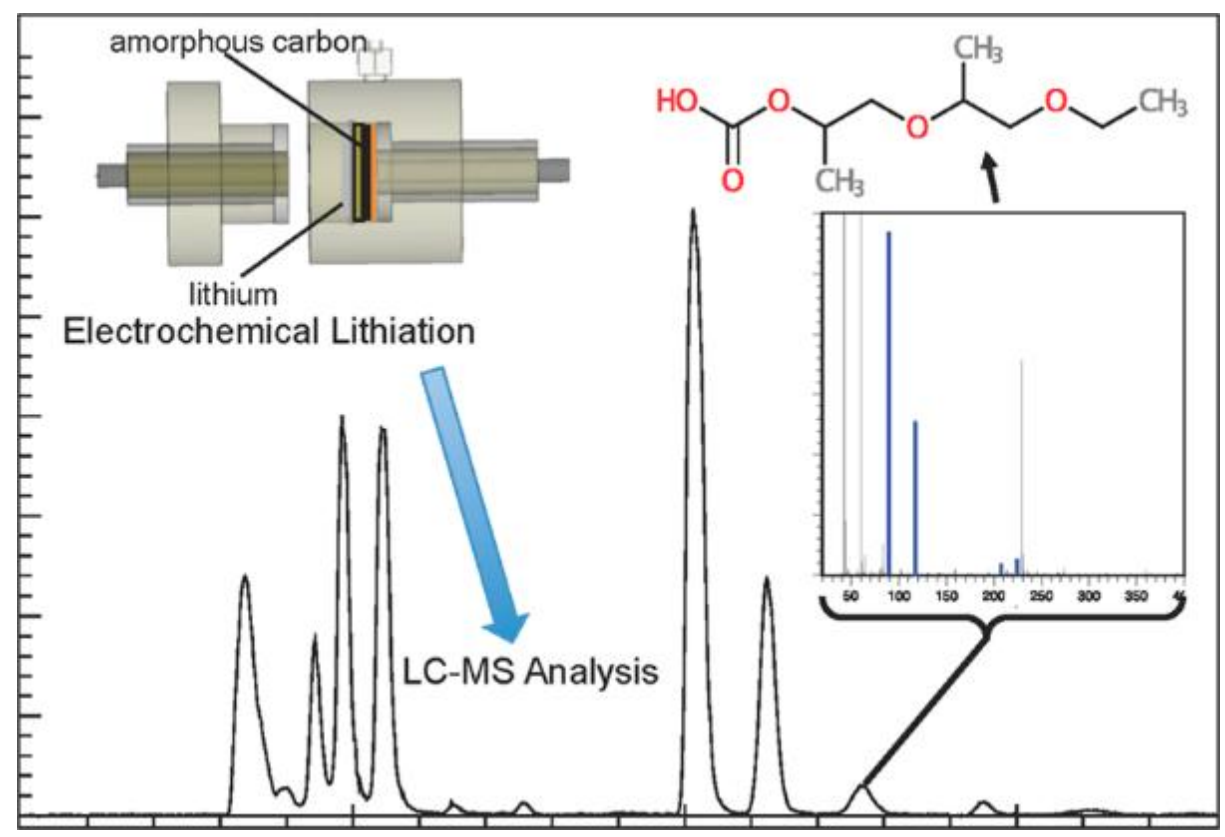

Figure 7. Schematic depiction of the analysis routine (electrochemical lithiation, LC-MS analysis, data evaluation) presented by Gourdin et al. Reprinted with permission from [163], Copyright 2014 American Chemical Society.

In the beginning of 2015, Schultz et al. developed a HPLC method with UV/vis detection for the separation and quantification of organic electrolyte components of LIBs [56]. Especially focusing on analytes with high boiling points that are not GC-accessible, this method shows good detection limits for the analytes of interest ( $\mathrm{LOD}_{\text {carbonates }} 110-380 \mathrm{ppm}$ ). Impurities as well as solvents could successfully be identified. Their results were interrelated with GC-based methods eventually recommending a combination of both methods for comprehensive analysis of LIB electrolytes.

In the same year, Tochihara and coworkers worked on a subject investigating the films on both electrodes after electrochemical cycling for structural elucidation of electrolyte degradation products [167]. The cycled cells were opened, and the electrodes underwent ultrasonic treatment using anhydrous acetonitrile. Subsequent analysis was performed with LC-MS using a high-resolution MS (QToF-MS); with a high resolution detector, probabilities regarding the structural elucidation were adequate. Several decomposition products i.e., carbonate oligomers and phosphate esters were found in the washing solution of the electrodes.

Via a rapid communication in 2016, Takeda and coworkers investigated the decomposition products of electrochemically aged electrolytes with LC-ESI-MS [168]. They found several decomposition products including carbonate oligomers, organo(fluoro)phosphates (also dimers) and intermixtures and gave a mechanistic estimation of possible formation that extended previous schemes of that kind. It was concluded that elevated temperatures enhance the variety and quantity of decomposition products in the electrolyte.

Kraft et al. investigated the species variety and quantity of organophosphates in electrochemically and thermally treated electrolytes [169]. They developed a LC-MS/MS method with multiple reaction 
monitoring that revealed total quantities of two exemplary organofluorophosphates in a range between 0.02 and $0.16 \mathrm{wt} . \%$. The aging of the electrolyte was performed at $95^{\circ} \mathrm{C}$ (thermal aging) and at elevated cut-off voltages of $5.5 \mathrm{~V}$ (electrochemical treatment) in $\mathrm{LiNi}_{0.5} \mathrm{Mn}_{1.5} \mathrm{O}_{4} / \mathrm{Li}$ cells. The authors also studied suppression effects caused by matrix for four different organo(fluoro)phosphates, which provided analytical insights of this highly relevant substance class.

The work of Schultz et al. in 2016 shows structural elucidation of carbonate decomposition products of LIB electrolytes using a novel LC-IT-ToF-MS method [55]. With the use of MS ${ }^{n}$ analysis, high reliability in terms of structural elucidation of oligocarbonates comprised of up to four carbonate monomer units could be shown. Furthermore, organo(fluoro)phosphates could be detected using this method. As long-chain oligomers were found in the electrolyte, they proposed a correlation or equilibrium between SEI components at the anode and decomposition products in the electrolyte phase. In a subsequent approach in 2017, Schultz and coworkers focused on the quantitative investigation of LIB electrolyte decomposition products [170]. Therefore, a HPLC-MS/MS method was developed using multiple reaction monitoring (MRM) mode for the electrolyte main components, i.e., solvent molecules and selected aging products. They could provide decent detection limits in the low ppb-range for the decomposition products of the carbonate and the conducting salt decomposition route. Concluding, with the addition of water (thermal treatment of electrolyte) and with elevated cut-off voltage (electrochemical treatment of electrolyte in LIBs) the formation of decomposition products is much more pronounced. Both studies used LC separation of species and could show a comprehensive understanding in terms of both structural elucidation (LC-IT-ToF-MS) and quantification (LC-ESI-MS).

In 2018, Henschel and coworkers presented an application of hydrophilic interaction liquid chromatography (HILIC) with ESI-MS and IT-ToF-MS detection [171]. Focusing on the decomposition route of $\mathrm{LiPF}_{6}$, both acidic and non-acidic organo(fluoro)phosphates could be identified with this method showing the comprehensive features of this method. Further insights into the structural diversity of phosphorus-based decomposition products were given by Henschel et al. in a follow-up study [172]. They found a high complexity of thermally aged electrolytes revealing 118 decomposition products (77 organophosphates, 28 organofluorophosphates and 13 cyclic organo(fluoro)phosphates) from which the majority was not known yet. A high structural certainty could be provided as MS was used in combination with different chromatographic separation techniques (RP and HILIC). Thus, comprehensive species information and high mass accuracy were proven to deliver credible qualitative results of decomposition compounds.

Bloom et al. investigated the effect of electrochemical overcharging of NCM/graphite cells [173]. The anode was scraped off the current collector and reconditioned in several steps for HPLC-MS analysis. The authors concluded the presence of organophosphates as reaction products of the decomposition route of the conducting salt.

\subsubsection{Ion Chromatography}

The first mentioning of IC in the LIB research context was presented in a paper by Tasaki and coworkers in 2003, dealing with the decomposition of $\mathrm{LiPF}_{6}$ and the stability in water and organic electrolyte [174]. Although theoretical calculations were in focus, IC was used for further analysis in this regard. It was concluded that the salt had a better stability in pure water compared dilution in organic carbonates with trace amounts of moisture.

A decade later, in 2012, Terborg et al. determined hydrolysis products of hexafluorophosphate (with different cations: $\mathrm{Li}^{+}, \mathrm{Na}^{+}, \mathrm{K}^{+}$) salts by IC and both $\mathrm{UV} /$ vis and conductivity detection [126]. Different columns were evaluated in terms of species separation eventually proposing a reaction pathway (hydrolysis) of the $\mathrm{PF}_{6}{ }^{-}$anion. In 2013, Terborg et al. explored the thermal aging and the hydrolysis mechanism of commercial electrolyte for LIBs with IC coupled to ESI-MS and ICP-OES [175]. An electrolyte salt decomposition mechanism was proposed after decomposition products could successfully be analyzed. The separation showed room for improvement as isocratic separation was 
used in this study. Nevertheless, the authors suggested a stronger influence of temperature on the decomposition of the conducting salt compared to the influence of moisture.

In 2014, thermal decomposition products of LIB electrolytes were studied via IC-ESI-MS by Kraft and coworkers [49]. Commercially available LIB electrolytes were investigated using IC columns with different capacity and stationary phases. Several new organophosphates were identified using IC-ESI-MS/MS including the possible reaction pathways of formation. Two-dimensional separation of compounds was recommended as procedure for future investigations, which was reported in 2015 with a developed two-dimensional IC technique with heart-cutting mode to separate ionic organophosphates in thermally aged LIB electrolytes [50]. The previously developed method was optimized by the separation of organophosphates from $\mathrm{PF}_{6}{ }^{-}$as highly concentrated analyte (Figure 8). On a second column, the species of interest were separated by probing several columns and eluent compositions. Eventually, groups of chemically similar compounds could successfully be baseline-separated. Moreover, proof of principle investigations were conducted with ICP-MS hyphenation, exhibiting the possibility of quantification of different groups of compounds. Mechanistic conclusions and identification of several OPs could be gained as well as conclusions about retention behavior on different columns. In the same year, Kraft and coworkers demonstrated an in-house developed method for the investigation of thermally decomposed LIB electrolytes by using IC-ESI-MS and GC-MS [176]. They studied the thermal decomposition behavior and proposed a reproducible thermal aging procedure for $\mathrm{LiPF}_{6}$-based electrolytes in a temperature range between $60^{\circ} \mathrm{C}$ and $80^{\circ} \mathrm{C}$ for two to three weeks. In addition, they supported the findings of Handel and coworkers and showed a strong influence of glass towards aging [177]. Glass vials or similar materials showed $\mathrm{BF}_{4}{ }^{-}$in the electrolyte as a reaction product of HF and boron oxide (as component of the glass).

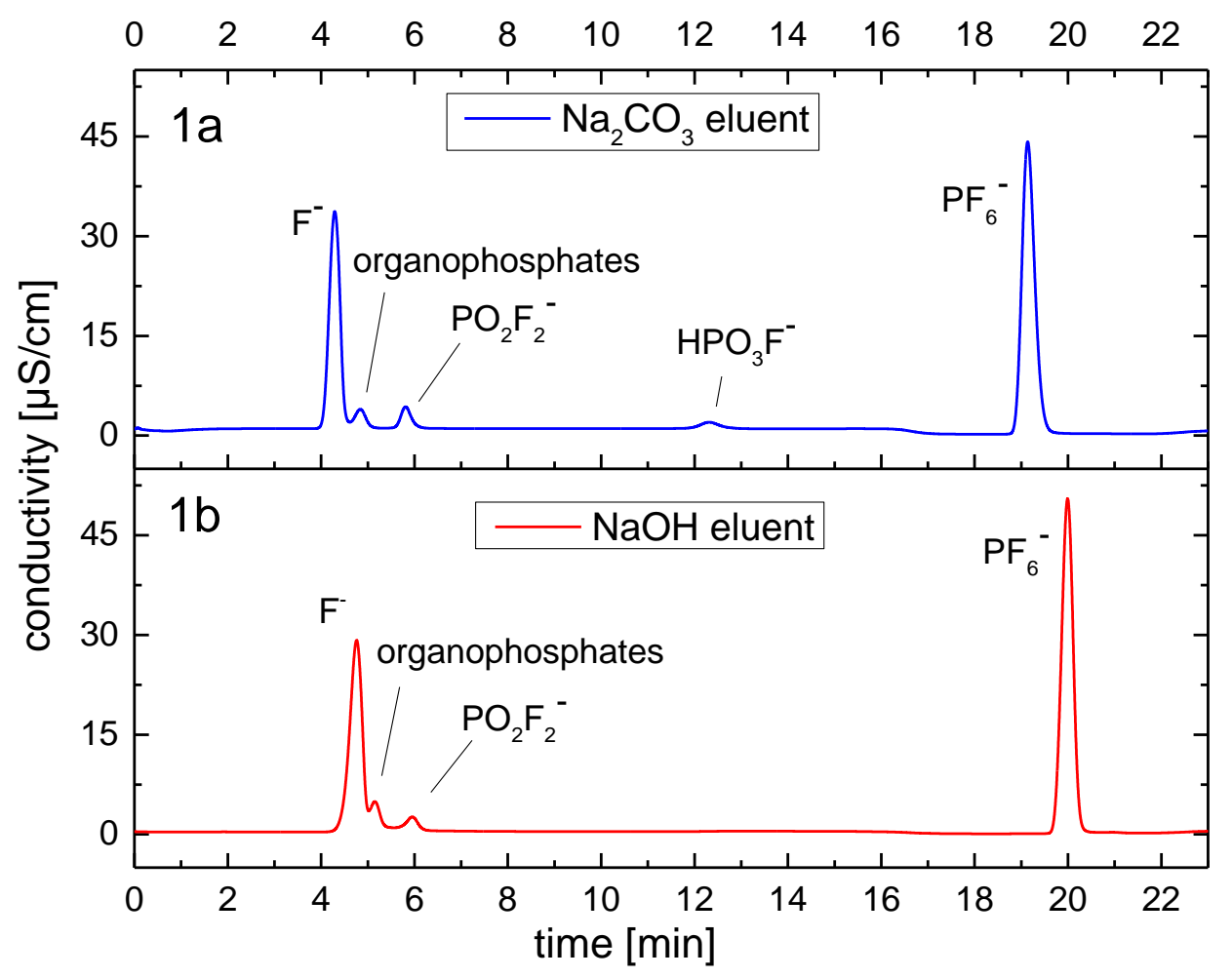

Figure 8. Anion conductivity chromatograms (aqueous $\mathrm{Na}_{2} \mathrm{CO}_{3}$ and $\mathrm{NaOH}$ eluents) of an LP50 electrolyte, which was stored for 15 days at $80^{\circ} \mathrm{C}\left(1 \mathrm{a}: 1.8 \mathrm{mM} \mathrm{Na}_{2} \mathrm{CO}_{3} / 1.7 \mathrm{mM} \mathrm{NaHCO}, 1 \mathrm{~b}: 9 \mathrm{mM}\right.$ $\mathrm{NaOH}$ ). The separation was performed with the A Supp 4 column. Reprinted with permission from [50], Copyright 2015 Elsevier. 
Menzel and coworkers proceeded previous works of this group [49,50] and implemented a quantitative analysis technique for acidic organo(fluoro)phosphates using 2D-IC-ICP-MS hyphenation (Figure 9) [178]. The composition of a thermally aged electrolyte (with water addition) could be characterized (with ESI-MS) and simultaneously quantified, while focusing on the decomposition pathway of the conducting salt. The authors concluded a high influence of moisture in the system affecting the decomposition behavior of the electrolyte as quantities of decomposition products increased immensely depending on the amount of added water.

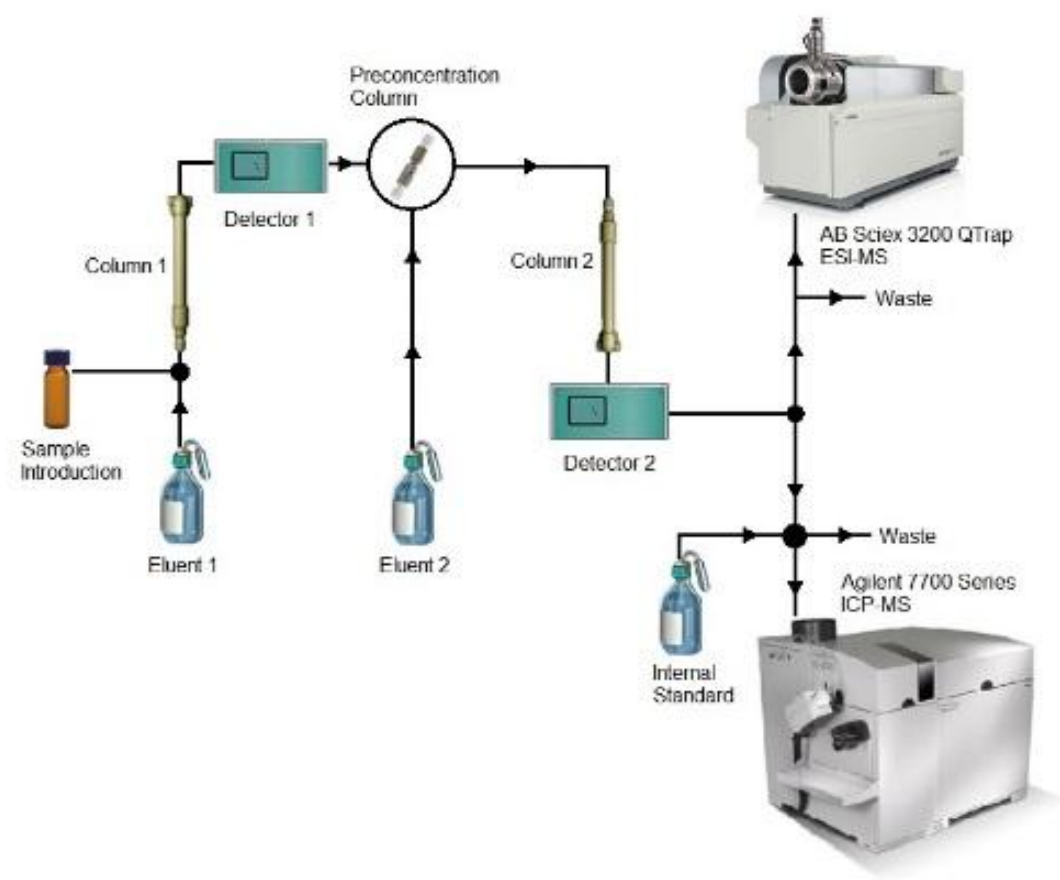

Figure 9. Experimental setup of a 2D-IC system hyphenated to ESI-MS and ICP-MS according to Menzel et al. [178]. Published by The Royal Society of Chemistry.

In 2018, Stich and coworkers compared the hydrolysis of $\mathrm{LiPF}_{6}$ in carbonate-based electrolytes for LIBs and in aqueous media [179]. They proposed the reaction of $\mathrm{POF}_{3}$, an intermediate of the decomposition route of the conducting salt, to be fast in order to align with the results of their study. Furthermore, the decomposition of $\mathrm{LiPF}_{6}$ in organic electrolyte does not follow rate laws of first or second order. Therefore, a kinetic model was proposed for the degradation pathway. As experimental data is missing, the adaptability of the model could not fully be verified.

\subsubsection{Pyrolysis-GC-MS}

A solid sample introduction system utilizing pyrolysis (PY) prior to a GC-MS system was reported in literature to investigate the active material surfaces. For the elucidation of surface films and reactions occurring at the interphases and interfaces, this branch of GC-based investigation was first reported in the LIB research context.

In 2001, Ota et al. investigated the SEI on graphite with moderate charge/discharge condition [180]. TPD GC-MS was used for the analysis of the thermally decomposed SEI components with a similar setup that was reported by Kominato and coworkers [158]. Analogously to previous findings, carbon dioxide and sulfur dioxide (electrolyte PC:ethylene sulfite (ES)) and ethylene glycol were the main decomposition products (reductive decomposition of both PC and ES). In addition, IC was used for the analysis of $\mathrm{Li}^{+}, \mathrm{CO}_{3}{ }^{2-}, \mathrm{SO}_{4}{ }^{-}$and $\mathrm{F}^{-}$. The use of pyrolysis or TPD GC-MS, respectively, was reported in a similar manner by Sano and coworkers in 2009, where they investigated the film on graphite surfaces by the analysis of trapped gases after pyrolysis [181]. The sample was heated to $200{ }^{\circ} \mathrm{C}$ after washing and drying. The emerging gases were trapped at $-70{ }^{\circ} \mathrm{C}$ and introduced into 
the GC-MS system. The $\mathrm{m} / \mathrm{z}$ ratios of polymerized 1,3,2-dioxathiolane-2,2-dioxide and ethylene oxide were identified.

In 2001, Ogumi et al. investigated the surface film formation on graphite flakes versus lithium metal without any binder addition to analyze the formed layer solely [182]. The method of choice was PY-GC-MS, which is schematically displayed in Figure 10. They could show that ethylene carbonate is reductively decomposed and forms a polymer-like structure with repeated oxyethylene units. Ethylene glycol and its oligomers but also monomers that could indicate crosslinking of the polymer could be separated with this analytical setup. Structural elucidation on an active material other than lithium was performed for the first time, they suggested that mainly cyclic EC is forming the SEI layer and that linear carbonates (DEC in that case) play only a minor role.

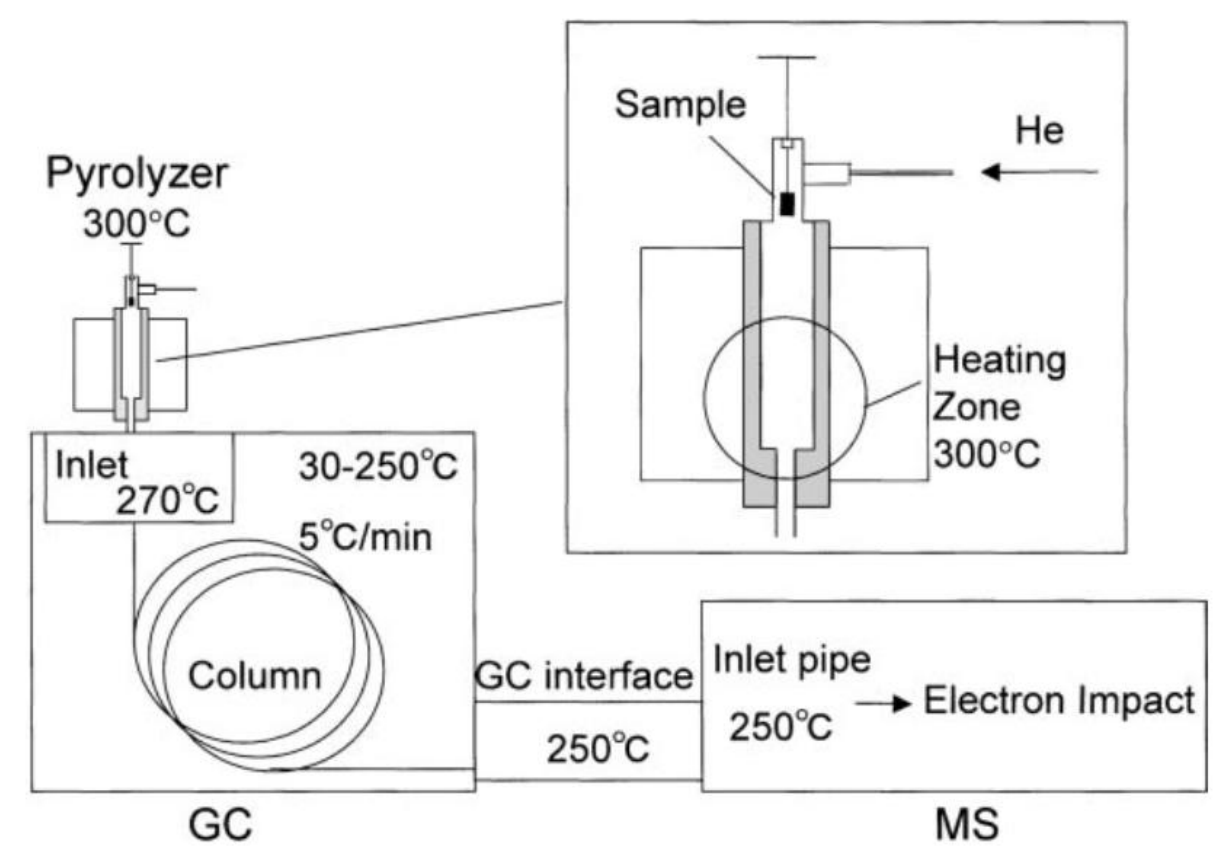

Figure 10. Schematic depiction of a typical Py-GC-MS system from Ogumi et al. Reprinted with permission from [182], Copyright 2001 Elsevier.

In 2003, Mogi and coworkers investigated the decomposition of alkylated carbonates on lithium metal using PY-GC-MS in two analogous studies [183]. After pyrolysis, separation and detection a mechanistic approach with regard to the decomposition mechanism was attempted to explain the found pyrolyzates. A comparison of the decomposition mechanism of EC on lithium and in the pyrolyzer were interrelated with respective reaction pathways. The formation of lithium alkoxides and/or lithium alkyl carbonates from linear carbonates could be shown. Furthermore, the elimination reaction of FEC to HF and VC was suggested since the film-forming properties of the electrolyte additive FEC could be shown with this analytical technique. A reaction pathway also indicating the formation of dimers initiated and accelerated by FEC were reported. Structures similar to the previously reported DMDOHC, EMDOHC and DEDOHC where the carbonate monomers are connected via a $\mathrm{C}_{3}$ bridge (most likely originating from PC) were detected. Since the formation of a uniform surface film is faster in presence of FEC, improved cycling efficiency is attributed to the additive. Eventually, a $\mathrm{LiPF}_{6}$-based electrolyte showed a much smaller amount of organic compounds and a more pronounced formation of inorganic compounds in the surface film compared to the electrolyte that used $\mathrm{LiClO}_{4}$ as conducting salt.

In 2017, Börner et al. showed the use of pyrolysis as an analysis technique for the investigation of surface films of commercial 18650-type cells [115]. The anode surface film of cells that were cycled at different temperatures to an $\mathrm{SOH}$ of $80 \%$ was investigated. They could show that with the sample introduction of pyrolysis individual compounds of the electrode organics, electrolyte residues and 
decomposition products can be analyzed. Oligocarbonates as well as organophosphates could be found in electrochemically aged electrolyte; these findings were attributed to the stability of the SEI in terms of more effective formation.

\subsubsection{GC Investigations on Electrolyte Components}

After first works, GC-based analysis of electrolyte components was widely used for structural elucidation of decomposition products and mechanistic conclusions as well as to obtain information about the degree of decomposition of LIB electrolytes.

In 2001, Sloop and coworkers investigated the chemical reactivity of $\mathrm{PF}_{5}$ in electrolyte solvents (EC/DMC) [127]. By using GC to compare decomposition products, it could be observed that both in a system of $\mathrm{LiPF}_{6}$ in the solvent mixture and the solvent mixture with $\mathrm{PF}_{5}$ gas show similar decomposition products. Thus, the equilibrium of $\mathrm{LiPF}_{6}$ and $\mathrm{LiF}+\mathrm{PF}_{5}$ is crucial when investigating electrolyte decomposition.

Zhang et al. studied high power 18650 cells after cycling with GC-FID [184]. The electrolyte was extracted from the separators using a mixture of dichloromethane (DCM) and water and pure DCM. They obtained a signal for DEDOHC, which was linked to a reaction of $\mathrm{PF}_{5}$ gas and performed experiments using $\mathrm{DEC}$ and $\mathrm{PF}_{5}$ gas to externally generate this bis carbonate. Among other reasons, the cell power loss was attributed to the decomposition of the conducting salt in the electrolyte at elevated temperatures.

Aurbach et al. published a study also focusing on cylindrical 18650 cells [185]. GC-MS was again proven a valuable tool for the post mortem analysis of the electrolyte showing trans-esterification of EMC, organic fluorinated compounds as well as organofluoro phosphorus compounds. The combination of high-resolution MS, spectral database comparison and chemical ionization for molecular weight confirmation gave comprehensive identification of compounds.

Ravdel and coworkers investigated the thermal stability of several electrolyte compositions [39]. GC-MS was used for analysis of thermally treated electrolytes; a distinct temperature-dependency with regard to the extent of decomposition and the variety of decomposition products could be determined with GC-MS. The formation of a variety of organophosphorus decomposition products could be proven. In this regard, EC free electrolyte was used, thus, from a mechanistic point of view the formation of organofluorophosphates was further resolved. The phosphorous decomposition products contained alkyl side chains depending on the linear solvent used (DMC $\rightarrow$ methyl, DEC $\rightarrow$ ethyl, EMC $\rightarrow$ ethyl).

Another approach to understand the reactivity of $\mathrm{PF}_{5}$ in a LIB electrolyte was conducted by Sloop and coworkers [128]. Solutions of $1 \mathrm{M} \mathrm{LiPF}_{6}$ in EC/DMC or EC/EMC were heated in sealed glass vials under He atmosphere. The solutions were analyzed in regular intervals by GC-FID. Furthermore, pure $\mathrm{LiPF}_{6}$ was heated to $100-120^{\circ} \mathrm{C}$ and the emerging gas was led through a vacuum line to a cooled mixture of EC/DMC. Then, the EC/DMC mixture was slowly warmed after the release of excess $\mathrm{PF}_{5}$. Sample preparation was done by dilution in DCM or quenching with excess water and DCM extraction in a comparable way to Zhang and coworkers [184]. The aqueous samples were investigated by HPLC and CE, the DCM samples by GC or GC-MS. DMC, DEC and the three transesterification products were found by GC analysis proving the equilibrium of $\mathrm{LiPF}_{5}$ and $\mathrm{PF}_{5}$ to be crucial with respect to decomposition reactions. The same decomposition products were obtained in analogous sampling of 18650-type cells. The presence of the transesterification products and polymers was confirmed by gel permeation chromatography (GPC).

In 2004, Campion and coworkers investigated the suppression of toxic alkyl fluorophosphate compounds in thermally treated LIB electrolytes [41]. They could show that quantitatively $30-50 \%$ of the initial hexafluorophosphate is converted to mono- and di-fluoro-ethylphosphate compounds $(1 \mathrm{M}$ $\mathrm{LiPF}_{6}$ in DEC). By using GC-MS and NMR an autocatalytic decomposition scheme of $\mathrm{LiPF}_{6}$ including decomposition products could be postulated. They showed that thermal decomposition is inhibited or at least less pronounced, when strong Lewis bases are present to stabilize the equilibrium of $\mathrm{LiPF}_{6}$ and 
$\mathrm{PF}_{5}$. The accumulation of $\mathrm{POF}_{3}$ that would be the consequence of this kind of decomposition scheme was not investigated further.

In a second study, the thermal decomposition of $\mathrm{LiPF}_{6}$-based electrolytes was again in focus of Campion et al. by using GC-MS [40]. Addition of $\mathrm{PF}_{5}$ and $\mathrm{POF}_{3}$ (a hydrolysis products of $\mathrm{PF}_{5}$ ) to electrolyte solutions were investigated by GC-MS. The obtained product distribution of the thermally treated electrolyte was also confirmed by NMR data. Again, an autocatalytic mechanism was suggested. The authors also proposed that the minimization of protic impurities should improve the thermal stability of the electrolyte radically; those impurities enhance the autocatalytic decomposition cycle and DEC reacting to ethylene as driving force for decomposition.

Sasaki and coworkers studied the formation of alkyl dicarbonates with an electrochemical aging setup in Li metal cells [53]. They concluded that lithium alkoxides are the active species for the formation of dicarbonate species, which occurs through a two-step nucleophilic reaction. The experimental setup involved pure solvent molecules as well as different electrolyte formulations. Identification of species was performed using GC-MS with LODs given at $1 \mathrm{ppm}$. In a second study, they tried to suppress the formation of carbonates via addition of $\mathrm{VC}$ as sacrificial carbonate and surface modification of the graphitic anode [52]. Free alkoxide anions could successfully be trapped forming cyclic carbonate compounds with alkoxide substituents. These results appeared to show this benefit of VC as electrolyte additive or co-solvent as it was shown to enhance the cycle and power performance.

Gireaud et al. showed a dependence of the material size and electrolyte regarding the electrolyte decomposition behavior [186]. GC was used for separation; detection was performed with a high resolution-MS also using chemical ionization for structural elucidation of compounds. Polyethylene glycol-like compounds that also showed crossover reactions with carbonate molecules could be identified. This study was the first using high resolution-MS for structural elucidation of electrolyte decomposition products in the LIB context.

$\mathrm{Li}$ and coworkers investigated thermal reactions of electrolyte with the surface of metal oxide cathode $\left(\mathrm{LiNi}_{0.8} \mathrm{Co}_{0.2} \mathrm{O}_{2}\right.$ and $\left.\mathrm{LiCoO}_{2}\right)$ particles [187]. They claimed that the thermal stability of the electrolyte at moderately elevated temperatures $\left(60-100^{\circ} \mathrm{C}\right)$ is enhanced due to the cathode particles but transesterification products were obtained. The experiments were conducted in glass vials at elevated temperatures, which could be problematic due to interactions of electrolyte decomposition products and the glass [177]. In a following study, they investigated the storage behavior of different cathode materials in a DMC, DEC, EC (1:1:1) electrolyte with and without dimethyl acetamide as stabilizer at different temperatures [188]. The changes in the liquid electrolyte of RT and $85{ }^{\circ} \mathrm{C}$ experiments were investigated by GC-MS. No changes could be observed for $\mathrm{LiNi}_{0.8} \mathrm{Co}_{0.2} \mathrm{O}_{2}, \mathrm{LiCoO}_{2}$, and $\mathrm{LiMn}_{2} \mathrm{O}_{4}$. The active material $\mathrm{LiFePO}_{4}$ showed bulk electrolyte decomposition when stored at elevated temperatures without additive.

A similar study compared to Li [187] was conducted by Xiao et al. showing transesterification products of electrolyte carbonates in the presence of anode material and at elevated temperatures [189]. It appears that the carbonaceous anode material does not inhibit any decomposition reactions in contrast to the findings of Li et al. Additionally, the surface film increased depending on the length of storage time and the temperatures which was concluded due to the presence of PEG-like oligomers.

A mechanistic approach was conducted by Gachot and coworkers to decipher the degradation mechanism of carbonate-based electrolytes of LIBs [190]. Electrolytes were electrochemically aged at low potential in a lithium-based cell in this regard. Previous findings were summarized in a well-organized manner and new results were implemented for the postulation of several reaction mechanisms. The authors also differentiated between the pure chemical and the electrochemical formation of species in the regard of formation of oligocarbonates. They postulated an electrochemical initiation of the decomposition that evolved chemically due to the formation of reactive intermediates resulting in a highly diverse reaction cascade (Figure 11). 


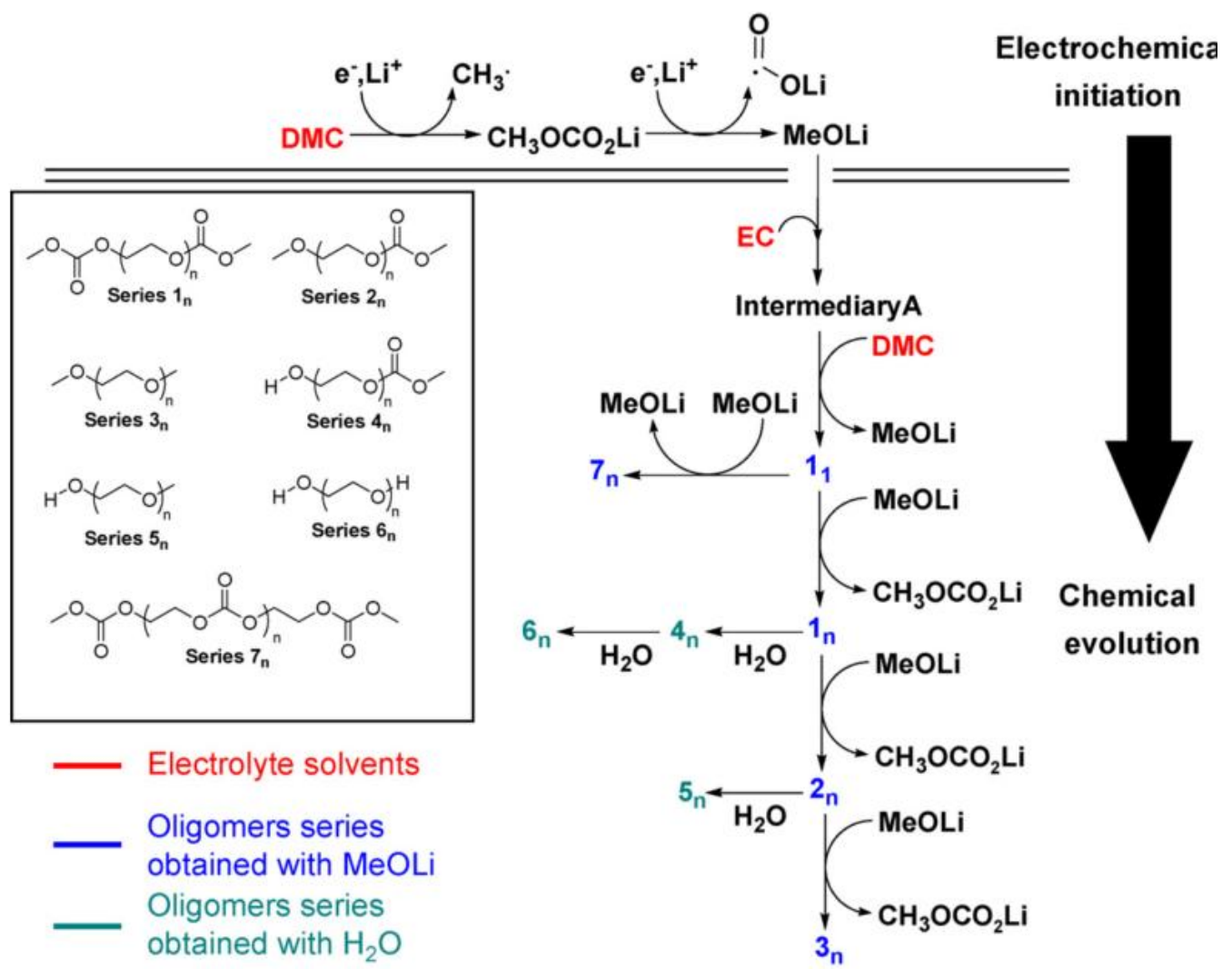

Figure 11. Global scheme of the decomposition routes of carbonate-based aging products according to Gachot et al. Reprinted with permission from [190], Copyright 2008 Elsevier.

Yang and coworkers studied six different electrolytes with different solvents (PC, dimethoxy ethane, 1,3-dioxolane) and 4 different conducting salts for lithium metal application [191]. As the group of Lucht proposed before [187], dimethyl acetamide (1\% addition) inhibited the decomposition reaction of the electrolyte. For the current state-of-the-art conducting salt, $\mathrm{POF}_{3}$, dimethyl ether, diglyme were found as aging products in a thermally treated electrolyte.

Eom et al. investigated the effect of VC on the storage behavior of 18650-type cells at elevated temperatures [192]. The gas was collected after the storage experiment time and then investigated using GC-TCD. The addition of VC showed a decrease of methane evolution during formation and thus a stable SEI formation. The residual electrolyte and thus the remaining VC was investigated using GC-FID. The formation of DEC seems to be less pronounced when VC was still present in the electrolyte and not consumed due to film forming reactions. These findings align with the proposition of VC as sort of sacrificial carbonate as it was proposed before [52].

This influence on the formation of bis carbonates was also studied by Petibon et al. [193]. The aging of different electrolytes in LCO/graphite and NCM/graphite pouch cells was investigated. The electrolyte was extracted by DCM, filtered and the ionic species were removed by water addition. The additive consumption as well as the possible inhibition of emerging bis carbonates was quantified by means of GC-MS. An addition of VC to the electrolyte prevents the conversion of EMC to DMC and DEC. The majority of VC consumption could be connected to the formation cycle. However, VC is, depending on its initial concentration, not completely consumed. It was shown, that the residual $\mathrm{VC}$ was then consumed slowly during the following cycling procedure. The formation procedure concerning the influence of additives towards VC was further investigated in 2014 [194]. The impact of the electrolyte additives methyl phenyl carbonate (MPC) and ethyl phenyl carbonate (EPC) and diphenyl carbonate (DPC) was investigated in presence of VC in NCM/graphite pouch cells. All additive mixtures suppressed the EMC transesterification, which was obtained at weight fractions of $20 \%$ in the 
control [195]. In 2016, Petibon et al. analyzed 10\% FEC in LP57 in LCO/Si-alloy:graphite pouch cells [196]. The reactivity of LiOR towards the electrolyte, especially in relation to the transesterification was investigated in the supplemental information of this study. FEC inhibited the transesterification while EC-OMe and EC-OEt were assigned to emerging signals (MS-spectra given). However, the electrolyte without FEC addition showed the reactivity reported in preceding papers of the group.

In 2011, Gachot and coworkers showed the importance of GC-MS to investigate degradation products in LIB analysis [197]. Especially for analytes in the lower mass range that are highly volatile, this paper demonstrates the importance of GC as analysis technique. Volatile compounds were collected after charge/discharge cycling and investigated using a sophisticated experimental setup (Figure 12). Carbonate oligomer as well as phosphate-based decomposition products could be identified successfully. The decomposition products were also assigned whether they originated from thermal degradation or the reduction of cyclic or linear carbonates.

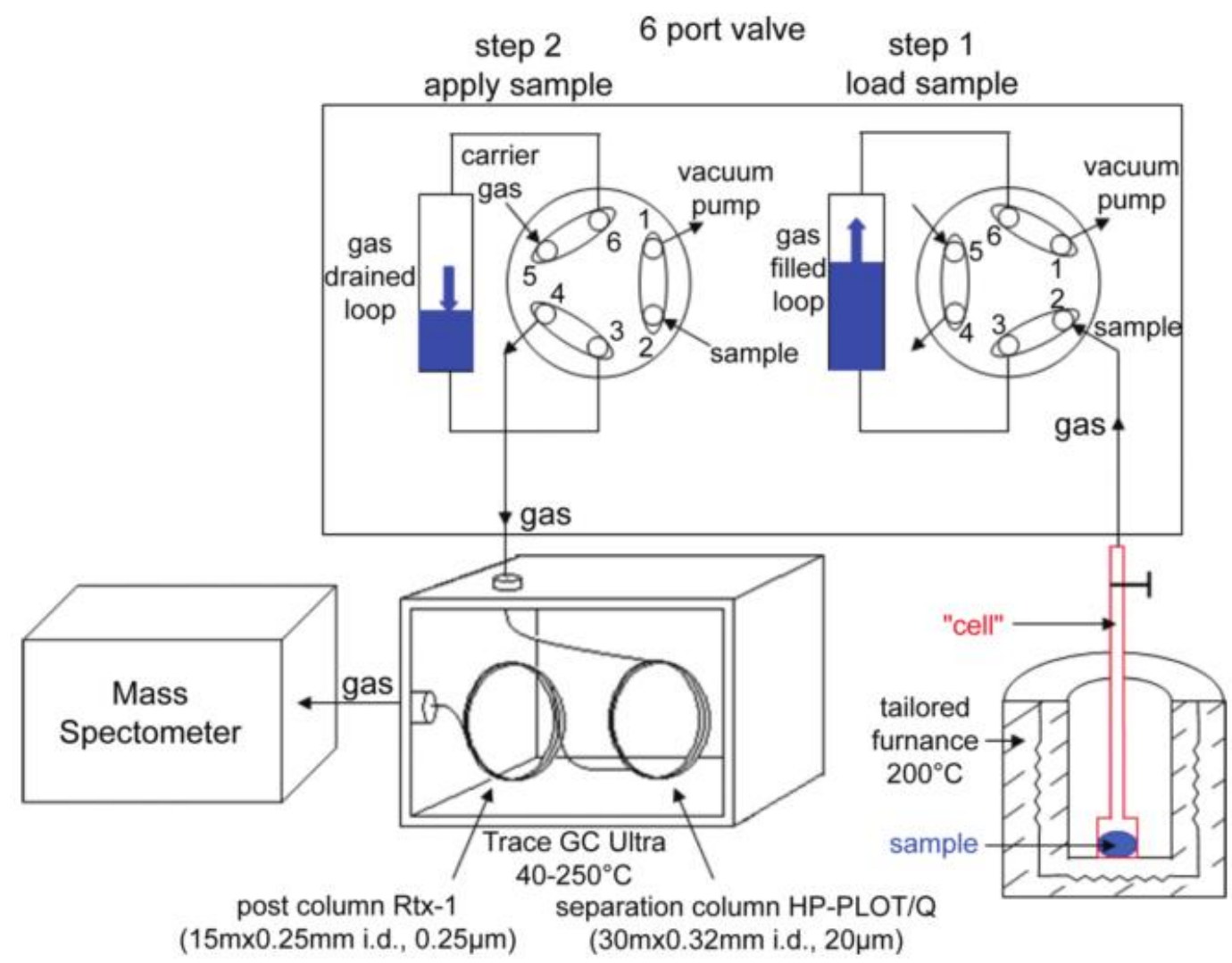

Figure 12. Schematic sampling setup applied by Gachot et al. that allows the analysis of volatile products that are released from LIB components under heating conditions. Reprinted with permission from [197], Copyright 2011 American Chemical Society.

Lithiated carbonaceous material and electrolytes was investigated by Gachot and coworkers in 2012 [54]. Using the same injection system as in previous studies [197], the authors could elucidate a large variety of highly volatile compounds that form using lithiated and delithiated graphite that is even more diverse at elevated temperatures. With that, conclusions of electrolyte solvent molecules and their influence on the SEI were possible also with regard to the solubility of the SEI itself. In a follow-up study, Gachot et al. investigated an electrolyte consisting of $\mathrm{LiPF}_{6}$ in DMC/EC $(1: 1 \mathrm{w} / \mathrm{w})$ which was heated to $200{ }^{\circ} \mathrm{C}$ in presence of $\mathrm{LiC}_{6}$ [198]. The volatile compounds were investigated by GC-FTIR and GC-MS. A wide variety of signals was obtained; some signals could only be seen using one detector, others are identified by both detectors. The compounds range from light hydrocarbons, carbon monoxide, carbon dioxide and small ethers to different esters and alcohols. Furthermore, methyl fluoride and ethyl 
fluoride were identified. The authors also investigated a commercially available cell that was bloated after charge/discharge cycling. Carbon monoxide, carbon dioxide, light hydrocarbons and different fluorinated alkanes, could be detected by either GC-FTIR, GC-MS or both experiments. The remaining liquid phase showed DEC, PC and EC with tert-amylbenzene as additive. Furthermore, DEDOHC, the transesterification product glycol group and 2-((diethoxyphosphoryl)oxy)ethyl ethyl carbonate were identified. They presented this method as a valuable tool for safety investigations of LIBs.

Kim et al. investigated the electrolytes containing different linear carbonates (DMC, EMC, DEC) in mixtures with EC [199]. The electrolyte was recovered from cells at different charge steps of the first cycle $(C / 50)$ and the emerged amount of DMDOHC, EMDOHC and DEDOHC was quantified (normalized versus EC). It was shown that DMDOHC and DEDOHC are predominantly formed at distinct potentials vs. $\mathrm{Li} / \mathrm{Li}^{+}(\sim 0.12 \mathrm{~V} ; 0.6-0.9 \mathrm{~V})$. This study proved the applicability and compatibility of analytical methods for LIB electrolytes. They also followed a mechanistic approach for the formation of the bis carbonates using several educts and showed different reactivity in this regard.

In 2014, Terborg et al. showed a newly developed method using GC-MS and GC-FID for the analysis of organic carbonate-based LIB electrolytes [200]. In addition, a headspace approach was conducted for the analysis of LIB electrodes and separators. All common carbonates that are used in LIB electrolytes were both separated and quantified with GC-FID. Real sample investigation including MS analysis showed the applicability of the developed method. Using HS-GC-MS, solid samples like electrodes and separators could be investigated and electrolyte compounds of interest were identified. Using this developed method (amongst others) of their working group, Grützke et al. reported the investigation of electrolyte after supercritical carbon dioxide extraction [201]. Method development for extraction could successfully be shown as well as real sample investigation. GC-MS (also including chemical ionization), GC-FID and IC were used for the analysis of extracted electrolytes. Carbonate oligomers could be identified as aging products as well as transesterification of solvent carbonates; $\mathrm{LiPF}_{6} \mathrm{was}_{\text {not }}$ extracted (only in traces) using this method. The combination of different chromatographic techniques exposed a comprehensive overview of extracted compounds. In a second study, a supercritical (and liquid) carbon dioxide extraction procedure also using additional solvents was presented by Grützke and coworkers [202]. As shown before, identification and quantification using GC and IC-based techniques could successfully be conducted also including the extraction of the conducting salt. Almost quantitative recovery rates could be achieved using a solvent-assisted liquid carbon dioxide extraction.

In this regard, Liu et al. investigated the extraction of an electrolyte (DMC, EMC, EC; 1:1:1) from a separator by static supercritical fluid extraction (SFE) [203]. The extract was afterward analyzed by GC-MS and no significant difference between the pristine electrolyte and the extract was obtained. They also put the SFE in the context of electrolyte recovery to prevent environmental pollution and to reduce waste of resources through a possible recycling approach. Liu et al. also investigated the extraction of a DMC/EMC/EC (1:1:1) from a polypropylene separator by flow-through SFE at different pressures in 2016 [204]. DEC was used as the internal standard after the extraction to resolve potential variations in the sample preparation/instrument behavior. The recovered electrolyte was quantified by GC-FID and the amount of regained carbonates were time resolved for different extraction times. The standardization using DEC could be problematic as the influence of the extraction in the regard of transesterification was not refined in this work.

In 2017, Mönnighoff et al. investigated commercially available 18650-type cells and studied the influence of the electrolyte on the strong capacity fading they observed at different temperatures $\left(20^{\circ} \mathrm{C}\right.$ and $\left.45^{\circ} \mathrm{C}\right)$ [205]. They could obtain different volatile organic aging products by investigations with GC-MS using EI and both positive and negative chemical ionization. As a result, 17 different compounds could be detected and identified from which seven compounds were not known to literature so far.

As methods that were developed for the analysis of lab cell size LIBs were available, the application for analysis of larger cells was also conducted by Grützke et al. in 2015 [51]. A study of the electrolyte 
of a field-tested hybrid vehicle with GC-MS, GC-FID and IC-ESI-MS was performed. Quantification of carbonate solvents could successfully be conducted as well as the quantities of ionic species in the electrolyte. Reactions of the carbonates and the conducting salt lead to the formation of organophosphates as it was reported before, thus, an extension of the decomposition pathway of the conducting salt was proposed.

Within the development of sample preparation methods, Horsthemke et al. investigated the influence of reduced pressure protocols applied during the manufacturing of 18650-type cells [206]. The used protocol was found to be non-destructive with respect to the ratio between the linear and cyclic carbonates. Furthermore, a short examination of the applied extraction procedure - centrifugation of the jelly roll in their case - was conducted and the authors found a discrimination of the linear carbonate in case of the analysis of certain cells. Due to the limited number of analyzed cells, a more precise investigation was recommended for future experiments.

Handel et al. investigated the influence of protic impurities on the thermal aging of LIB electrolytes [177]. The addition of water (also as trace moisture in cathode materials) at different temperatures was studied with HS-GC-MS. In addition, the influence of glass vials was investigated with headspace-GC-MS showing a large influence of the material in which the aging is conducted. The influence of undried active material was found to be small whereas the addition of moisture to the system resulted in a larger content of decomposition products.

Next to thermal and electrochemical aging, Ortiz and coworkers introduced radiolysis as a tool for accelerated aging studies of LIB electrolytes [207]. DMC and DEC have been treated by radiolysis experiments and the liquid decomposition products have been evaluated by GC-MS. They concluded that the detected electrolyte decomposition products were partially consistent with electrochemical aging procedures. Thus, radiolysis introduced a radical-induced decomposition to the reported model aging by thermal treatment or water addition. In a follow-up study of the aging procedure, the behavior of a PC electrolyte using radiolytical and electrochemical degradation was investigated with respect to the forming aging products in the gas phase and the liquid residue [208]. The addition of $\mathrm{LiPF}_{6}$ to the irradiated sample led to shifted intensities for the already identified compounds and the introduction of additional reaction products. Some could be assigned to (fluoro)phosphorous-containing species. This new model approach showed that radically induced decomposition might deliver decomposition products (on a short timescale) that are mechanistically closer to electrochemical than thermal treatment.

In 2015, an approach for the identification of organophosphates in LIB electrolytes was performed by Weber et al. via GC-based techniques and MS detection using different ionization principles [209]. To obtain a large variety of decomposition compounds thermal aging of the electrolyte was conducted. Fifteen organo(fluoro)phosphates could be identified and described by characteristic EI fragments. Mechanistic consideration led to the conclusion that electrolyte quality can be determined using typical decomposition products as fingerprint marker that could indicate the age or the aging of the battery electrolyte. One year later, a comprehensive study including GC-MS and IC-ESI-MS techniques was performed by Weber and coworkers [48]. They focused on acidic and non-acidic organophosphates as decomposition products of electrolytes from electrochemically treated LIBs (cut-off voltage $>4.5 \mathrm{~V}$ vs. $\mathrm{Li} / \mathrm{Li}^{+}$). GC-investigations focused on the non-acidic decomposition products. A high dependency of the applied upper cut-off voltage on the variety of decomposition products was discovered. In addition, new fingerprint compounds were determined (as reported before in [209]) to describe the electrolyte status in terms of aging. The possibility of the determination of the age of the electrolyte and concomitant the LIB is of high value with regard to safety and also recycling.

Börner and coworkers studied the degradation effects of commercial layered cathode materials [121]. In that context, HS-GC-MS was used for the investigations of electrolyte that was electrochemically aged at elevated cut-off voltages. The formation of organophosphates could be shown only in the framework of this study next to carbonate oligomers as described before. Evertz et al. showed the applicability of GC-MS and IC methods for the identification of aging products in electrolyte that were previously developed in this group [119]. Reliable information about 
oligocarbonates, transesterification products and fluoride content could be given as routine analysis by then.

The relative quantities of decomposition products in relation to their storage time (in shredded state) was examined by Grützke and coworkers [210]. Positive and negative chemical ionization was used to precisely describe a large variety of different decomposition products including phosphorous and oligocarbonate compounds. The method was optimized to separate all compounds of interest (28 signals) in a short analysis time of twelve minutes.

Michan et al. investigated the reduction products of pure VC and FEC emerging by a reaction with lithium naphthalenide [211]. The analytes of the liquid residue in their study showed traces of VC for the reaction of FEC. An elimination produces HF and VC as a reaction of FEC; this makes these two carbonates especially noteworthy for film formation in LIBs with FEC additionally delivering HF for the formation of inorganic LiF in the films.

Horsthemke and coworkers showed a fast screening method of the electrolyte of a commercial LIB cell using solid phase microextraction (SPME) hyphenated to GC-MS [212]. General electrolyte compounds as well as additives and decomposition products (oligocarbonates) could successfully be described with this easy and fast analysis technique. All cell components were investigated by the extraction technique and interrelated. In addition, alkane structures of the electrolyte of industrial cells were accessible with this setup. A subsequent study was focused on the enhanced availability of carbonate-based decomposition products achieved by the applied preconcentration method [213]. MS with chemical ionization was applied to achieve additional information and the assigned structures-namely carbonates with $\mathrm{C} 3 / \mathrm{C} 4$ moieties - were verified by synthesized standards. The authors concluded that a carbon-carbon bond formation occurred during cell operation.

Strehlau et al. showed an approach for toxicological investigations of LIB electrolytes after liquid-liquid extraction and GC-MS investigation of a cell culture medium that was incubated with electrolyte [214]. The stability of carbonates in the medium was studied and it was concluded that transfer of organic carbonates through the blood-(blood-cerebrospinal fluid) barrier occurred in this experimental setup. The method showed decent recovery rates and analytical figures of merit. The highly relevant aspect of toxicity of electrolytes and the influence towards mammals in general was presented.

In the regard of possible toxicological influences of LIB electrolytes and their decomposition products, Stenzel and coworkers investigated organo(fluoro)phosphates using GC for the separation of species with a hyphenated ICP-sector field-MS [215]. After method development, thermally aged electrolyte could successfully be investigated giving quantities of the identified organophosphates as decomposition products of LIB electrolytes. In a following study, Stenzel et al. showed the applicability of derivatization of phosphorous species for simultaneous analysis of non-acidic and (previously not GC-accessible) acidic decomposition products with only one method [216]. The mainly formed decomposition products could be identified after silylation, which proves the possibility of simultaneous analysis of both non-acidic and acidic with GC-MS. The authors concluded that the silylation did not affect the electrolyte matrix significantly and that the influence on aging products was negligible.

\subsubsection{Permanent Gas Analysis}

A clear differentiation of typical permanent gases emerging from LIB electrolyte and the analysis of the liquid electrolytes is challenging. On the one hand, the solubility of various gases in organic electrolytes leads to their presence in analysis attempts with liquid injection; on the other hand, the low vapor pressure of the linear carbonates, their surrogates and decomposition products causes their presence in the gas phase. Nevertheless, different GC system and especially the selected columns provide a differentiation between analyses focusing on either the liquid phase or the permanent gases. The columns developed to analyze the permanent gases typically show high retentions for the linear carbonates while being able to separate the permanent gases of interest. Standard columns for liquid 
injections, on the other hand, typically lead to co-elution of permanent gases. A direct comparison of columns developed to separate permanent gases (Figure 13a,b; polystyrene-divinylbenzene-based, $20 \mu \mathrm{m}$ film thickness) and the liquid constituents (Figure 13c; cyanopropyl polysilene-siloxane-based, $0.25 \mu \mathrm{m}$ film thickness) was among others reported by Gachot et al. [198]. Thereby, the importance of choosing the column that is best suited for the respective analysis is shown. Diethyl carbonate is present in both the gas and the liquid sample of the investigated swollen pouch cell. However, the observed retention times are completely different with DEC being the last analyte eluting from the column $(a, b)$ and exhibiting the lowest retention time in case of the liquid analytes (c). Furthermore, the experimental part and the supplemental information of this paper exhibit a comprehensive summary about all technically relevant information to analyze permanent gases-e.g., injector and detector temperatures and gas flows; oven program. Studies reporting analysis techniques for permanent gases in similar detail were done by Bai [217], Ortiz [208], and the Dahn group [195,218].
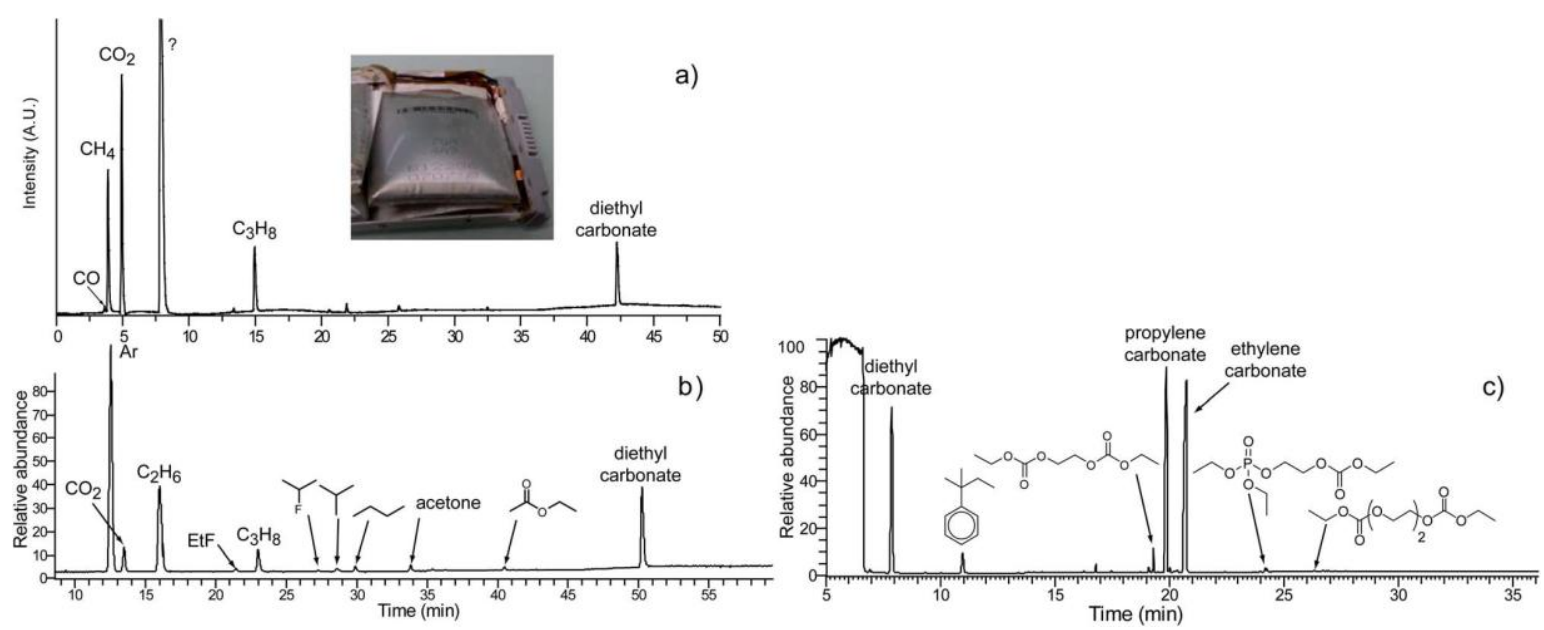

Figure 13. (a) GC/FTIR Gram-Schmidt with picture of the swollen battery. (b) GC/MS chromatogram of the gas formed in a swollen commercial battery. (c) GC/MS chromatogram of the electrolyte solvent and less volatile degradation compounds formed in the battery. Reprinted with permission from [198], Copyright 2014 Royal Society of Chemistry.

In the last two decades, the analysis of emerging gases by online electrochemical mass spectrometry (OEMS) has been frequently reported within the LIB context [219-223]. The method benefits in comparison to GC-based techniques from a time-resolved signal, which can be directly connected to the reactions occurring in the cells. However, analytes emerging at the same time are not separated from each other and thereby detected simultaneously. Therefore, the wide variety of emerging permanent gases, which often show similar fragments, cause complex mass spectra leading to challenging qualifications and quantifications. Although being an important analytical tool in the field of LIB analysis the OEMS technique is not in the focus of this review, as separation is not given.

The sampling of permanent gases and especially their quantitation leads to a variety of challenges. The accessibility of gases emerging in the cells is limited and requires specifically designed cells or devices to puncture the cell housings without affecting the cell performance. Furthermore, the amount of emerging gas during normal charge/discharge cycling is explicitly small. Several sampling methods, which are prone to sample losses, require the flushing of sampling loops or vials. Apart from typical charge/discharge cycling conditions, different reasons are known to induce the formation of higher amounts of permanent gases. Therefore, the presence of high amounts of permanent gases is strongly connected to four main reasons:

a) Gases emerging during cell formation procedure

b) Overcharge of the cells and related electrode/electrolyte reactions 
c) Elevated temperature conditions

d) External abuse of the cells ultimately leading to thermal runaway

In case of excessive reactions typically taking place during thermal runaway or overcharge, the emerging gas amount simplifies the sampling procedures. For instance, the gases formed during thermal runaway in an accelerated rate calorimetry (ARC) system can be sampled in vessels comprising sufficient volumes and overpressure. In addition to the above list of origins of permanent gases, experiments based on different model aging of LIB components and the subsequent identification of emerging permanent gases adds a fifth category of the gas origin. Table 1 summarizes the discussed literature with respect to the origin of the analyzed gases and the utilized detectors.

Table 1. Literature including the chromatographic analysis of permanent gases emerging in LIBs.

\begin{tabular}{|c|c|c|}
\hline Origin of the Gases & Detector & References \\
\hline \multirow{4}{*}{ Formation } & AED & [224] \\
\hline & MS & {$[195,218,225,226]$} \\
\hline & TCD & {$[57,196,227]$} \\
\hline & $\mathrm{n} / \mathrm{a}$ & [228] \\
\hline \multirow{4}{*}{ Cyclic Aging } & FID & [229] \\
\hline & MS & [230] \\
\hline & TCD & [229] \\
\hline & $\mathrm{n} / \mathrm{a}$ & [231] \\
\hline \multirow{5}{*}{ Overcharge } & FID & [152] \\
\hline & FTIR & {$[152,153]$} \\
\hline & MS & [232] \\
\hline & TCD & [153] \\
\hline & $\mathrm{n} / \mathrm{a}$ & [233] \\
\hline \multirow{6}{*}{$\begin{array}{l}\text { Thermal Runaway/Abuse Conditions } \\
\text { (ARC, etc.) }\end{array}$} & FID & [234] \\
\hline & FTIR & [198] \\
\hline & MS & {$[198,235]$} \\
\hline & TCD & {$[234,236-240]$} \\
\hline & VUV & [217] \\
\hline & $\mathrm{n} / \mathrm{a}$ & {$[241,242]$} \\
\hline \multirow{4}{*}{$\begin{array}{l}\text { Model Aging of LIB Components } \\
\text { (Thermal; Radiolysis, etc.) }\end{array}$} & FTIR & {$[243,244]$} \\
\hline & MS & {$[151,207,208,211,243-250]$} \\
\hline & TCD & {$[207,208,249,250]$} \\
\hline & $\mathrm{n} / \mathrm{a}$ & [251-253] \\
\hline
\end{tabular}

The analyses of permanent gases emerging during the formation procedure was investigated by a variety of different research groups. Yoshida et al. [57] focused their work on open prismatic cells and their findings are already discussed in 3.3, while Ota et al. [228] used an assembly-type cell (stainless steel). They described the investigation of permanent gases emerging during the formation procedure of cells containing $1 \mathrm{M} \mathrm{LiPF}_{6}$ in DMC/EC (1:1). The applied GC setup consisted of two different columns at isothermal conditions $\left(70^{\circ} \mathrm{C}\right)$ while the utilized detection method was not specified. Carbon monoxide, carbon dioxide and different hydrocarbons were found in the standard electrolyte with methane, carbon monoxide and ethene as main components. The addition of $2 \% \mathrm{VC}$ shifted the ratio in direction of carbon dioxide and an electrolyte consisting of $\mathrm{LiPF}_{6}$ in $\mathrm{VC}$ showed carbon dioxide and 
low amounts of carbon monoxide while the authors reported the presence of ethyne traces in this case. Furthermore, the authors found that the presence of hydrogen was only confirmed in case of increased water content of the cell materials.

However, all of the other referenced studies were based on pouch cells. The cell format provides easy access to the emerging gas volume i.e., by directly puncturing the foil with a syringe. Onuki et al. subsequently utilized a GC system with atomic emission detector (AED) to analyze the gases emerging from NCA-based cells with DEC/EC electrolyte stored at elevated temperatures [224]. Hydrogen, carbon monoxide and carbon dioxide were identified. The application of ${ }^{13} \mathrm{C}$ marked carbonates enabled a more precise classification of their origin using the shifted $\mathrm{C}-\mathrm{O}$ emission line (177.49 to $176.93 \mathrm{~nm}$ ). Further experiments were performed with anode and cathode materials in presence of the electrolyte. Carbon dioxide was reported to be formed at the cathode side. Subsequently the developed method was applied to analyze gas emerging during the formation procedure. The main constituents were identified as hydrogen, ethene and carbon monoxide and the isotope analyses showed that ethene was exclusively attributed to EC, while the origin of ethane, which was found in traces, was assigned to DEC.

As already described in the section focusing on the electrolyte analysis (3.3.4) the formation behavior of a variety of different additives was investigated by the group of Dahn. Besides the electrolyte, emerging gases were examined. Self et al. analyzed the gas expansions in NCM-based pouch cells including the qualification of the emerging formation gas [218]. Therefore, a special gas extraction device was developed, enabling a punctuation of the cells in a closed environment, which was evacuated (100 mTorr) prior to the cell opening. Afterwards, the extracted gas was diluted by argon to reach atmospheric pressure, withdrawn by a gastight syringe and injected into the GC-MS system. Carbon dioxide, ethene and ethane were found to be the most prominent components in all cases. In contrast, the addition of VC to the EMC/EC-based electrolyte reduced the signals related to methane and propene. Furthermore, the authors note that a detection of hydrogen, which is expected to emerge during the LIB formation, was not possible with the used MS detector. Petibon et al. investigated the formation gases emerging during formation of cells with EMC/EC-based electrolytes and methyl phenyl carbonate and diphenyl carbonate as additives [195]. In compliance to the findings of Self et al. carbon dioxide, ethene and ethane showed the most prominent signals. Furthermore, the authors proposed different decomposition pathways of the applied additives resulting in the found permanent gases and e.g., benzene, which was identified besides the permanent gases. The study focused on the film forming behavior of ethylene sulfite (ES) and VC by Madec et al. [226] utilized the same experimental setup as Self et al. [218] and Petibon et al. [195]. Formation of the cells at $2.4 \mathrm{~V}$ and $3.5 \mathrm{~V}$ showed a significant difference in the present permanent gases. The formation at $3.5 \mathrm{~V}$ showed carbon dioxide, ethene and ethane as main components for all electrolyte formulations. Whereas the signal corresponding to ethane is missing in the composition of the $2.4 \mathrm{~V}$ formation. Furthermore, the authors concluded that the presence of VC lowers the ethene signal originating from an EC reduction, while the ES does not seem to influence the gassing behavior other than adding sulfur-containing permanent gases.

Based on the qualification method described in the previous studies, Petibon et al. quantified the permanent gases emerging during the formation of cells based on a silicon alloy/graphite blend vs. LCO [196]. The applied electrolyte consisted of $1 \mathrm{M} \mathrm{LiPF}_{6}$ in EMC/EC/FEC (63:27:10) with increased amount of film forming additive, which is typical for electrolytes applied in silicon-containing anodes. Furthermore, the MS detection system was replaced and a TCD detector was used - the advantages and disadvantages of the different detector systems will be discussed in the end of this chapter. Based on a standard mixture containing hydrogen, nitrogen, carbon monoxide, carbon dioxide and different hydrocarbons the emerged gas $(0.17 \mathrm{~mL})$ was reported to consist of hydrogen $(7.9 \%)$, carbon dioxide $(92.1 \%)$ and trace amounts of carbon monoxide.

Ellis et al. investigated the gassing behavior of a cell with graphite/NCM chemistry by GC-TCD [227]. First experiments showed that a cell initially charged to $\approx 3.5 \mathrm{~V}$ resulted in less gas formation than in the fully charged state $<4.5 \mathrm{~V}$. The main constituents of the emerging gas 
at the two different charge voltages were similar except for carbon dioxide, which was absent in the gas sampled at the lower voltage. Furthermore, the gas of an initially charged cell (4.5 V) was monitored under open circuit voltage conditions over a period of $300 \mathrm{~h}$ and the amounts of hydrogen, carbon monoxide, carbon dioxide and ethene were found to be decreasing. The authors concluded that the gas is partially consumed in the full cell system and separately investigated the influence of charged anodes and cathodes. These findings were further investigated by measuring the volume changes of pouch bags comprising of the gases of interest and charged electrodes. Furthermore, the authors verified the tightness of the applied measurement systems by gas storage experiments summarized in the supplemental information.

In contrast to the gases emerging during the formation procedures, the gas amounts present in case of normal cycling are typically lower. Thus, their accessibility is limited and the utilization of cells with larger sizes beneficial. Matasso et al. used a custom battery test chamber (Figure 14) for cells of the 26650-type with LCO vs. graphite chemistry and analyzed the emerging gases applying different charge/discharge protocols [230]. The emerging gases were withdrawn after the end of life criterion (SOH 60\%) of the commercially available cells (1 M LiPF 6 in DMC:EMC:EC; 1:1:1) was reached. The gases were investigated by GC-MS and methane, carbon dioxide and ethane were identified in all cases. Furthermore, cells cycled with doubled discharge current (1 C to $2 \mathrm{C}$ ) showed an additional signal assigned to propane.

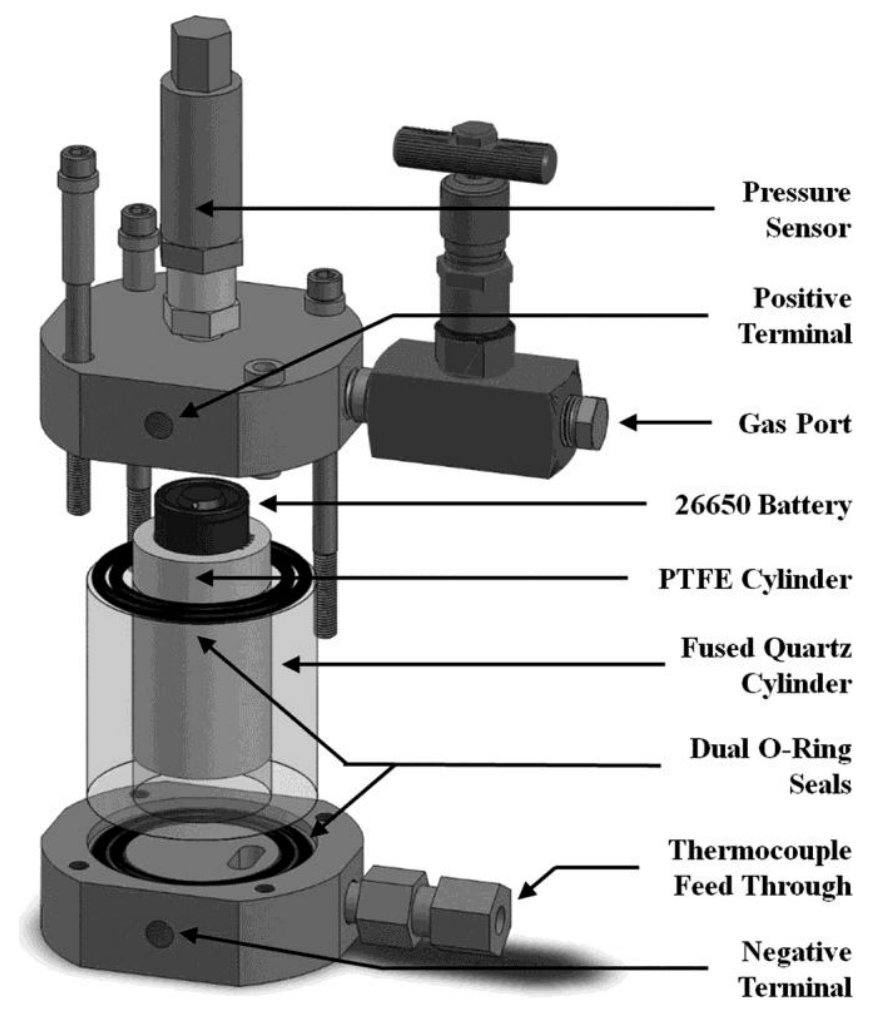

Figure 14. Custom battery test chamber designed to examine in situ pressure evolution of 26650-type LIBs, from Matasso et al. Reprinted from [230], Copyright 2015 according to CC BY-NC-ND 4.0 published by ECS - The Electrochemical Society.

Permanent gases emerging during overcharge cycling of LIBs comprising different cathode materials have been analyzed by Kong et al. [232]. They investigated 18650 cells, which were preparated by drilling a hole into the cap prior to cell assembly. The GC-MS experiments of the gas fraction from cells cycled under normal conditions showed several signals. In the case of normal charge/discharge conditions, the number of peaks-assigned to methane, ethene, ethane, fluoro ethane, propene and propane-did not significantly differ with changed cathode material. However, the changes 
induced by overcharge cycling were found to be strongly related to the utilized cathode material. LCO- and LFP-based cells showed a strong increase of the peak assigned to carbon dioxide, while ethyne was reported in the case of LMO-based cells. The authors suggested an oxidation of ethene to explain these findings.

Safety investigations of LIBs have been an important research topic from the beginning of LIB application $[235,242,254]$. Especially accelerated rate calorimetry (ARC) analyses of cells driven into thermal runaway benefit from a high amount of gases, which are formed in a hermetically closed environment. The direct introduction of the gases into GC systems and the trapping of gases in extraction vessels is possible and the quantification of these gases was realized. However, in case of some early works detailed information about the applied analytical procedures and systems would be beneficial for comparison and interrelation between different studies.

Gachot et al. investigated the gas phase emerging during the reaction of lithiated graphite with a DMC/EC-based electrolyte at $200{ }^{\circ} \mathrm{C}$ using a parallel GC-FTIR-MS system [198]. A variety of different signals was obtained, and structural elucidation was performed using the information of both detector systems. In addition to the already described permanent gases like carbon monoxide, carbon dioxide and hydrocarbons, different compounds containing ether and ester moieties have been identified. Furthermore, the authors reported the presence of fluorinated alkanes and alcohols. Additionally, the gas phase extracted from a swollen pouch cell was investigated and methane, carbon dioxide, ethane and propane were identified as main constituents (Figure 13) while some of the previously identified decomposition products were found in traces.

Commercially available 18650-type cells with different cathodes materials were deliberately driven into thermal runaway by Golubkov et al. and the emerging gases were analyzed by GC-TCD [236]. Except for ethane, which was not identified in case of NCM-based cells the same gases were present in all cases. However, the quantification showed distinct differences with respect to the concentrations of the constituents. Especially the ratio of carbon monoxide to carbon dioxide shifts strongly. LFP cells showed about $50 \mathrm{~mol} \%$ carbon dioxide and only $5 \mathrm{~mol} \%$ carbon monoxide, whereas the LCO/NCM cells showed about $25 \mathrm{~mol} \%$ for both components. In a subsequent study the influence of the SOC including overcharged cells was investigated and a shift from carbon dioxide to carbon monoxide and hydrogen was found with increasing SOC [237].

Lammer et al. developed a test rig enabling the automated sampling of emerging gases during the thermal runaway of 18650 cells (Figure 15) [238]. A gas portion from different defined points during the thermal runaway of NCA-based cells was sampled and analyzed by $\mu$-GC. During the first venting incident and the thermal runaway carbon dioxide is the most prominent constituent in all investigated systems, whereas, the gaseous deflagration products shift to hydrogen and carbon monoxide. A subsequent study using the same test rig was carried out by the same author focusing on changes introduced by cyclic aging or calendric aging at elevated temperatures prior to the thermal runaway [239]. Therein, distinct changes were reported, e.g., the strongly increased ethene fractions in the gas obtained from the first venting incident of the cells stored at $60^{\circ} \mathrm{C}$.

A variety of fully charged NCM-based cells dedicated to automotive applications was forced into thermal runaway by Koch et al. [240]. The emerging gases were extracted from the utilized autoclave setup and quantified by GC-TCD. The authors identified seven different permanent gases and their combined volume fractions were reported to be responsible for 99 vol. $\%$ of the emitted gases in most cases. The gases were assigned into three groups; (a) main components with around $30 \mathrm{vol} . \%$ including carbon monoxide, carbon dioxide and hydrogen; (b) methane and ethene with about 5 vol. \%; (c) trace components with concentrations below 1 vol.\% (ethane and propane). Furthermore, the total amount of emerging gas did not show an influence on the volume ratio of the constituents. Note that the authors refer to a German ISO equivalent for detailed information about the utilized system parameters and use the German abbreviation WLD (Wärmeleitfähigkeitsdetektor) for the detection system. 


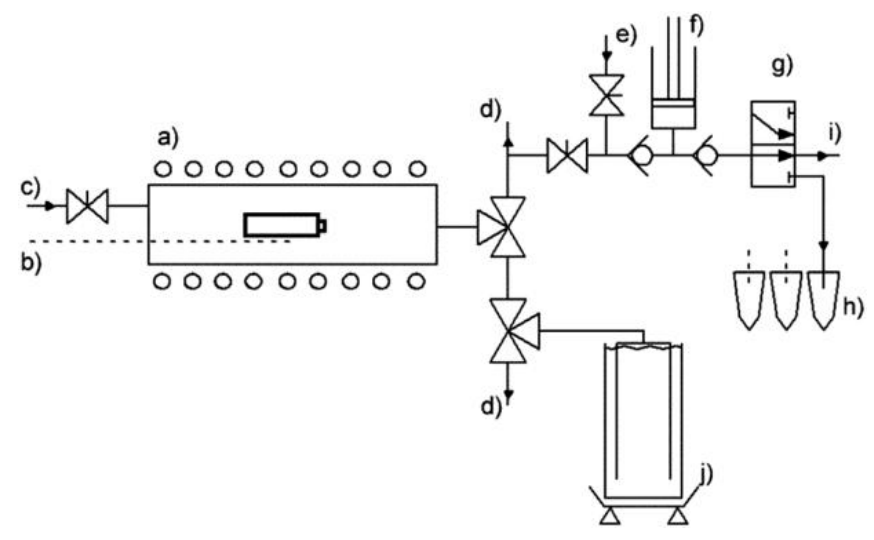

Figure 15. Schematic of the test rig consisting of electric resistance furnace containing the cell under test (a), thermocouples (b), inert gas inlet (c), off gas releases (d), purge gas inlet (e), syringe pump (f), automated multi-port valve (g), sample vials for GC-analysis (h), purge port (i) and fluid displacement tubes including scales (j). Reprinted from [238]. Published by The Royal Society of Chemistry.

Bai et al. showed the power of a recently introduced detector for GC systems to analyze complex gas mixtures [217]. Among other samples, commercially available 18650 cells with different cathode chemistries were driven into thermal runaway and the emerging gases collected in sampling bags. After GC separation, the analytes were identified by a vacuum ultraviolet (VUV) detector, which uses the absorption of the analytes in the wavelength area between $115-240 \mathrm{~nm}$. Besides the commonly identified gases, carbonyl sulfide, chloromethane, different ethers and aldehydes were assigned to the obtained signals. The characteristic absorption of the analytes even enabled the identification of co-eluting species by signal deconvolution.

Seo et al. examined different carbonate solvents on their reactivity towards lithium naphthalenide, which was used as one electron reducing agent with a potential close to lithiated graphite [246]. The permanent gases, which emerged in these reactions were analyzed by GC-MS. EC, PC, DMC and DEC were reported to produce ethylene, propylene, methane and ethane, respectively. Michan et al. expanded the study and investigated the film forming additives VC and FEC [211]. In the case of $\mathrm{VC}$, an absence of carbon dioxide was reported and only carbon monoxide was found. These results are contradictory to the results of Ota et al.; they reported almost exclusively detected carbon dioxide during the formation of an electrolyte consisting of $\mathrm{LiPF}_{6}$ in $\mathrm{VC}$ [228]. Whereas the FEC reduction showed both gases. All reaction products were discussed with respect to proposed reaction schemes.

Ortiz et al. examined radiolysis experiments as model aging methods for LIB electrolytes. The samples were irradiated using different doses and the emerging gaseous decomposition products were qualified and quantified by GC-MS and $\mu$-GC [207]. Carbon dioxide, hydrogen, ethane and carbon monoxide were identified as main products and their respective abundance increased in a linear manner with higher irradiation doses. Other hydrocarbons and compounds with ether or aldehyde moieties were reported to be present in low concentrations. The study was expanded to the investigation of PC and mixtures of different conducting salts in PC in a follow-up paper [208]. The irradiated PC showed hydrogen, carbon monoxide and carbon dioxide as main constituents of the gaseous phase. Moreover, the addition of $\mathrm{LiPF}_{6}$ to $\mathrm{PC}$ led to almost doubled radiolytic yields of carbon dioxide while the yields of the other compounds stayed almost constant. In order to classify the results of the radiolysis experiments an electrolysis of $1 \mathrm{M} \mathrm{LiPF}_{6}$ in $\mathrm{PC}$ was performed. The emerging gases were analyzed using GC-FTIR-TCD for the inorganic gases and GC-FTIR-FID to detect the organic gas fractions. The authors concluded that the high dose rate radiolysis may mimic, with a fair approximation and within much shorter times, the degradation processes involved in electrochemical experiments. Further investigations focusing on radiolysis experiments as model aging techniques of LIB electrolytes and their components were performed by Wang et al., who investigated the differences 
between single carbonates and their binary mixtures [249]. Varenne et al. used radiolysis in presence of active materials to investigate the forming agglomerates [250].

Xiong et al. investigated the gassing behavior of differently charged cells and single electrodes at elevated temperatures [247]. The cells were employing NCM cathodes with different stoichiometry vs. graphite charged to 4.2 or $4.4 \mathrm{~V}$ after formation. Afterwards the cells were either disassembled and the electrodes separately transferred to pouch bags with control electrolyte. Cells and pouch bags were stored at elevated temperatures $\left(40^{\circ} \mathrm{C}, 60^{\circ} \mathrm{C}\right)$ for a period of $500 \mathrm{~h}$ and emerging gases were analyzed by GC-MS. No gas evolution was observed in case of the charged anodes, while the cells and pouch bags with charged cathodes showed gas formation. The main difference between the cells and pouch bags with cathodes was found for the amount of carbon dioxide that was formed. The pouch bags showed carbon dioxide as main constituent and different hydrocarbons and compounds with ether moieties. Whereas the carbon dioxide showed only minor signals in the gases extracted from LIB full cells. This leads to the conclusion that a fraction of the emerging gases from the cathode side might be reduced again on the anodes of full cells. In a follow-up study, the influence of different additives on the gassing behavior was investigated. Known film forming additives were reported to show no significant difference on the gas volume and the carbon dioxide content of the pouch bags [248].

The summarized literature focusing on the analysis of permanent gases (Table 1) reveals four mainly applied detector types-namely FID, FTIR, MS and TCD-and two detectors, which were only applied in one single study (AED, VUV). The FID and TCD systems do not provide any information other than the retention time, signal intensity and in case of the FID the number of contained carbon atoms (exception: highly oxidized carbon atoms). Whereas the FTIR and MS detectors provide additional information about the detected analytes and thereby are favored for non-target analysis and structural elucidation. However, the TCD is able to detect hydrogen besides the other permanent gases, while the FID detector benefits from low LODs and LOQs of hydrocarbons and a wide linear range. Summing up the qualified permanent gases with respect to the LIB research, hydrogen, oxygen, carbon monoxide, carbon dioxide, a variety of light hydrocarbons and some fluorinated hydrocarbons have been reported as main components. Therefore, the typically present gas mixtures have a moderate complexity and the probability of a co-elution of compounds of interest can be minimized utilizing appropriate columns and temperature programs. Thus, the applicability of TCD and FID detection systems in association with gas mixtures used as standards should be given. Nevertheless, a verification of the assigned compounds using FTIR or MS detectors would always be beneficial - especially in case of the addition of sulfur or nitrogen e.g., as heteroatoms deployed in electrolyte additives. Within this context i.e., Madec et al. detected sulfur-containing permanent gases, which add to the sample's complexity [226].

Therefore, the authors recommend a description of the following parameters when studying the permanent gases:

a) Column parameters (stationary phase, length, inner diameter, coating thickness)

b) Carrier gas and column flow

c) Oven parameters (injector temperature, oven program, transfer line/interface temperature)

d) Detector system and utilized parameters (e.g., temperature, gas flow, detector voltages, etc.)

e) A chromatogram displaying the retention times of the investigated analytes

In case of quantitative analyses, a clarification of the reference for the often-listed vol.\% or mol.\% would be appreciated-e.g., mol.\% relative to the quantified compounds. Since the recovery-rates of $98 \%-102 \%$ are typical for analysis systems-even when analyzing known compositions-a recovery-rate of exactly $100 \%$ in case of numerous different, complex samples should not be obtainable. Among others Koch et al. discussed these issues and concluded that in case of the ARC measurements they conducted in most cases seven species add up to over 99 vol.\% of the total gas volume [240]. However, by missing the hydrogen, i.e., in case of the utilization of MS detectors, the quantification would miss roughly $20 \%$ of the generated gas volume. 


\section{Further Literature}

Since chromatography has become an important technique in LIB research, other sources already reviewed some overlapping literature works in part and in different contexts. Ranging from the description of post mortem analyses techniques for LIBs by Waldmann et al., representing a summary of applicable cell opening processes and subsequent analysis techniques [255]. Nowak et al. described the analysis techniques applied with respect to transition metal dissolution and lithium distribution [122]. The focus of other literature was solely on the sub- and supercritical fluid extraction of LIB electrolytes, followed by chromatographic analysis of the extracts [132]. Moreover, Nowak et al. reviewed the efforts in the chromatographic method development mainly focusing on the emerging, toxic organofluorophosphates compounds within a mini-review [47]. Rosenberg et al. summarized the developments in the early stages of chromatography-based analyses of LIB electrolytes [256].

\section{Summary and Conclusions}

In this review, we report on the use of a variety of chromatographic and related separation methods for the investigation of LIB materials. The progress of methodology suggests a clear progression of the analytical tools and related understanding. The characterization of pristine battery materials (especially electrolytes) was the first approach of chromatographic analysis. Decomposition products could be identified and quantified, and thus mechanistic conclusions were possible that improved the general understanding of LIBs. Carbonates and ionic liquids as media/solvents for conductive salts were investigated as well as the conductive salts that are used in (state-of-the-art) LIB electrolytes. The reactivity of both individual components and their interrelation were extensively studied and the resulting compounds such as main and side products of SEI and CEI film formation, fluid oligomers, active materials or possible hazardous decomposition products were identified and interpreted. A universal overview of analysis fields with a large quota of chromatographic-based techniques is shown in Figure 16. Ranging from extraction techniques like SFE, liquid-liquid or SPME over to chromatographic set-ups (GC, LC, IC, CE) in all their varieties up to a wide range of molecular and elemental detection systems, the broad applicability of chromatography in LIB analysis was shown by numerous examples. Despite the bandwidth of methods that were discussed in this review, total numbers of publications although showing an increasing trend (Figure 5) are still relatively underrepresented. As chromatographic or separation techniques heavily used analytical techniques, increasing numbers of investigations with a focus on the identification and quantification including validation and comprehensive studying of the matter are in need. Right now, analytical and "battery analytical" publications show differences regarding the extent of metrology elements, validation and comprehensiveness. We suggest collaborative work including expertise in battery investigations and analytical expositions of findings to meet the high standards of both fields. Additionally, as the presence of analytical standards is still lacking, we also encourage the authors to conclude (next to their results) difficulties they encountered during their research to address and appeal to the community to find solutions and to initiate research ideas in the respective regard. The profit, especially for a topic with a global interest like energy storage in general and the lithium ion battery in particular, would be enormous. Further, with regard to the application of LIBs, studying of aging mechanisms is of great importance as recycling strategies or second life application are up and coming. Thus, a final understanding of the black box aged LIB also regarding ecological influences, as well as occupational safety is imperative. 


\section{Chromatographic Techniques in Lithium Ion Battery Research}

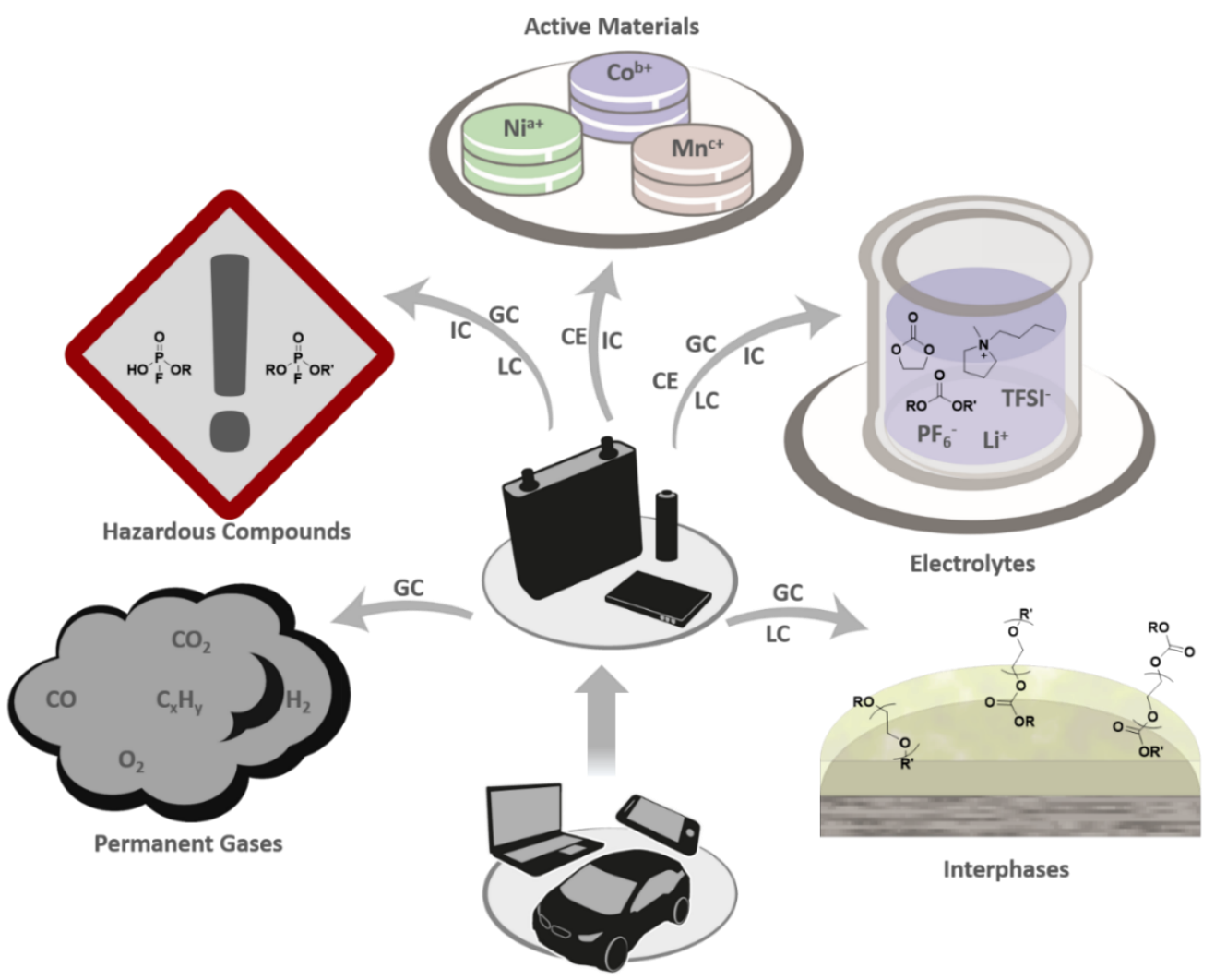

Figure 16. Schematic depiction of the main fields of chromatography in lithium ion battery analysis. The most commonly used separation techniques are depicted at the respective arrows of the fields of analysis of (i) permanent gases, (ii) hazardous compounds, (iii) active materials, (iv) electrolyte in general and (v) interphases (from left to right).

Universally valid conclusions of the analyzed LIB samples are thus meaningful, but we encourage improvements in terms of sample preparation, sample transfer and treatment prior to analysis to ensure validity of results and thus insightful knowledge transfer from analytics to the respective LIB-related scientific fields. The conclusions that were obtained in the reported literature studies shed new light on the lithium ion battery, as we know it today. Continuation and improvement of analysis methods now seem to provide many state-of-the-art techniques for every analysis problem. The investigated topics show both battery-technical and analytical value and prove that a synergy of both disciplines is key for the optimization and understanding of non-aqueous batteries of today and the future.

Author Contributions: Y.P.S., F.H. and S.N. wrote the paper with input, and editing from S.N. and M.W.

Funding: We kindly acknowledge the Federal Ministry of Education and Research (BMBF) for funding the projects "Elektrolytlabor" (project grant number: 03X4632) and "EffiForm" (project grant number: 03XP0034H), the Federal Ministry for Economic Affairs and Energy (BMWI) for funding the project "TRFA_KAL" (project grant number: 03TNH000D), the Federal Ministry for the Environment, Nature Conservation and Nuclear Safety (BMU) for funding of the project "LithoRec II" (project grant number: 16EM1025) and BMBF as well as the National Platform Electromobility for funding the project "iFaaB" (02PJ2512).

Conflicts of Interest: The authors declare no conflict of interest. 


\section{Abbreviations}

\begin{tabular}{|c|c|}
\hline $\mathrm{AChE}$ & acetylcholinesterase \\
\hline AED & atomic emissions detector \\
\hline $\mathrm{AMIM}^{+}$ & 1-amyl-3-methyl-imidazolium [cation] \\
\hline ARC & accelerated rate calorimetry \\
\hline $\mathrm{BETI}^{-}$ & bis-perfluoroethylsulfonylimide [anion] \\
\hline $\mathrm{BMIM}^{+}$ & 1-butyl-3-methyl-imidazolium [cation] \\
\hline $\mathrm{BOB}^{-}$ & bis-(oxalate)borate [anion] \\
\hline CE & capillary electrophoresis \\
\hline CEI & cathode electrolyte interphase \\
\hline CZE & capillary zone electrophoresis \\
\hline DCM & dichloromethane \\
\hline DEC & diethyl carbonate \\
\hline DEDOHC & diethyl-2,5-dioxahexane dicarboxylate \\
\hline $\mathrm{DFOB}^{-}$ & difluoro(oxalate)borate [anion] \\
\hline DFP & difluoro phosphate \\
\hline $\mathrm{DMC}$ & dimethyl carbonate \\
\hline $\mathrm{DMDOHC}$ & dimethyl-2,5-dioxahexane dicarboxylate \\
\hline DPC & diphenyl carbonate \\
\hline $\mathrm{EC}$ & ethylene carbonate \\
\hline EMC & ethyl methyl carbonate \\
\hline EMDOHC & ethylmethyl-2,5-dioxahexane dicarboxylate \\
\hline EMIM $^{+}$ & 1-ethyl-3-methyl-imidazolium [cation] \\
\hline EPC & ethyl phenyl carbonate \\
\hline ES & ethylene sulfite \\
\hline ESI & electrospray ionization \\
\hline$x E V$ & electric vehicle \\
\hline FID & flame ionization detector \\
\hline $\mathrm{FSI}^{-}$ & bis(trifluoromethane)sulfonamide [anion] \\
\hline FTIR & fourier transform infrared spectrometer \\
\hline GC & gas chromatography \\
\hline GPC & gel permeation chromatography \\
\hline HILIC & hydrophilic interaction liquid chromatography \\
\hline HS & headspace \\
\hline IC & ion chromatography \\
\hline ICP & inductively coupled plasma \\
\hline IL & ionic liquid \\
\hline ISE & ion selective electrode \\
\hline IT & ion trap \\
\hline $\mathrm{LC}$ & liquid chromatography \\
\hline $\mathrm{LCO}$ & lithium cobalt oxide $\left(\mathrm{LiCoO}_{2}\right)$ \\
\hline LFP & lithium iron phosphate $\left(\mathrm{LiFePO}_{4}\right)$ \\
\hline LOD & limit of detection \\
\hline LOQ & limit of quantification \\
\hline LTO & lithium titanate $\left(\mathrm{Li}_{4} \mathrm{Ti}_{5} \mathrm{O}_{12}\right)$ \\
\hline MFP & monofluoro phosphate \\
\hline MP & methyl propionate \\
\hline MPC & methyl phenyl carbonate \\
\hline MRM & multi reaction monitoring \\
\hline MS & mass spectrometry \\
\hline $\mathrm{NCM}$ & lithium nickel cobalt manganese oxide $\left(\mathrm{LiNi}_{\mathrm{x}} \mathrm{Co}_{\mathrm{y}} \mathrm{Mn}_{\mathrm{z}} \mathrm{O}_{2} ; \mathrm{x}+\mathrm{y}+\mathrm{z}=1\right)$ \\
\hline OEMS & online electrochemical mass spectrometry \\
\hline OES & optical emissions spectroscopy \\
\hline PC & propylene carbonate \\
\hline PEG & polyethylene glycol \\
\hline
\end{tabular}




$\begin{array}{ll}\text { PMIM }^{+} & \text {1-propyl-3-methyl-imidazolium [cation] } \\ \text { PNS } & \text { peripheral nervous system } \\ \text { PY } & \text { pyrolysis } \\ \text { PYR }_{13}{ }^{+} & \text {1-methyl-1-propylpyrrolidinium [cation] } \\ \text { PYR }_{14}{ }^{+} & \text {1-butyl-1-methylpyrrolidinium [cation] } \\ \text { QToF } & \text { quadrupole time-of-flight [mass spectrometer] } \\ \text { RP } & \text { reversed phase } \\ \text { RSD } & \text { relative standard deviation } \\ \text { SEI } & \text { solid electrolyte interphase } \\ \text { SFE } & \text { supercritical fluid extraction } \\ \text { SPME } & \text { solid phase microextraction } \\ \text { TCD } & \text { thermal conductivity detector } \\ \text { TFSI } & \text { bis-(trifluoromethanesulfonyl)imide [anion] } \\ \text { TMD } & \text { transition metal dissolution } \\ \text { TPD } & \text { temperature-programmed decomposition } \\ \text { VC } & \text { vinylene carbonate } \\ \text { VUV } & \text { vacuum ultraviolet [detector] }\end{array}$

\section{References}

1. Nishi, Y. Lithium ion secondary batteries; past 10 years and the future. J. Power Sources 2001, 100, 101-106. [CrossRef]

2. Ozawa, K. Lithium-ion rechargeable batteries with $\mathrm{LiCoO} 2$ and carbon electrodes: The $\mathrm{LiCoO} 2 / \mathrm{C}$ system. Solid State Ionics 1994, 69, 212-221. [CrossRef]

3. Winter, M.; Barnett, B.; Xu, K. Before Li ion batteries. Chem. Rev. 2018, 118, 11433-11456. [CrossRef]

4. Wagner, R.; Preschitschek, N.; Passerini, S.; Leker, J.; Winter, M. Current research trends and prospects among the various materials and designs used in lithium-based batteries. J. Appl. Electrochem. 2013, 43, 481-496. [CrossRef]

5. Broussely, M.; Biensan, P.; Bonhomme, F.; Blanchard, P.; Herreyre, S.; Nechev, K.; Staniewicz, R. Main aging mechanisms in Li ion batteries. J. Power Sources 2005, 146, 90-96. [CrossRef]

6. Schmuch, R.; Wagner, R.; Hörpel, G.; Placke, T.; Winter, M. Performance and cost of materials for lithium-based rechargeable automotive batteries. Nat. Energy 2018, 3, 267. [CrossRef]

7. Placke, T.; Kloepsch, R.; Duehnen, S.; Winter, M. Lithium ion, lithium metal, and alternative rechargeable battery technologies: The odyssey for high energy density. J. Solid State Electrochem. 2017, 21, 1939-1964. [CrossRef]

8. Bieker, P.; Winter, M. Lithium-Ionen-Technologie und was danach kommen könnte. Chem. Unserer Zeit 2016, 50, 172-186. [CrossRef]

9. Andruleit, H.; Bahr, A.; Babies, H.; Franke, D.; Meßner, J.; Pierau, R.; Schauer, M.; Schmidt, S.; Weihmann, S. Energiestudie 2013. Reserven, Ressourcen und Verfügbarkeit von Energierohstoffen. Fachbereich B 2013, 1, 397-406.

10. VDI Nachrichten, Technik \& Wirtschaft; VDI Verlag GmbH: Düsseldorf, Germany, 2013; p. 34.

11. Meister, P.; Jia, H.; Li, J.; Kloepsch, R.; Winter, M.; Placke, T. Best practice: Performance and cost evaluation of lithium ion battery active materials with special emphasis on energy efficiency. Chem. Mater. 2016, 28, 7203-7217. [CrossRef]

12. Winter, M.; Moeller, K.-C.; Besenhard, J. Carbonaceous and graphitic anodes. In Lithium Batteries; Springer: Boston, MA, USA, 2009; pp. 145-194.

13. Winter, M.; Besenhard, J.O. Lithiated carbons. In Handbook of Battery Materials; John Wiley \& Sons: Hoboken, NJ, USA, 1999; pp. 383-418.

14. Abraham, K.M. Directions in Secondary Lithium Battery Research-and-Development. Electrochim. Acta 1993, 38, 1233-1248. [CrossRef]

15. Balbuena, P.B.; Wang, Y. Lithium-Ion Batteries: Solid-Electrolyte Interphase; World Scientific: Singapore, 2004; p. 424.

16. Besenhard, J.O.; Winter, M. Insertion reactions in advanced electrochemical energy storage. Pure Appl. Chem. 1998, 70, 603-608. [CrossRef] 
17. Buqa, H.; Golob, P.; Winter, M.; Besenhard, J. Modified carbons for improved anodes in lithium ion cells. J. Power Sources 2001, 97, 122-125. [CrossRef]

18. Buqa, H.; Blyth, R.; Golob, P.; Evers, B.; Schneider, I.; Alvarez, M.S.; Hofer, F.; Netzer, F.; Ramsey, M.; Winter, M. Negative electrodes in rechargeable lithium ion batteries-Influence of graphite surface modification on the formation of the solid electrolyte interphase. Ionics 2000, 6, 172-179. [CrossRef]

19. Winter, M.; Brodd, R.J. What Are Batteries, Fuel Cells, and Supercapacitors? Chem. Rev. 2004, 104, 4245-4270. [CrossRef] [PubMed]

20. Kohs, W.; Santner, H.; Hofer, F.; Schröttner, H.; Doninger, J.; Barsukov, I.; Buqa, H.; Albering, J.; Möller, K.-C.; Besenhard, J. A study on electrolyte interactions with graphite anodes exhibiting structures with various amounts of rhombohedral phase. J. Power Sources 2003, 119, 528-537. [CrossRef]

21. Andre, D.; Kim, S.J.; Lamp, P.; Lux, S.F.; Maglia, F.; Paschos, O.; Stiaszny, B. Future generations of cathode materials: An automotive industry perspective. J. Mater. Chem. A 2015, 3, 6709-6732. [CrossRef]

22. He, P.; Yu, H.; Zhou, H. Layered lithium transition metal oxide cathodes towards high energy lithium-ion batteries. J. Mater. Chem. 2012, 22, 3680-3695. [CrossRef]

23. Börner, M.; Klamor, S.; Hoffmann, B.; Schroeder, M.; Nowak, S.; Würsig, A.; Winter, M.; Schappacher, F. Investigations on the C-Rate and Temperature Dependence of Manganese Dissolution/Deposition in LiMn2O4/Li4Ti5O12 Lithium Ion Batteries. J. Electrochem. Soc. 2016, 163, A831-A837. [CrossRef]

24. Scrosati, B.; Garche, J. Lithium batteries: Status, prospects and future. J. Power Sources 2010, 195, $2419-2430$. [CrossRef]

25. Garche, J.; Dyer, C.K.; Moseley, P.T.; Ogumi, Z.; Rand, D.A.; Scrosati, B. Encyclopedia of Electrochemical Power Sources, 1st ed.; Elsevier Science: Amsterdam, The Netherlands, 2013; p. 4538.

26. Winter, M.; Besenhard, J.O.; Spahr, M.E.; Novák, P. Insertion electrode materials for rechargeable lithium batteries. Adv. Mater. 1998, 10, 725-763. [CrossRef]

27. Winter, M.; Besenhard, J.O. Wiederaufladbare Batterien. Chem. Unserer Zeit 1999, 33, 252-266. [CrossRef]

28. $\mathrm{Xu}, \mathrm{K}$. Electrolytes and interphases in Li-ion batteries and beyond. Chem. Rev. 2014, 114, 11503-11618. [CrossRef]

29. Xu, K. Nonaqueous liquid electrolytes for lithium-based rechargeable batteries. Chem. Rev. 2004, 104, 4303-4418. [CrossRef] [PubMed]

30. Jow, T.R.; Xu, K.; Borodin, O.; Makoto, U. Electrolytes for Lithium and Lithium-Ion Batteries; Springer: Berlin, Germany, 2014; Volume 58.

31. Tasaki, K.; Goldberg, A.; Winter, M. On the difference in cycling behaviors of lithium-ion battery cell between the ethylene carbonate-and propylene carbonate-based electrolytes. Electrochim. Acta 2011, 56, 10424-10435. [CrossRef]

32. Ue, M. Mobility and Ionic Association of Lithium and Quaternary Ammonium Salts in Propylene Carbonate and $\gamma$-Butyrolactone. J. Electrochem. Soc. 1994, 141, 3336-3342. [CrossRef]

33. Park, M.; Zhang, X.; Chung, M.; Less, G.B.; Sastry, A.M. A review of conduction phenomena in Li-ion batteries. J. Power Sources 2010, 195, 7904-7929. [CrossRef]

34. Ahmadi, L.; Young, S.B.; Fowler, M.; Fraser, R.A.; Achachlouei, M.A. A cascaded life cycle: Reuse of electric vehicle lithium-ion battery packs in energy storage systems. Int. J. Life Cycle Assess. 2017, 22, 111-124. [CrossRef]

35. Dewulf, J.; Van der Vorst, G.; Denturck, K.; Van Langenhove, H.; Ghyoot, W.; Tytgat, J.; Vandeputte, K. Recycling rechargeable lithium ion batteries: Critical analysis of natural resource savings. Resour. Conserv. Recycle 2010, 54, 229-234. [CrossRef]

36. Xu, J.; Thomas, H.; Francis, R.W.; Lum, K.R.; Wang, J.; Liang, B. A review of processes and technologies for the recycling of lithium-ion secondary batteries. J. Power Sources 2008, 177, 512-527. [CrossRef]

37. Vetter, J.; Novák, P.; Wagner, M.; Veit, C.; Möller, K.-C.; Besenhard, J.; Winter, M.; Wohlfahrt-Mehrens, M.; Vogler, C.; Hammouche, A. Ageing mechanisms in lithium-ion batteries. J. Power Sources 2005, 147, $269-281$. [CrossRef]

38. Lux, S.; Lucas, I.; Pollak, E.; Passerini, S.; Winter, M.; Kostecki, R. The mechanism of HF formation in LiPF6 based organic carbonate electrolytes. Electrochem. Commun. 2012, 14, 47-50. [CrossRef]

39. Ravdel, B.; Abraham, K.; Gitzendanner, R.; DiCarlo, J.; Lucht, B.; Campion, C. Thermal stability of lithium-ion battery electrolytes. J. Power Sources 2003, 119, 805-810. [CrossRef] 
40. Campion, C.L.; Li, W.; Lucht, B.L. Thermal decomposition of LiPF6-based electrolytes for lithium-ion batteries. J. Electrochem. Soc. 2005, 152, A2327-A2334. [CrossRef]

41. Campion, C.L.; Li, W.; Euler, W.B.; Lucht, B.L.; Ravdel, B.; DiCarlo, J.F.; Gitzendanner, R.; Abraham, K. Suppression of toxic compounds produced in the decomposition of lithium-ion battery electrolytes. Electrochem. Solid-State Lett. 2004, 7, A194-A197. [CrossRef]

42. Wilken, S.; Treskow, M.; Scheers, J.; Johansson, P.; Jacobsson, P. Initial stages of thermal decomposition of LiPF 6-based lithium ion battery electrolytes by detailed Raman and NMR spectroscopy. RSC Adv. 2013, 3, 16359-16364. [CrossRef]

43. Tripathi, H.L.; Dewey, W.L. Comparison of the effects of diisopropylfluorophosphate, sarin, soman, and tabun on toxicity and brain acetylcholinesterase activity in mice. J. Toxicol. Environ. Health 1989, 26, 437-446. [CrossRef]

44. Silver, S. The Toxieity of Dimethyl-, Diethyl-, and Diisopropyl Fluorophosphate Vapors. J. Ind. Hygiene Toxicol. 1948, 30, 307-311.

45. Costa, L.G. Current issues in organophosphate toxicology. Clin. Chim. Acta 2006, 366, 1-13. [CrossRef]

46. Raushel, F.M. Chemical biology: Catalytic detoxification. Nature 2011, 469, 310-311. [CrossRef]

47. Nowak, S.; Winter, M. Review-Chemical Analysis for a Better Understanding of Aging and Degradation Mechanisms of Non-Aqueous Electrolytes for Lithium Ion Batteries: Method Development, Application and Lessons Learned. J. Electrochem. Soc. 2015, 162, A2500-A2508. [CrossRef]

48. Weber, W.; Wagner, R.; Streipert, B.; Kraft, V.; Winter, M.; Nowak, S. Ion and gas chromatography mass spectrometry investigations of organophosphates in lithium ion battery electrolytes by electrochemical aging at elevated cathode potentials. J. Power Sources 2016, 306, 193-199. [CrossRef]

49. Kraft, V.; Grützke, M.; Weber, W.; Winter, M.; Nowak, S. Ion chromatography electrospray ionization mass spectrometry method development and investigation of lithium hexafluorophosphate-based organic electrolytes and their thermal decomposition products. J. Chromatogr. A 2014, 1354, 92-100. [CrossRef] [PubMed]

50. Kraft, V.; Grützke, M.; Weber, W.; Menzel, J.; Wiemers-Meyer, S.; Winter, M.; Nowak, S. Two-dimensional ion chromatography for the separation of ionic organophosphates generated in thermally decomposed lithium hexafluorophosphate-based lithium ion battery electrolytes. J. Chromatogr. A 2015, 1409, 201-209. [CrossRef]

51. Grützke, M.; Kraft, V.; Hoffmann, B.; Klamor, S.; Diekmann, J.; Kwade, A.; Winter, M.; Nowak, S. Aging investigations of a lithium-ion battery electrolyte from a field-tested hybrid electric vehicle. J. Power Sources 2015, 273, 83-88. [CrossRef]

52. Sasaki, T.; Abe, T.; Iriyama, Y.; Inaba, M.; Ogumi, Z. Suppression of an alkyl dicarbonate formation in li-ion cells. J. Electrochem. Soc. 2005, 152, A2046-A2050. [CrossRef]

53. Sasaki, T.; Abe, T.; Iriyama, Y.; Inaba, M.; Ogumi, Z. Formation mechanism of alkyl dicarbonates in Li-ion cells. J. Power Sources 2005, 150, 208-215. [CrossRef]

54. Gachot, G.; Grugeon, S.; Eshetu, G.G.; Mathiron, D.; Ribière, P.; Armand, M.; Laruelle, S. Thermal behaviour of the lithiated-graphite/electrolyte interface through GC/MS analysis. Electrochim. Acta 2012, 83, 402-409. [CrossRef]

55. Schultz, C.; Vedder, S.; Winter, M.; Nowak, S. Qualitative Investigation of the Decomposition of Organic Solvent Based Lithium Ion Battery Electrolytes with LC-IT-TOF-MS. Anal. Chem. 2016, 88, 11160-11168. [CrossRef]

56. Schultz, C.; Kraft, V.; Pyschik, M.; Weber, S.; Schappacher, F.; Winter, M.; Nowak, S. Separation and Quantification of Organic Electrolyte Components in Lithium-Ion Batteries via a Developed HPLC Method. J. Electrochem. Soc. 2015, 162, A629-A634. [CrossRef]

57. Yoshida, H.; Fukunaga, T.; Hazama, T.; Terasaki, M.; Mizutani, M.; Yamachi, M. Degradation mechanism of alkyl carbonate solvents used in lithium-ion cells during initial charging. J. Power Sources 1997, 68, 311-315. [CrossRef]

58. Winter, M. The Solid Electrolyte Interphase - The Most Important and the Least Understood Solid Electrolyte in Rechargeable Li Batteries. Zeitschrift Fur Physikalische Chemie 2009, 223, 1395-1406. [CrossRef]

59. Schwieters, T.; Evertz, M.; Mense, M.; Winter, M.; Nowak, S. Lithium loss in the solid electrolyte interphase: Lithium quantification of aged lithium ion battery graphite electrodes by means of laser ablation inductively coupled plasma mass spectrometry and inductively coupled plasma optical emission spectroscopy. J. Power Sources 2017, 356, 47-55. [CrossRef] 
60. Peled, E. The electrochemical behavior of alkali and alkaline earth metals in nonaqueous battery systems-the solid electrolyte interphase model. J. Electrochem. Soc. 1979, 126, 2047-2051. [CrossRef]

61. Dey, A. Lithium anode film and organic and inorganic electrolyte batteries. Thin Solid Films 1977, 43, 131-171. [CrossRef]

62. Nordh, T.; Younesi, R.; Hahlin, M.; Duarte, R.F.; Tengstedt, C.; Brandell, D.; Edstrom, K. Manganese in the SEI Layer of Li4Ti5O12 Studied by Combined NEXAFS and HAXPES Techniques. J. Phys. Chem. C 2016, 120, 3206-3213. [CrossRef]

63. Nitta, N.; Benson, J.; Lee, J.T.; Kovalenko, I.; Tighe, S.; Fuller, T.F.; Yushin, G. A Combined Investigation into the Effect of $\mathrm{Ni} / \mathrm{Mn} / \mathrm{Co}$ Ions on Lithium-Ion Battery Anodes Using X-Ray Photoelectron Spectroscopy and Secondary Ion Mass Spectrometry. ECS Meeting Abstracts 2014, 245.

64. Shin, H.; Park, J.; Sastry, A.M.; Lu, W. Degradation of the solid electrolyte interphase induced by the deposition of manganese ions. J. Power Sources 2015, 284, 416-427. [CrossRef]

65. Joshi, T.; Eom, K.; Yushin, G.; Fuller, T.F. Effects of dissolved transition metals on the electrochemical performance and SEI growth in lithium-ion batteries. J. Electrochem. Soc. 2014, 161, A1915-A1921. [CrossRef]

66. Delacourt, C.; Kwong, A.; Liu, X.; Qiao, R.; Yang, W.; Lu, P.; Harris, S.; Srinivasan, V. Effect of manganese contamination on the solid-electrolyte-interphase properties in Li-ion batteries. J. Electrochem. Soc. 2013, 160, A1099-A1107. [CrossRef]

67. Würsig, A.; Buqa, H.; Holzapfel, M.; Krumeich, F.; Novák, P. Film formation at positive electrodes in lithium-Ion batteries. Electrochem. Solid-State Lett. 2005, 8, A34-A37. [CrossRef]

68. Kim, J.-M.; Chung, H.-T. The first cycle characteristics of Li [Ni 1/3 Co 1/3 Mn 1/3] O 2 charged up to $4.7 \mathrm{~V}$. Electrochim. Acta 2004, 49, 937-944. [CrossRef]

69. Lee, Y.-S.; Lee, K.-S.; Sun, Y.-K.; Lee, Y.M.; Kim, D.-W. Effect of an organic additive on the cycling performance and thermal stability of lithium-ion cells assembled with carbon anode and LiNi 1/3 Co 1/3 Mn 1/3 O 2 cathode. J. Power Sources 2011, 196, 6997-7001. [CrossRef]

70. Qian, Y.; Schultz, C.; Niehoff, P.; Schwieters, T.; Nowak, S.; Schappacher, F.M.; Winter, M. Investigations on the electrochemical decomposition of the electrolyte additive vinylene carbonate in Li metal half cells and lithium ion full cells. J. Power Sources 2016, 332, 60-71. [CrossRef]

71. Qian, Y.; Niehoff, P.; Börner, M.; Grützke, M.; Mönnighoff, X.; Behrends, P.; Nowak, S.; Winter, M.; Schappacher, F.M. Influence of electrolyte additives on the cathode electrolyte interphase (CEI) formation on LiNi1/3Mn1/3Co1/3O2 in half cells with Li metal counter electrode. J. Power Sources 2016, 329, 31-40. [CrossRef]

72. Antolini, E. LiCoO 2: Formation, structure, lithium and oxygen nonstoichiometry, electrochemical behaviour and transport properties. Solid State Ionics 2004, 170, 159-171. [CrossRef]

73. Thackeray, M.M.; Kang, S.H.; Johnson, C.S.; Vaughey, J.T.; Benedek, R.; Hackney, S.A. Li2MnO3-stabilized LiMO2 (M = Mn, Ni, Co) electrodes for lithium-ion batteries. J. Mater. Chem. 2007, 17, 3112. [CrossRef]

74. Liu, X.; Liu, J.; Qiao, R.; Yu, Y.; Li, H.; Suo, L.; Hu, Y.-s.; Chuang, Y.-D.; Shu, G.; Chou, F.; et al. Phase Transformation and Lithiation Effect on Electronic Structure of LixFePO4: An In-Depth Study by Soft X-ray and Simulations. J. Am. Chem. Soc. 2012, 134, 13708-13715. [CrossRef]

75. Goodenough, J.; Mizushima, K.; Takeda, T. Solid-solution oxides for storage-battery electrodes. Jpn. J. Appl. Phys. 1980, 19, 305. [CrossRef]

76. Krueger, S.; Kloepsch, R.; Li, J.; Nowak, S.; Passerini, S.; Winter, M. How do reactions at the anode/electrolyte interface determine the cathode performance in lithium-ion batteries? J. Electrochem. Soc. 2013, 160, A542-A548. [CrossRef]

77. Ohzuku, T.; Makimura, Y. Layered lithium insertion material of LiCo1/3Ni1/3Mn1/3O2 for lithium-ion batteries. Chem. Lett. 2001, 30, 642-643. [CrossRef]

78. Hu, M.; Pang, X.; Zhou, Z. Recent progress in high-voltage lithium ion batteries. J. Power Sources 2013, 237, 229-242. [CrossRef]

79. Zheng, H.; Sun, Q.; Liu, G.; Song, X.; Battaglia, V.S. Correlation between dissolution behavior and electrochemical cycling performance for LiNi 1/3 Co 1/3 Mn 1/3 O 2-based cells. J. Power Sources 2012, 207, 134-140. [CrossRef]

80. Jia, H.P.; Kloepsch, R.; He, X.; Evertz, M.; Nowak, S.; Li, J.; Winter, M.; Placke, T. Nanostructured ZnFe2O4 as Anode Material for Lithium-Ion Batteries: Ionic Liquid-Assisted Synthesis and Performance Evaluation with Special Emphasis on Comparative Metal Dissolution. Acta Chim. Slov. 2016, 63, 470-483. [CrossRef] 
81. Goriparti, S.; Miele, E.; De Angelis, F.; Di Fabrizio, E.; Proietti Zaccaria, R.; Capiglia, C. Review on recent progress of nanostructured anode materials for Li-ion batteries. J. Power Sources 2014, 257, 421-443. [CrossRef]

82. Qian, Y.; Niehoff, P.; Zhou, D.; Adam, R.; Mikhailova, D.; Pyschik, M.; Börner, M.; Klöpsch, R.; Rafaja, D.; Schumacher, $\mathrm{G}$. Investigation of nano-sized $\mathrm{Cu}$ (II) $\mathrm{O}$ as a high capacity conversion material for Li-metal cells and lithium-ion full cells. J. Mater. Chem. A 2017, 5, 6556-6568. [CrossRef]

83. Novák, P.; Goers, D.; Spahr, M. Carbon Materials in Lithium-Ion Batteries. In Carbons for Electrochemical Energy Storage and Conversion Systems; CRC Press: Boca Raton, FL, USA, 2009.

84. Endo, M.; Kim, Y.; Park, K. Advanced Battery Applications of Carbons. In Carbons for Electrochemical Energy Storage and Conversion Systems; CRC Press: Boca Raton, FL, USA, 2009.

85. Brodd, R. Carbon in Batteries and Energy Conversion Devices. In Carbons for Electrochemical Energy Storage and Conversion Systems; CRC Press: Boca Raton, FL, USA, 2009.

86. Flandrois, S.; Simon, B. Carbon materials for lithium-ion rechargeable batteries. Carbon 1999, 37, $165-180$. [CrossRef]

87. Schmitz, R.W.; Murmann, P.; Schmitz, R.; Müller, R.; Krämer, L.; Kasnatscheew, J.; Isken, P.; Niehoff, P.; Nowak, S.; Röschenthaler, G.-V. Investigations on novel electrolytes, solvents and SEI additives for use in lithium-ion batteries: Systematic electrochemical characterization and detailed analysis by spectroscopic methods. Prog. Solid State Chem. 2014, 42, 65-84. [CrossRef]

88. Newman, G.; Francis, R.; Gaines, L.; Rao, B. Hazard investigations of LiClO4/dioxolane electrolyte. J. Electrochem. Soc. 1980, 127, 2025-2027. [CrossRef]

89. Aurbach, D.; Talyosef, Y.; Markovsky, B.; Markevich, E.; Zinigrad, E.; Asraf, L.; Gnanaraj, J.S.; Kim, H.-J. Design of electrolyte solutions for Li and Li-ion batteries: A review. Electrochim. Acta 2004, 50, 247-254. [CrossRef]

90. Ding, M.S.; Xu, K.; Jow, T.R. Conductivity and Viscosity of PC-DEC and PC-EC Solutions of LiBOB. J. Electrochem. Soc. 2005, 152, A132-A140. [CrossRef]

91. Schedlbauer, T.; Krüger, S.; Schmitz, R.; Schmitz, R.W.; Schreiner, C.; Gores, H.J.; Passerini, S.; Winter, M. Lithium difluoro(oxalato)borate: A promising salt for lithium metal based secondary batteries? Electrochim. Acta 2013, 92, 102-107. [CrossRef]

92. Böttcher, T.; Duda, B.; Kalinovich, N.; Kazakova, O.; Ponomarenko, M.; Vlasov, K.; Winter, M.; Röschenthaler, G.V. Syntheses of novel delocalized cations and fluorinated anions, new fluorinated solvents and additives for lithium ion batteries. Prog. Solid State Chem. 2014, 42, 202-217. [CrossRef]

93. Zhang, S.S. A review on electrolyte additives for lithium-ion batteries. J. Power Sources 2006, 162, $1379-1394$. [CrossRef]

94. Murmann, P.; Mönnighoff, X.; von Aspern, N.; Janssen, P.; Kalinovich, N.; Shevchuk, M.; Kazakova, O.; Röschenthaler, G.-V.; Cekic-Laskovic, I.; Winter, M. Influence of the fluorination degree of organophosphates on flammability and electrochemical performance in lithium ion batteries: Studies on fluorinated compounds deriving from triethyl phosphate. J. Electrochem. Soc. 2016, 163, A751-A757. [CrossRef]

95. Dagger, T.; Rad, B.R.; Schappacher, F.M.; Winter, M. Comparative Performance Evaluation of Flame Retardant Additives for Lithium Ion Batteries-I. Safety, Chemical and Electrochemical Stabilities. Energy Technol. 2018, 6, 2011-2022. [CrossRef]

96. Dagger, T.; Niehoff, P.; Lürenbaum, C.; Schappacher, F.M.; Winter, M. Comparative Performance Evaluation of Flame Retardant Additives for Lithium Ion Batteries-II. Full Cell Cycling and Postmortem Analyses. Energy Technol. 2018, 6, 2023-2035. [CrossRef]

97. Winter, M.; Imhof, R.; Joho, F.; Novak, P. FTIR and DEMS investigations on the electroreduction of chloroethylene carbonate-based electrolyte solutions for lithium-ion cells. J. Power Sources 1999, 81, 818-823. [CrossRef]

98. Tobishima, S.; Ogino, Y.; Watanabe, Y. Influence of electrolyte additives on safety and cycle life of rechargeable lithium cells. J. Appl. Electrochem. 2003, 33, 143-150. [CrossRef]

99. Shigematsu, Y.; Kinoshita, S.-i.; Ue, M. Thermal behavior of a C/ LiCoO2 cell, its components, and their combinations and the effects of electrolyte additives. J. Electrochem. Soc. 2006, 153, A2166-A2170. [CrossRef]

100. Möller, K.-C.; Santner, H.; Kern, W.; Yamaguchi, S.; Besenhard, J.; Winter, M. In situ characterization of the SEI formation on graphite in the presence of a vinylene group containing film-forming electrolyte additives. J. Power Sources 2003, 119, 561-566. [CrossRef] 
101. Korepp, C.; Santner, H.; Fujii, T.; Ue, M.; Besenhard, J.; Möller, K.-C.; Winter, M. 2-Cyanofuran-A novel vinylene electrolyte additive for PC-based electrolytes in lithium-ion batteries. J. Power Sources 2006, 158, 578-582. [CrossRef]

102. Santner, H.; Möller, K.-C.; Ivančo, J.; Ramsey, M.; Netzer, F.P.; Yamaguchi, S.; Besenhard, J.; Winter, M. Acrylic acid nitrile, a film-forming electrolyte component for lithium-ion batteries, which belongs to the family of additives containing vinyl groups. J. Power Sources 2003, 119, 368-372. [CrossRef]

103. Schranzhofer, H.; Bugajski, J.; Santner, H.J.; Korepp, C.; Möller, K.C.; Besenhard, J.O.; Winter, M.; Sitte, W. Electrochemical impedance spectroscopy study of the SEI formation on graphite and metal electrodes. J. Power Sources 2006, 153, 391. [CrossRef]

104. Liu, Y.-M.; Nicolau, B.G.; Esbenshade, J.L.; Gewirth, A.A. Characterization of the Cathode Electrolyte Interface in Lithium Ion Batteries by Desorption Electrospray Ionization Mass Spectrometry. Anal. Chem. 2016, 88, 7171-7177. [CrossRef] [PubMed]

105. Thomas, M.G.S.R.; Bruce, P.G.; Goodenough, J.B. AC Impedance Analysis of Polycrystalline Insertion Electrodes: Application to Li1 - x CoO2. J. Electrochem. Soc. 1985, 132, 1521-1528. [CrossRef]

106. Fung, Y.S.; Zhou, R.Q. Room temperature molten salt as medium for lithium battery. J. Power Sources 1999, 81-82, 891-895. [CrossRef]

107. Galiński, M.; Lewandowski, A.; Stępniak, I. Ionic liquids as electrolytes. Electrochim. Acta 2006, 51, 5567-5580. [CrossRef]

108. König, A.; Weckesser, D.; Jensen, D. Ionische Flüssigkeiten - Analyse mittels Ionenchromatographie. GIT Labor-Fachzeitschrift 2006, 6, 546-549.

109. Armand, M.; Endres, F.; MacFarlane, D.R.; Ohno, H.; Scrosati, B. Ionic-liquid materials for the electrochemical challenges of the future. Nat. Mater. 2009, 8, 621-629. [CrossRef]

110. Holzapfel, M.; Jost, C.; Novak, P. Stable cycling of graphite in an ionic liquid based electrolyte. Chem. Commun. 2004, 2098-2099. [CrossRef] [PubMed]

111. Johnson, K.E. What's an ionic liquid? Interface 2007, 16, 38.

112. Appetecchi, G.B.; Scaccia, S.; Tizzani, C.; Alessandrini, F.; Passerini, S. Synthesis of hydrophobic ionic liquids for electrochemical applications. J. Electrochem. Soc. 2006, 153, A1685-A1691. [CrossRef]

113. Nakagawa, H.; Izuchi, S.; Kuwana, K.; Nukuda, T.; Aihara, Y. Liquid and Polymer Gel Electrolytes for Lithium Batteries Composed of Room-Temperature Molten Salt Doped by Lithium Salt. J. Electrochem. Soc. 2003, 150, A695-A700. [CrossRef]

114. Klett, M.; Svens, P.; Tengstedt, C.; Seyeux, A.; Światowska, J.; Lindbergh, G.r.; Wreland Lindström, R. Uneven film formation across depth of porous graphite electrodes in cycled commercial Li-ion batteries. J. Phys. Chem. C 2014, 119, 90-100. [CrossRef]

115. Börner, M.; Friesen, A.; Grützke, M.; Stenzel, Y.; Brunklaus, G.; Haetge, J.; Nowak, S.; Schappacher, F.; Winter, M. Correlation of aging and thermal stability of commercial 18650-type lithium ion batteries. J. Power Sources 2017, 342, 382-392. [CrossRef]

116. Zhan, C.; Lu, J.; Jeremy Kropf, A.; Wu, T.; Jansen, A.N.; Sun, Y.K.; Qiu, X.; Amine, K. Mn(II) deposition on anodes and its effects on capacity fade in spinel lithium manganate-carbon systems. Nat. Commun. 2013, 4, 2437. [CrossRef] [PubMed]

117. Banerjee, A.; Ziv, B.; Luski, S.; Aurbach, D.; Halalay, I.C. Increasing the durability of Li-ion batteries by means of manganese ion trapping materials with nitrogen functionalities. J. Power Sources 2017, 341, 457-465. [CrossRef]

118. Evertz, M.; Lürenbaum, C.; Vortmann, B.; Winter, M.; Nowak, S. Development of a method for direct elemental analysis of lithium ion battery degradation products by means of total reflection $\mathrm{X}$-ray fluorescence. Spectrochim. Acta Part B 2015, 112, 34-39. [CrossRef]

119. Evertz, M.; Horsthemke, F.; Kasnatscheew, J.; Börner, M.; Winter, M.; Nowak, S. Unraveling transition metal dissolution of Li1.04Ni1/3Co1/3Mn1/3O2 (NCM 111) in lithium ion full cells by using the total reflection X-ray fluorescence technique. J. Power Sources 2016, 329, 364-371. [CrossRef]

120. Kasnatscheew, J.; Evertz, M.; Streipert, B.; Wagner, R.; Nowak, S.; Cekic Laskovic, I.; Winter, M. Changing established belief on capacity fade mechanisms: Thorough investigation of LiNi1/3Co1/3Mn1/3O2 (NCM111) under high voltage conditions. J. Phys. Chem. C 2017, 121, 1521-1529. [CrossRef] 
121. Börner, M.; Horsthemke, F.; Kollmer, F.; Haseloff, S.; Friesen, A.; Niehoff, P.; Nowak, S.; Winter, M.; Schappacher, F.M. Degradation effects on the surface of commercial LiNi0.5Co0.2Mn0.3O2 electrodes. J. Power Sources 2016, 335, 45-55. [CrossRef]

122. Nowak, S.; Winter, M. Elemental analysis of lithium ion batteries. J. Anal. Atom. Spectrom. 2017, 32, $1833-1847$. [CrossRef]

123. Evertz, M.; Schwieters, T.; Börner, M.; Winter, M.; Nowak, S. Matrix-matched standards for the quantification of elemental lithium ion battery degradation products deposited on carbonaceous negative electrodes using pulsed-glow discharge-sector field-mass spectrometry. J. Anal. Atom. Spectrom. 2017, 32, 1862-1867. [CrossRef]

124. Schwieters, T.; Evertz, M.; Fengler, A.; Börner, M.; Dagger, T.; Stenzel, Y.; Harte, P.; Winter, M.; Nowak, S. Visualizing elemental deposition patterns on carbonaceous anodes from lithium ion batteries: A laser ablation-inductively coupled plasma-mass spectrometry study on factors influencing the deposition of lithium, nickel, manganese and cobalt after dissolution and migration from the Li1[Ni1/3Mn1/3Co1/3]O2 and LiMn1.5 Ni0.5O4 cathode. J. Power Sources 2018, 380, 194-201.

125. Harte, P.; Evertz, M.; Schwieters, T.; Diehl, M.; Winter, M.; Nowak, S. Adaptation and improvement of an elemental mapping method for lithium ion battery electrodes and separators by means of laser ablation-inductively coupled plasma-mass spectrometry. Anal. Bioanal. Chem. 2019, 411, 581-589. [CrossRef] [PubMed]

126. Terborg, L.; Nowak, S.; Passerini, S.; Winter, M.; Karst, U.; Haddad, P.R.; Nesterenko, P.N. Ion chromatographic determination of hydrolysis products of hexafluorophosphate salts in aqueous solution. Anal. Chim. Acta 2012, 714, 121-126. [CrossRef]

127. Sloop, S.E.; Pugh, J.K.; Wang, S.; Kerr, J.; Kinoshita, K. Chemical Reactivity of PF 5 and LiPF6 in Ethylene Carbonate/Dimethyl Carbonate Solutions. Electrochem. Solid-State Lett. 2001, 4, A42-A44. [CrossRef]

128. Sloop, S.E.; Kerr, J.B.; Kinoshita, K. The role of Li-ion battery electrolyte reactivity in performance decline and self-discharge. J. Power Sources 2003, 119, 330-337. [CrossRef]

129. Blomgren, G.E. Electrolytes for advanced batteries. J. Power Sources 1999, 81, 112-118. [CrossRef]

130. Kawamura, T.; Okada, S.; Yamaki, J.-i. Decomposition reaction of LiPF 6-based electrolytes for lithium ion cells. J. Power Sources 2006, 156, 547-554. [CrossRef]

131. Plakhotnyk, A.V.; Ernst, L.; Schmutzler, R. Hydrolysis in the system LiPF 6-propylene carbonate-dimethyl carbonate-H 2 O. J. Fluorine Chem. 2005, 126, 27-31. [CrossRef]

132. Nowak, S.; Winter, M. The role of sub-and supercritical CO2 as "Processing Solvent" for the recycling and sample preparation of lithium ion battery electrolytes. Molecules 2017, 22, 403. [CrossRef]

133. Patnaik, P. A Comprehensive Guide to the Hazardous Properties of Chemical Substances; John Wiley \& Sons: Hoboken, NJ, USA, 2007.

134. Delfino, R.T.; Ribeiro, T.S.; Figueroa-Villar, J.D. Organophosphorus compounds as chemical warfare agents: A review. J. Brazil. Chem. Soc. 2009, 20, 407-428. [CrossRef]

135. Vortmann-Westhoven, B.; Lürenbaum, C.; Winter, M.; Nowak, S. Determination of lithium and transition metals in Li1Ni1/3Co1/3Mn1/3O2 (NCM) cathode material for lithium-ion batteries by capillary electrophoresis. Electrophoresis 2017, 38, 540-546. [CrossRef]

136. Vortmann-Westhoven, B.; Diehl, M.; Winter, M.; Nowak, S. Ion Chromatography with Post-column Reaction and Serial Conductivity and Spectrophotometric Detection Method Development for Quantification of Transition Metal Dissolution in Lithium Ion Battery Electrolytes. Chromatographia 2018, 1-8. [CrossRef]

137. Hao, F.; Haddad, P.R.; Ruther, T. IC Determination of Halide Impurities in Ionic Liquids. Chromatographia 2008, 67, 495-498. [CrossRef]

138. Villagrán, C.; Deetlefs, M.; Pitner, W.R.; Hardacre, C. Quantification of Halide in Ionic Liquids Using Ion Chromatography. Anal. Chem. 2004, 76, 2118-2123. [CrossRef]

139. Zhou, S.; Yu, H.; Yang, L.; Ai, H. Fast determination of tetrafluoroborate by high-performance liquid chromatography using a monolithic column. J. Chromatogr. A 2008, 1206, 200-203. [CrossRef]

140. Gao, W.; Yu, H.; Zhou, S. Determination of Imidazolium Ionic Liquid Cations by Ion-Pair Chromatography Using a Monolithic Column and Direct Conductivity Detection. Chromatographia 2010, 71, 475-479. [CrossRef]

141. Meng, L.; Yu, H.; Liu, Y. Determination of Pyridinium Ionic Liquid Cations by Reversed Phase Ion-Pair Chromatography Using Gradient Elution. Chromatographia 2011, 73, 367-371. [CrossRef] 
142. Markuszewski, M.J.; Stepnowski, P.; Marszałł, M.P. Capillary electrophoretic separation of cationic constituents of imidazolium ionic liquids. Electrophoresis 2004, 25, 3450-3454. [CrossRef]

143. Qin, W.; Wei, H.; Li, S.F.Y. Separation of ionic liquid cations and related imidazole derivatives by $\alpha$-cyclodextrin modified capillary zone electrophoresis. Analyst 2002, 127, 490-493. [CrossRef]

144. Markowska, A.; Stepnowski, P. Capillary isotachophoresis for the analysis of ionic liquid entities. J. Sep. Sci. 2010, 33, 1991-1996. [CrossRef]

145. Kosobucki, P.; Buszewski, B. Isotachophoretic separation of selected imidazolium ionic liquids. Talanta 2008, 74, 1670-1674. [CrossRef]

146. Pyschik, M.; Klein-Hitpaß, M.; Girod, S.; Winter, M.; Nowak, S. Capillary electrophoresis with contactless conductivity detection for the quantification of fluoride in lithium ion battery electrolytes and in ionic liquids-A comparison to the results gained with a fluoride ion-selective electrode. Electrophoresis 2017, 38, 533-539. [CrossRef]

147. Wilken, A.; Kraft, V.; Girod, S.; Winter, M.; Nowak, S. A fluoride-selective electrode (Fse) for the quantification of fluoride in lithium-ion battery (Lib) electrolytes. Anal. Methods 2016, 8, 6932-6940. [CrossRef]

148. Pyschik, M.; Kraft, V.; Passerini, S.; Winter, M.; Nowak, S. Thermal aging of anions in ionic liquids containing lithium salts by IC/ESI-MS. Electrochim. Acta 2014, 130, 426-430. [CrossRef]

149. Pyschik, M.; Schultz, C.; Passerini, S.; Winter, M.; Nowak, S. Aging of cations of ionic liquids monitored by ion chromatography hyphenated to an electrospray ionization mass spectrometer. Electrochim. Acta 2015, 176, 1143-1152. [CrossRef]

150. Pyschik, M.; Winter, M.; Nowak, S. Determination and quantification of cations in ionic liquids by capillary electrophoresis-mass spectrometry. J. Chromatogr. A 2017, 1485, 131-141. [CrossRef]

151. Chancelier, L.; Diallo, A.; Santini, C.; Marlair, G.; Gutel, T.; Mailley, S.; Len, C. Targeting adequate thermal stability and fire safety in selecting ionic liquid-based electrolytes for energy storage. Phys. Chem. Chem. Phys. 2014, 16, 1967-1976. [CrossRef]

152. Chancelier, L.; Benayad, A.; Gutel, T.; Mailley, S.; Santini, C.C. Characterisation of LTO//NMC Batteries Containing Ionic Liquids or Carbonates after Cycling and Overcharge. ECS Trans. 2014, 62, 235-246. [CrossRef]

153. Chancelier, L.; Benayad, A.; Gutel, T.; Mailley, S.; Santini, C. Characterization of LTO//NMC Batteries Containing Ionic Liquid or Carbonate Electrolytes after Cycling and Overcharge. J. Electrochem. Soc. 2015, 162, A1008-A1013. [CrossRef]

154. Gudzinowicz, B.; Driscoll, J. Separation and Analysis of Organic Carbonates by Gas Chromatography. Anal. Chem. 1961, 33, 1508-1510. [CrossRef]

155. Yoza, N.; Nakashima, S.; Ueda, N.; Miyajima, T.; Nakamura, T.; Vast, P. High-performance liquid chromatographic characterization of monofluorophosphate, difluorophosphate and hexafluorophosphate. J. Chromatogr. A 1994, 664, 111-116. [CrossRef]

156. Arakawa, M.; Yamaki, J.-i. Anodic oxidation of propylene carbonate and ethylene carbonate on graphite electrodes. J. Power Sources 1995, 54, 250-254. [CrossRef]

157. Ohta, A.; Koshina, H.; Okuno, H.; Murai, H. Relationship between carbonaceous materials and electrolyte in secondary lithium-ion batteries. J. Power Sources 1995, 54, 6-10. [CrossRef]

158. Kominato, A.; Yasukawa, E.; Sato, N.; Ijuuin, T.; Asahina, H.; Mori, S. Analysis of surface films on lithium in various organic electrolytes. J. Power Sources 1997, 68, 471-475. [CrossRef]

159. Mori, S.; Asahina, H.; Suzuki, H.; Yonei, A.; Yokoto, K. Chemical properties of various organic electrolytes for lithium rechargeable batteries: 1 . Characterization of passivating layer formed on graphite in alkyl carbonate solutions. J. Power Sources 1997, 68, 59-64. [CrossRef]

160. Johnson, B.A.; White, R.E. Characterization of commercially available lithium-ion batteries. J. Power Sources 1998, 70, 48-54. [CrossRef]

161. Heider, U.; Oesten, R.; Jungnitz, M. Challenge in manufacturing electrolyte solutions for lithium and lithium ion batteries quality control and minimizing contamination level. J. Power Sources 1999, 81, 119-122. [CrossRef]

162. Kumai, K.; Miyashiro, H.; Kobayashi, Y.; Takei, K.; Ishikawa, R. Gas generation mechanism due to electrolyte decomposition in commercial lithium-ion cell. J. Power Sources 1999, 81, 715-719. [CrossRef]

163. Gourdin, G.; Collins, J.; Zheng, D.; Foster, M.; Qu, D. Spectroscopic compositional analysis of electrolyte during initial SEI layer formation. J. Phys. Chem. C 2014, 118, 17383-17394. [CrossRef] 
164. Liu, Y.-H.; Takeda, S.; Kaneko, I.; Yoshitake, H.; Yanagida, M.; Saito, Y.; Sakai, T. An approach of evaluating the effect of vinylene carbonate additive on graphite anode for lithium ion battery at elevated temperature. Electrochem. Commun. 2015, 61, 70-73. [CrossRef]

165. Liu, Y.-H.; Takeda, S.; Kaneko, I.; Yoshitake, H.; Yanagida, M.; Saito, Y.; Sakai, T. Formation of thermally resistant films induced by vinylene carbonate additive on a hard carbon anode for lithium ion batteries at elevated temperature. RSC Adv. 2016, 6, 75777-75781. [CrossRef]

166. Liu, Y.-H.; Takeda, S.; Kaneko, I.; Yoshitake, H.; Mukai, T.; Yanagida, M.; Saito, Y.; Sakai, T. Understanding the Improved High-Temperature Cycling Stability of a LiNi0. 5Mn0. 3Co0. 2O2/Graphite Cell with Vinylene Carbonate: A Comprehensive Analysis Approach Utilizing LC-MS and DART-MS. J. Phys. Chem. C 2018, 122, 5864-5870. [CrossRef]

167. Tochihara, M.; Nara, H.; Mukoyama, D.; Yokoshima, T.; Momma, T.; Osaka, T. Liquid chromatography-quadruple time of flight mass spectrometry analysis of products in degraded lithium-ion batteries. J. Electrochem. Soc. 2015, 162, A2008-A2015. [CrossRef]

168. Takeda, S.; Morimura, W.; Liu, Y.H.; Sakai, T.; Saito, Y. Identification and formation mechanism of individual degradation products in lithium-ion batteries studied by liquid chromatography/electrospray ionization mass spectrometry and atmospheric solid analysis probe mass spectrometry. Rapid Commun. Mass Spectrom. 2016, 30, 1754-1762. [CrossRef] [PubMed]

169. Kraft, V.; Weber, W.; Streipert, B.; Wagner, R.; Schultz, C.; Winter, M.; Nowak, S. Qualitative and quantitative investigation of organophosphates in an electrochemically and thermally treated lithium hexafluorophosphate-based lithium ion battery electrolyte by a developed liquid chromatography-tandem quadrupole mass spectrometry method. RSC Adv. 2016, 6, 8-17. [CrossRef]

170. Schultz, C.; Vedder, S.; Streipert, B.; Winter, M.; Nowak, S. Quantitative investigation of the decomposition of organic lithium ion battery electrolytes with LC-MS/MS. RSC Adv. 2017, 7, 27853-27862. [CrossRef]

171. Henschel, J.; Winter, M.; Nowak, S.; Jiang, W. Analysis of organophosphates in lithium ion battery electrolytes by HILIC-ESI-MS. LC GC 2018, 30, 691.

172. Henschel, J.; Schwarz, L.; Glorius, F.; Winter, M.; Nowak, S. Further insights into structural diversity of phosphorus-based decomposition products in lithium ion battery electrolytes via liquid chromatographic techniques hyphenated to ion trap - time of flight mass spectrometry. Anal. Chem. 2019, 91, 3980-3988. [CrossRef]

173. Bloom, I.; Bareño, J.; Dietz Rago, N.; Dogan, F.; Graczyk, D.G.; Tsai, Y.; Naik, S.R.; Han, S.-D.; Lee, E.; Du, Z.; et al. Effect of overcharge on $\mathrm{Li}(\mathrm{Ni} 0.5 \mathrm{Mn} 0.3 \mathrm{Co} 0.2) \mathrm{O} 2$ cathodes: NMP-soluble binder. II-Chemical changes in the anode. J. Power Sources 2018, 385, 156-164. [CrossRef]

174. Tasaki, K.; Kanda, K.; Nakamura, S.; Ue, M. Decomposition of LiPF6and Stability of PF 5 in Li-Ion Battery Electrolytes Density Functional Theory and Molecular Dynamics Studies. J. Electrochem. Soc. 2003, 150, A1628-A1636. [CrossRef]

175. Terborg, L.; Weber, S.; Blaske, F.; Passerini, S.; Winter, M.; Karst, U.; Nowak, S. Investigation of thermal aging and hydrolysis mechanisms in commercial lithium ion battery electrolyte. J. Power Sources 2013, 242, 832-837. [CrossRef]

176. Kraft, V.; Weber, W.; Grützke, M.; Winter, M.; Nowak, S. Study of decomposition products by gas chromatography-mass spectrometry and ion chromatography-electrospray ionization-mass spectrometry in thermally decomposed lithium hexafluorophosphate-based lithium ion battery electrolytes. RSC Adv. 2015, 5, 80150-80157. [CrossRef]

177. Handel, P.; Fauler, G.; Kapper, K.; Schmuck, M.; Stangl, C.; Fischer, R.; Uhlig, F.; Koller, S. Thermal aging of electrolytes used in lithium-ion batteries-An investigation of the impact of protic impurities and different housing materials. J. Power Sources 2014, 267, 255-259. [CrossRef]

178. Menzel, J.; Schultz, H.; Kraft, V.; Badillo, J.P.; Winter, M.; Nowak, S. Quantification of ionic organo (fluoro) phosphates in decomposed lithium battery electrolytes. RSC Adv. 2017, 7, 39314-39324. [CrossRef]

179. Stich, M.; Göttlinger, M.; Kurniawan, M.; Schmidt, U.; Bund, A. Hydrolysis of LiPF6 in Carbonate-Based Electrolytes for Lithium-Ion Batteries and in Aqueous Media. J. Phys. Chem. C 2018, 122, 8836-8842. [CrossRef]

180. Ota, H.; Sato, T.; Suzuki, H.; Usami, T. TPD-GC/MS analysis of the solid electrolyte interface (SEI) on a graphite anode in the propylene carbonate/ethylene sulfite electrolyte system for lithium batteries. J. Power Sources 2001, 97, 107-113. [CrossRef] 
181. Sano, A.; Kurihara, M.; Ogawa, K.; Iijima, T.; Maruyama, S. Decreasing the initial irreversible capacity loss of graphite negative electrode by alkali-addition. J. Power Sources 2009, 192, 703-707. [CrossRef]

182. Ogumi, Z.; Sano, A.; Inaba, M.; Abe, T. Pyrolysis/gas chromatography/mass spectroscopy analysis of the surface film formed on graphite negative electrode. J. Power Sources 2001, 97, 156-158. [CrossRef]

183. Mogi, R.; Inaba, M.; Iriyama, Y.; Abe, T.; Ogumi, Z. Study of the Decomposition of Propylene Carbonate on Lithium Metal Surface by Pyrolysis- Gas Chromatography- Mass Spectroscopy. Langmuir 2003, 19, 814-821. [CrossRef]

184. Zhang, X.; Ross, P.; Kostecki, R.; Kong, F.; Sloop, S.; Kerr, J.; Striebel, K.; Cairns, E.; McLarnon, F. Diagnostic characterization of high power lithium-ion batteries for use in hybrid electric vehicles. J. Electrochem. Soc. 2001, 148, A463-A470. [CrossRef]

185. Aurbach, D.; Markovsky, B.; Rodkin, A.; Cojocaru, M.; Levi, E.; Kim, H.-J. An analysis of rechargeable lithium-ion batteries after prolonged cycling. Electrochim. Acta 2002, 47, 1899-1911. [CrossRef]

186. Gireaud, L.; Grugeon, S.; Pilard, S.; Guenot, P.; Tarascon, J.-M.; Laruelle, S. Mass spectrometry investigations on electrolyte degradation products for the development of nanocomposite electrodes in lithium ion batteries. Anal. Chem. 2006, 78, 3688-3698. [CrossRef] [PubMed]

187. Li, W.; Lucht, B.L. Lithium-ion batteries: Thermal reactions of electrolyte with the surface of metal oxide cathode particles. J. Electrochem. Soc. 2006, 153, A1617-A1625. [CrossRef]

188. Li, W.; Lucht, B.L. Inhibition of solid electrolyte interface formation on cathode particles for lithium-ion batteries. J. Power Sources 2007, 168, 258-264. [CrossRef]

189. Xiao, A.; Li, W.; Lucht, B.L. Thermal reactions of mesocarbon microbead (MCMB) particles in LiPF6-based electrolyte. J. Power Sources 2006, 162, 1282-1288. [CrossRef]

190. Gachot, G.; Grugeon, S.; Armand, M.; Pilard, S.; Guenot, P.; Tarascon, J.-M.; Laruelle, S. Deciphering the multi-step degradation mechanisms of carbonate-based electrolyte in Li batteries. J. Power Sources 2008, 178, 409-421. [CrossRef]

191. Yang, L.; Smith, C.; Patrissi, C.; Schumacher, C.R.; Lucht, B.L. Surface reactions and performance of non-aqueous electrolytes with lithium metal anodes. J. Power Sources 2008, 185, 1359-1366. [CrossRef]

192. Eom, J.-Y.; Jung, I.-H.; Lee, J.-H. Effects of vinylene carbonate on high temperature storage of high voltage Li-ion batteries. J. Power Sources 2011, 196, 9810-9814. [CrossRef]

193. Petibon, R.; Rotermund, L.; Nelson, K.; Gozdz, A.; Xia, J.; Dahn, J. Study of electrolyte components in Li ion cells using liquid-liquid extraction and gas chromatography coupled with mass spectrometry. J. Electrochem. Soc. 2014, 161, A1167-A1172. [CrossRef]

194. Petibon, R.; Xia, J.; Burns, J.; Dahn, J. Study of the Consumption of Vinylene Carbonate in Li [Ni0. 33Mn0. 33Co0. 33] O2/Graphite Pouch Cells. J. Electrochem. Soc. 2014, 161, A1618-A1624. [CrossRef]

195. Petibon, R.; Rotermund, L.; Dahn, J. Evaluation of phenyl carbonates as electrolyte additives in lithium-ion batteries. J. Power Sources 2015, 287, 184-195. [CrossRef]

196. Petibon, R.; Chevrier, V.; Aiken, C.; Hall, D.; Hyatt, S.; Shunmugasundaram, R.; Dahn, J. Studies of the capacity fade mechanisms of LiCoO2/Si-alloy: Graphite cells. J. Electrochem. Soc. 2016, 163, A1146-A1156. [CrossRef]

197. Gachot, G.; Ribière, P.; Mathiron, D.; Grugeon, S.; Armand, M.; Leriche, J.-B.; Pilard, S.; Laruelle, S. Gas chromatography/mass spectrometry as a suitable tool for the Li-ion battery electrolyte degradation mechanisms study. Anal. Chem. 2011, 83, 478-485. [CrossRef]

198. Gachot, G.; Grugeon, S.; Jimenez-Gordon, I.; Eshetu, G.G.; Boyanov, S.; Lecocq, A.; Marlair, G.; Pilard, S.; Laruelle, S. Gas chromatography/Fourier transform infrared/mass spectrometry coupling: A tool for Li-ion battery safety field investigation. Anal. Methods 2014, 6, 6120-6124. [CrossRef]

199. Kim, H.; Grugeon, S.; Gachot, G.; Armand, M.; Sannier, L.; Laruelle, S. Ethylene bis-carbonates as telltales of SEI and electrolyte health, role of carbonate type and new additives. Electrochim. Acta 2014, 136, 157-165. [CrossRef]

200. Terborg, L.; Weber, S.; Passerini, S.; Winter, M.; Karst, U.; Nowak, S. Development of gas chromatographic methods for the analyses of organic carbonate-based electrolytes. J. Power Sources 2014, 245, 836-840. [CrossRef]

201. Grützke, M.; Kraft, V.; Weber, W.; Wendt, C.; Friesen, A.; Klamor, S.; Winter, M.; Nowak, S. Supercritical carbon dioxide extraction of lithium-ion battery electrolytes. J. Supercrit. Fluid. 2014, 94, 216-222. [CrossRef] 
202. Grützke, M.; Mönnighoff, X.; Horsthemke, F.; Kraft, V.; Winter, M.; Nowak, S. Extraction of lithium-ion battery electrolytes with liquid and supercritical carbon dioxide and additional solvents. RSC Adv. 2015, 5, 43209-43217. [CrossRef]

203. Liu, Y.; Mu, D.; Zheng, R.; Dai, C. Supercritical CO 2 extraction of organic carbonate-based electrolytes of lithium-ion batteries. RSC Adv. 2014, 4, 54525-54531. [CrossRef]

204. Liu, Y.; Mu, D.; Dai, Y.; Ma, Q.; Zheng, R.; Dai, C. Analysis on Extraction Behaviour of Lithium-ion Battery Electrolyte Solvents in Supercritical CO2 by Gas Chromatography. Int. J. Electrochem. Sci. 2016, 11, 7594-7604. [CrossRef]

205. Mönnighoff, X.; Friesen, A.; Konersmann, B.; Horsthemke, F.; Grützke, M.; Winter, M.; Nowak, S. Supercritical carbon dioxide extraction of electrolyte from spent lithium ion batteries and its characterization by gas chromatography with chemical ionization. J. Power Sources 2017, 352, 56-63. [CrossRef]

206. Horsthemke, F.; Winkler, V.; Diehl, M.; Winter, M.; Nowak, S. Concept of the Analysis of the Electrolyte Composition Within the Cell Manufacturing Process: From Sealing to Sample Preparation. Energy Technol. 2019. [CrossRef]

207. Ortiz, D.; Steinmetz, V.; Durand, D.; Legand, S.; Dauvois, V.; Maître, P.; Le Caër, S. Radiolysis as a solution for accelerated ageing studies of electrolytes in Lithium-ion batteries. Nat. Commun. 2015, 6, 6950. [CrossRef]

208. Ortiz, D.; Jimenez Gordon, I.; Legand, S.; Dauvois, V.; Baltaze, J.-P.; Marignier, J.-L.; Martin, J.-F.; Belloni, J.; Mostafavi, M.; Le Caër, S. Role of PF6- in the radiolytical and electrochemical degradation of propylene carbonate solutions. J. Power Sources 2016, 326, 285-295. [CrossRef]

209. Weber, W.; Kraft, V.; Grützke, M.; Wagner, R.; Winter, M.; Nowak, S. Identification of alkylated phosphates by gas chromatography-mass spectrometric investigations with different ionization principles of a thermally aged commercial lithium ion battery electrolyte. J. Chromatogr. A 2015, 1394, 128-136. [CrossRef]

210. Grützke, M.; Krüger, S.; Kraft, V.; Vortmann, B.; Rothermel, S.; Winter, M.; Nowak, S. Investigation of the Storage Behavior of Shredded Lithium-Ion Batteries from Electric Vehicles for Recycling Purposes. ChemSusChem 2015, 8, 3433-3438. [CrossRef]

211. Michan, A.L.; Parimalam, B.S.; Leskes, M.; Kerber, R.N.; Yoon, T.; Grey, C.P.; Lucht, B.L. Fluoroethylene carbonate and vinylene carbonate reduction: Understanding lithium-ion battery electrolyte additives and solid electrolyte interphase formation. Chem. Mater. 2016, 28, 8149-8159. [CrossRef]

212. Horsthemke, F.; Friesen, A.; Mönnighoff, X.; Stenzel, Y.P.; Grützke, M.; Andersson, J.T.; Winter, M.; Nowak, S. Fast screening method to characterize lithium ion battery electrolytes by means of solid phase microextraction-gas chromatography-mass spectrometry. RSC Adv. 2017, 7, 46989-46998. [CrossRef]

213. Horsthemke, F.; Friesen, A.; Ibing, L.; Klein, S.; Winter, M.; Nowak, S. Possible carbon-carbon bond formation during decomposition? Characterization and identification of new decomposition products in lithium ion battery electrolytes by means of SPME-GC-MS. Electrochim. Acta 2019, 295, 401-409. [CrossRef]

214. Strehlau, J.; Weber, T.; Lürenbaum, C.; Bornhorst, J.; Galla, H.-J.; Schwerdtle, T.; Winter, M.; Nowak, S. Towards quantification of toxicity of lithium ion battery electrolytes-development and validation of a liquid-liquid extraction GC-MS method for the determination of organic carbonates in cell culture materials. Anal. Bioanal. Chem. 2017, 409, 6123-6131. [CrossRef] [PubMed]

215. Stenzel, Y.P.; Winter, M.; Nowak, S. Evaluation of different plasma conditions and resolutions for understanding elemental organophosphorus analysis via GC-ICP-SF-MS. J. Anal. Atom. Spectrom. 2018, 33, 1041-1048. [CrossRef]

216. Stenzel, Y.P.; Wiemers-Meyer, S.; Edel, J.; Winter, M.; Nowak, S. Analysis of acidic organo(fluoro)phosphates as decomposition product of lithium ion battery electrolytes via derivatization Gas Chromatography-Mass Spectrometry. J. Chromatogr. A 2019, 1592, 188-191. [CrossRef] [PubMed]

217. Bai, L.; Smuts, J.; Walsh, P.; Fan, H.; Hildenbrand, Z.; Wong, D.; Wetz, D.; Schug, K.A. Permanent gas analysis using gas chromatography with vacuum ultraviolet detection. J. Chromatogr. A 2015, 1388, 244-250. [CrossRef] [PubMed]

218. Self, J.; Aiken, C.; Petibon, R.; Dahn, J. Survey of gas expansion in Li-ion NMC pouch cells. J. Electrochem. Soc. 2015, 162, A796-A802. [CrossRef]

219. Wagner, M.R.; Raimann, P.; Trifonova, A.; Moeller, K.-C.; Besenhard, J.; Winter, M. Electrolyte decomposition reactions on tin-and graphite-based anodes are different. Electrochem. Solid-State Lett. 2004, 7, A201-A205. [CrossRef] 
220. Imhof, R.; Novák, P. In situ investigation of the electrochemical reduction of carbonate electrolyte solutions at graphite electrodes. J. Electrochem. Soc. 1998, 145, 1081-1087. [CrossRef]

221. Wagner, M.R.; Raimann, P.; Trifonova, A.; Möller, K.-C.; Besenhard, J.; Winter, M. Dilatometric and mass spectrometric investigations on lithium ion battery anode materials. Anal. Bioanal. Chem. 2004, 379, $272-276$. [PubMed]

222. Tsiouvaras, N.; Meini, S.; Buchberger, I.; Gasteiger, H. A novel on-line mass spectrometer design for the study of multiple charging cycles of a Li-O2 battery. J. Electrochem. Soc. 2013, 160, A471-A477. [CrossRef]

223. Metzger, M.; Strehle, B.; Solchenbach, S.; Gasteiger, H.A. Origin of H2 evolution in LIBs: H2O reduction vs. electrolyte oxidation. J. Electrochem. Soc. 2016, 163, A798-A809. [CrossRef]

224. Onuki, M.; Kinoshita, S.; Sakata, Y.; Yanagidate, M.; Otake, Y.; Ue, M.; Deguchi, M. Identification of the Source of Evolved Gas in Li-Ion Batteries Using\# 2\# 1-labeled Solvents. J. Electrochem. Soc. 2008, 155, A794-A797.

225. Yang, C.; Wang, Y.; Wan, C. Composition analysis of the passive film on the carbon electrode of a lithium-ion battery with an EC-based electrolyte. J. Power Sources 1998, 72, 66-70. [CrossRef]

226. Madec, L.; Petibon, R.; Tasaki, K.; Xia, J.; Sun, J.-P.; Hill, I.; Dahn, J. Mechanism of action of ethylene sulfite and vinylene carbonate electrolyte additives in LiNi 1/3 Mn 1/3 Co 1/3 O 2/graphite pouch cells: Electrochemical, GC-MS and XPS analysis. Phys. Chem. Chem. Phys. 2015, 17, 27062-27076. [CrossRef] [PubMed]

227. Ellis, L.; Allen, J.; Thompson, L.; Harlow, J.; Stone, W.; Hill, I.; Dahn, J. Quantifying, Understanding and Evaluating the Effects of Gas Consumption in Lithium-Ion Cells. J. Electrochem. Soc. 2017, 164, A3518-A3528. [CrossRef]

228. Ota, H.; Sakata, Y.; Inoue, A.; Yamaguchi, S. Analysis of vinylene carbonate derived SEI layers on graphite anode. J. Electrochem. Soc. 2004, 151, A1659-A1669. [CrossRef]

229. Shin, J.-S.; Han, C.-H.; Jung, U.-H.; Lee, S.-I.; Kim, H.-J.; Kim, K. Effect of Li2CO3 additive on gas generation in lithium-ion batteries. J. Power Sources 2002, 109, 47-52. [CrossRef]

230. Matasso, A.; Wong, D.; Wetz, D.; Liu, F. Effects of high-rate cycling on the bulk internal pressure rise and capacity degradation of commercial LiCoO2 cells. J. Electrochem. Soc. 2015, 162, A885-A891. [CrossRef]

231. Wu, K.; Yang, J.; Zhang, Y.; Wang, C.; Wang, D. Investigation on Li4Ti5O12 batteries developed for hybrid electric vehicle. J. Appl. Electrochem. 2012, 42, 989-995. [CrossRef]

232. Kong, W.; Li, H.; Huang, X.; Chen, L. Gas evolution behaviors for several cathode materials in lithium-ion batteries. J. Power Sources 2005, 142, 285-291. [CrossRef]

233. Ohsaki, T.; Kishi, T.; Kuboki, T.; Takami, N.; Shimura, N.; Sato, Y.; Sekino, M.; Satoh, A. Overcharge reaction of lithium-ion batteries. J. Power Sources 2005, 146, 97-100. [CrossRef]

234. Lamb, J.; Orendorff, C.J.; Roth, E.P.; Langendorf, J. Studies on the Thermal Breakdown of Common Li-Ion Battery Electrolyte Components. J. Electrochem. Soc. 2015, 162, A2131-A2135. [CrossRef]

235. Abraham, D.; Roth, E.; Kostecki, R.; McCarthy, K.; MacLaren, S.; Doughty, D. Diagnostic examination of thermally abused high-power lithium-ion cells. J. Power Sources 2006, 161, 648-657. [CrossRef]

236. Golubkov, A.W.; Fuchs, D.; Wagner, J.; Wiltsche, H.; Stangl, C.; Fauler, G.; Voitic, G.; Thaler, A.; Hacker, V. Thermal-runaway experiments on consumer Li-ion batteries with metal-oxide and olivin-type cathodes. RSC Adv. 2014, 4, 3633-3642. [CrossRef]

237. Golubkov, A.W.; Scheikl, S.; Planteu, R.; Voitic, G.; Wiltsche, H.; Stangl, C.; Fauler, G.; Thaler, A.; Hacker, V. Thermal runaway of commercial $18650 \mathrm{Li}$-ion batteries with LFP and NCA cathodes-impact of state of charge and overcharge. RSC Adv. 2015, 5, 57171-57186. [CrossRef]

238. Lammer, M.; Königseder, A.; Hacker, V. Holistic methodology for characterisation of the thermally induced failure of commercially available 18650 lithium ion cells. RSC Adv. 2017, 7, 24425-24429. [CrossRef]

239. Lammer, M.; Königseder, A.; Gluschitz, P.; Hacker, V. Influence of aging on the heat and gas emissions from commercial lithium ion cells in case of thermal failure. J. Electrochem. Sci. Eng. 2018, 8, 101-110. [CrossRef]

240. Koch, S.; Fill, A.; Birke, K.P. Comprehensive gas analysis on large scale automotive lithium-ion cells in thermal runaway. J. Power Sources 2018, 398, 106-112. [CrossRef]

241. Doughty, D.H.; Roth, E.P.; Crafts, C.C.; Nagasubramanian, G.; Henriksen, G.; Amine, K. Effects of additives on thermal stability of Li ion cells. J. Power Sources 2005, 146, 116-120. [CrossRef]

242. Roth, E.P. Abuse response of 18650 Li-ion cells with different cathodes using EC: EMC/LiPF6 and EC: PC: DMC/LiPF6 electrolytes. ECS Trans. 2008, 11, 19-41. 
243. Eshetu, G.G.; Grugeon, S.; Gachot, G.; Mathiron, D.; Armand, M.; Laruelle, S. LiFSI vs. LiPF6 electrolytes in contact with lithiated graphite: Comparing thermal stabilities and identification of specific SEI-reinforcing additives. Electrochim. Acta 2013, 102, 133-141. [CrossRef]

244. Dugas, R.; Ponrouch, A.; Gachot, G.; David, R.; Palacín, M.R.; Tarascon, J.-M. Na reactivity toward carbonate-based electrolytes: The effect of FEC as additive. J. Electrochem. Soc. 2016, 163, A2333-A2339. [CrossRef]

245. Roth, E.P.; Orendorff, C.J. How electrolytes influence battery safety. Electrochem. Soc. Interf. 2012, $21,45-49$. [CrossRef]

246. Seo, D.M.; Chalasani, D.; Parimalam, B.S.; Kadam, R.; Nie, M.; Lucht, B.L. Reduction reactions of carbonate solvents for lithium ion batteries. ECS Electrochem. Lett. 2014, 3, A91-A93. [CrossRef]

247. Xiong, D.; Petibon, R.; Nie, M.; Ma, L.; Xia, J.; Dahn, J.R. Interactions between positive and negative electrodes in Li-Ion cells operated at high temperature and high voltage. J. Electrochem. Soc. 2016, 163, A546-A551. [CrossRef]

248. Xiong, D.; Ellis, L.; Nelson, K.; Hynes, T.; Petibon, R.; Dahn, J. Rapid Impedance Growth and Gas Production at the Li-Ion Cell Positive Electrode in the Absence of a Negative Electrode. J. Electrochem. Soc. 2016, 163, A3069-A3077. [CrossRef]

249. Wang, F.; Varenne, F.; Ortiz, D.; Pinzio, V.; Mostafavi, M.; Le Caer, S. Degradation mechanisms of the ethylene carbonate/diethyl carbonate mixture studied by radiolysis. ChemPhysChem 2017, 18, 2799-2806. [CrossRef]

250. Varenne, F.; Alper, J.; Miserque, F.; Bongu, C.S.; Boulineau, A.; Martin, J.-F.; Dauvois, V.; Demarque, A.; Bouhier, M.; Boismain, F. Ex situ solid electrolyte interphase synthesis via radiolysis of Li-ion battery anode-electrolyte system for improved coulombic efficiency. Sustain. Energy Fuels 2018, 2, 2100-2108. [CrossRef]

251. Lee, K.H.; Song, E.H.; Lee, J.Y.; Jung, B.H.; Lim, H.S. Mechanism of gas build-up in a Li-ion cell at elevated temperature. J. Power Sources 2004, 132, 201-205. [CrossRef]

252. Wu, K.; Yang, J.; Liu, Y.; Zhang, Y.; Wang, C.; Xu, J.; Ning, F.; Wang, D. Investigation on gas generation of Li4Ti5O12/LiNi1/3Co1/3Mn1/3O2 cells at elevated temperature. J. Power Sources 2013, 237, 285-290. [CrossRef]

253. Liu, M.; He, Y.-B.; Lv, W.; Zhang, C.; Du, H.; Li, B.; Yang, Q.-H.; Kang, F. High catalytic activity of anatase titanium dioxide for decomposition of electrolyte solution in lithium ion battery. J. Power Sources 2014, 268, 882-886. [CrossRef]

254. Korepp, C.; Kern, W.; Lanzer, E.; Raimann, P.; Besenhard, J.; Yang, M.; Möller, K.-C.; Shieh, D.-T.; Winter, M. 4-Bromobenzyl isocyanate versus benzyl isocyanate-New film-forming electrolyte additives and overcharge protection additives for lithium ion batteries. J. Power Sources 2007, 174, 637-642. [CrossRef]

255. Waldmann, T.; Iturrondobeitia, A.; Kasper, M.; Ghanbari, N.; Aguesse, F.; Bekaert, E.; Daniel, L.; Genies, S.; Gordon, I.J.; Löble, M.W. Post-mortem analysis of aged lithium-ion batteries: Disassembly methodology and physico-chemical analysis techniques. J. Electrochem. Soc. 2016, 163, A2149-A2164. [CrossRef]

256. Rosenberg, E.; Kanakaki, C.; Amon, A.; Gocheva, I.; Trifonova, A. Understanding the degradation processes of the electrolyte of lithium ion batteries by chromatographic analysis. Bulg. Chem. Commun. 2017, 49, 242-253.

(C) 2019 by the authors. Licensee MDPI, Basel, Switzerland. This article is an open access article distributed under the terms and conditions of the Creative Commons Attribution (CC BY) license (http://creativecommons.org/licenses/by/4.0/). 